\title{
Um Sistema de Apoio à Identificação de Suspeitos com Reconhecimento Automático de Faces
}

\author{
Pedro Luis Fagá Celli
}

Orientadora: Profa. Dra. Rosane Minghim

Dissertação apresentada ao Instituto de Ciências Matemáticas e de Computação, da Universidade de São Paulo, como parte dos requisitos para obtenção do título de mestre, na área de "Ciências de Computação e Matemática Computactonal" 
Dedico este trabalho aos meus pais. 


\section{Agradecimentos}

A todos aqueles que fazem parte do Departamento de Computação da USP/SC, meu eterno agradecimento.

A Marília, Laura e Bete, da Secretaria da Pós-Graduação, que cuidam da parte burocrática.

Ao amigo Xyko que me ajudou muito na parte de tradução dos textos e nos treinamentos para a apresentação.

Obrigado ao conjunto Queen, especialmente, ao seu vocalista Freddy Mercury, que com sua música e voz, embalaram a escrita desta dissertação.

Ao Magnus pela ajuda nos momentos mais desesperadores.

Ao time do Corinthians, que tantas alegrias me deu durante os momentos difíceis e mais complicados.

Ao Cleso pela companhia que me fez durante as atividades do PAE.

Ao Pisca por ter cedido sua "linda carinha" para as telas de demonstração do sistema multimídia.

Ao Bill Gates, que me ajudou muito a evoluir e praticar minha paciencia e calma, mediante as intermináveis telas-azuis dos seus programas.

À minha orientadora pela paciência que teve comigo.

À Polícia Militar de São Carlos, que deu total apoio a tudo que foi preciso para o desenvolvimento do projeto.

E finalmente aos meus pais, tios, primos, namorada e o Lord (o cachorrinho da família) que muito me ajudaram. 


\section{Um Sistema de Apoio à Identificação de Suspeitos com Reconhecimento Automático de Faces}

Índice

1. INTRODUÇÃO 1

1.1 ESTRUTURA DA DISSERTAÇÃO 3

2. RECONHECIMENTO AUTOMÁTICO E IDENTIFICAÇÃO DE SUSPEITOS 4

2.1 RECONHECIMENTO DE PADRŐES 4

2.2 RECONHECIMENTO DE FACES 6

2.3 SISTEMAS DE IDENTIFICAÇÃO DE SUSPEITOS POR COMPUTADOR 11

2.4 SISTEMAS DE RETRATO FALADO __ 15

2.5 ANÁLISE DE APLICAÇŐES ___ 20

3. ALGORITMOS PARA RECONHECIMENTO DE FACES ___ 24

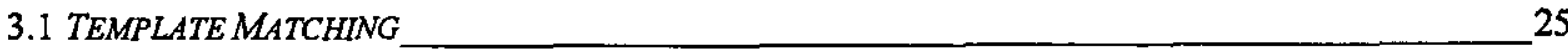

3.2 ANÁLISE DO COMPONENTE PRINCIPAL ___ 26

3.3 REDES NEURAIS ___ 32

3.4 OUTRAS TÉCNICAS ___ 35

4. SISTEMA MULTIMÍdIA PARA IDENTIFICAÇÃO DE SUSPEITOS COM RECONHECIMENTO AUTOMÁTICO DE FACES 48

4.1 O SISTEMA DE BANCO DE DADOS PARA A APLICAÇÃo POLICIAL___ 49

4.2 ALGORITMO PARA RECONHECIMENTO AUTOMÁTICO DE FACES __ 56

4.3 ALGUNS TESTES DO RECONHECIMENTO AUTOMÁTICO ___ 63

4.4 INTEGRAÇÃo ENTRE O SISTEMA MULTIMIDIA E O PCA ___ 69

4.5 TRABALHOS FUTUROS E CONCLUSÕES ___ 70

5. BIBLIOGRAFIA ___ 73

APÊNDICE I

APÊNDICE II 97 


\section{Lista de Figuras}

Figura 2.1: O padrão do tecido que forma a íris do olho humano é único para cada ser. Ele é estável durante toda a vida, tomando-se uma característica ideal para a identificação biométrica [Ve198].....5

Figura 2.2: O fluxo de sangue sob a pele cria um padrão de emissão de calor que é diferente para cada pessoa, e que pode ser detectada por uma câmera infravermelha. Os gêmeos dessa figura podem parecer iguais para um olho humano, mas não para o computador [Vel98].

Figura 2.3: Ilustra um dos problemas encontrados na utilização de senhas convencionais. Traduzido do livro de Scott Adams.

Figura 2.4: Apresentação gráfica da representação geométrica de uma face. O vetor de características contém os comprimentos dos segmentos de reta e ângulos mostrados. .10

Figura 2.5 : Diagrama genérico das etapas que compõem uma investigação criminal [Per95b].................17

Figura 2.6: A foto da esquerda é um retrato falado criado pelo software E-FIT, do lado tem-se a foto original [Asp95].

Figura 2.7: Passos envolvidos para o reconhecimento de face: 1) obtenção das fotos para a criação da base de dados, 2) captura da imagem "ao vivo" da pessoa, 3) localização da face na imagem total capturada, 4) comparação da imagem capturada "ao vivo" com a da base de dados. .22

Figura 3.1: Conjunto inicial de 20 imagens faciais [Gro94] .................................................................29

Figura 3.2: Vetor médio (canto superior esquerdo) e auto-vetores do conjunto de dados [Gro94]...........29

Figura 3.3: 4 imagens faciais e suas reconstruções usando 1 auto-vetor [Gro94] .....................................29

Figura 3.4: 4 imagens faciais e suas reconstruções com 5 e 10 auto-vetores [Gro94] .............................29

Figura 3.5: Imagens faciais e suas reconstruçōes com 15 e 20 auto-vetores [Gro94]...............................30

Figura 3.6: Esquema geral para reconhecimento de faces usando PCA [Gro94]......................................31

Figura 3.7: MLP/Backpropagation de três camadas [Ray96] ..............................................................34

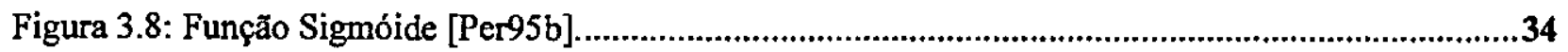

Figura 3.9: Imagem após aplicação de filtro para detecção de contomos [Bru93]......................................36

Figura 3.10: Mapas de arestas horizontal e vertical [Bru93] ...............................................................36

Figura 3.11: Restrições horizontal e vertical para o nariz e restrição horizontal para a boca [Bru92]. .......37

Figura 3.12: Perfil elíptico do contomo do rosto.................................................................................37

Figura 3.13: Exemplos de faces e suas projeçð̃es [Jia94] ..........................................................................38

Figura 3.14: Comparação entre faces usando o espectro de potência de Walsh. .......................................39

Figura 3.15: Técnica de amostragem [Sam93a]. ..............................................................................

Figura 3.16: Bandas faciais para HMM de 5 estados [Sam93a].......................................................42

Figura 3.17: HMM de esquerda para direita [Sam93a]...................................................................42

Figura 3.18: Diagrama alto nível do sistema híbrido para reconhecimento de faces [Law94].................. 43

Figura 3.19: Diagrama de um sistema e suas várias opções [Law94] ......................................................44

Figura 3.20: Processo de amostragem da imagem original. Uma região é sobreposta sobre a imagem e um vetor é criado para cada posição [Law94] ...................................................................................44

Figura 3.21: Configuração de um sistema para captura das imagens parciais da face. .............................45 
Figura 3.22: Captura das imagens feitas por 2 câmeras............................................................................ 45

Figura 3.23: Processamento das imagens. ............................................................................................46

Figura 3.24: Exemplos de imagens do olho e do nariz .......................................................................46

Figura 3.25: Diagramas de blocos das etapas de reconhecimento. ...........................................................46

Figura 4.1: Diagrama dos componentes do projeto. ............................................................................53

Figura 4.2: Diagrama de relacionamento para os arquivos de suspeitos..................................................53

Figura 4.3: Diagrama de relacionamento para os arquivos de policiais.................................................54

Figura 4.4: imagem média das faces da base de dados........................................................................57

Figura 4.5: llustra a transformação da Matriz 64x64 em um Vetor de 4096 posições..............................58

Figura 4.6: Mostra a organização das fotos como vetores e os resultados dos auto-vetores na aplicação do

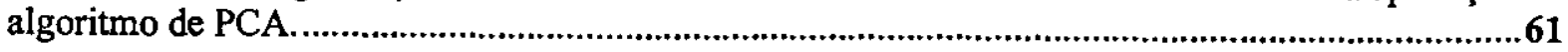

Figura 4.7: Imagens utilizadas para a base de fotos de teste.............................................................64

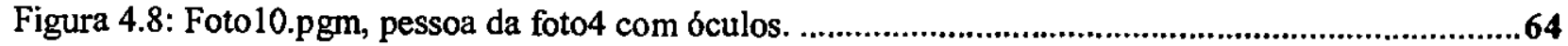

Figura 4.9: Foto11.pgm, pessoa da foto 3 com peruca. ........................................................................65

Figura 4.10: Foto12.pgm, pessoa da foto 3 com outro tipo de peruca. .....................................................65

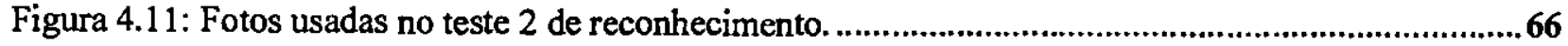

Figura 4.12: $50 \%$ da metamorfose da pessoa da foto0 com a da foto3 ..................................................66

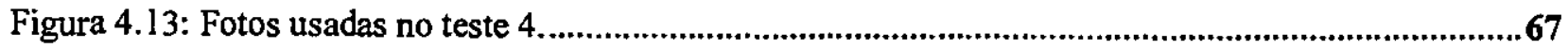

Figura 4.14: Exemplo de um arquivo ordem.txt, com as imagens ordenadas por ordem de semelhança...70 


\section{Lista de Tabelas}

Tabela 2.1: A tabela mostra o número de fotos recuperadas de acordo com a porcentagem de omissão de características e de acordo com a porcentagem de erro estipuladas para as testemunhas [Lee93].....14

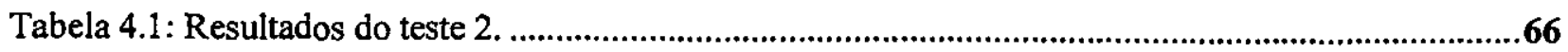

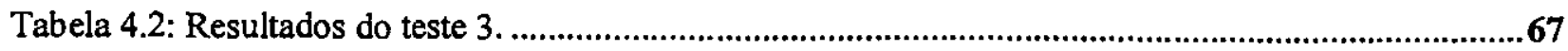

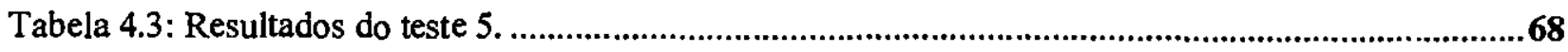

Tabela II.1: Tabela DBF do FoxPro com as informações sobre a base de dados de suspeitos...................98

Tabela II.2: Tabela DBF do FoxPro com as informações sobre a base de dados de policiais...................100 


\section{Resumo}

O reconhecimento automático de faces é um dos problemas mais desafiadores no campo da visão computacional e de reconhecimento. Métodos seguros e robustos podem ser usados em uma grande variedade de aplicações, como em sistemas de identificação de suspeitos pela polícia. A identificação de suspeitos com auxílio de testemunhas ou vítimas é muito usada na solução de crimes. Um dos métodos mais usados na identificação é o álbum de fotografia, que é desgastante, toma tempo, e confunde a testemunha que examina milhares de fotos. Pode-se, entretanto, desenvolver um sistema que combine a descrição da testemunha com as descrições contidas numa base de dados, ordenando as fotos a serem apresentadas para a vitima em ordem de similaridade, tornando menos tediosa e mais rápida a identificação correta do suspeito pela testemunha.

Este trabalho diz respeito à seleção de técnicas e à criação de um sistema de cadastramento multimídia de suspeitos, com utilização de um algoritmo de reconhecimento de fotos para apoio à ordenação da base de fotografias policiais. Entre os algoritmos existentes para reconhecimento de faces, foi selecionado o PCA (Principal Component Analisys). Uma base de dados para cadastramento foi criada, incluindo fotografias, e o algoritmo de reconhecimento foi implementado para completar a funcionalidade do sistema. Testes sugerem bom grau de reconhecimento e boa adaptação à tarefa de ordenação do conjunto de fotos. 


\begin{abstract}
Face recognition is one of the most challenging subjects in computational vision. Methods that are safe and reliable are employed in a variety of applications, like the suspect identification case treated here. Suspect identification is usually carried out with help from witnesses and victims, with the use of photo albums. However, this method is tiresome, time consuming and misleading to the victim, particularly after a number of photos have been examined. It is possible, nowadays, to use available algorithms and techniques to support suspect identification tasks, by sorting photographs using similarities as keys.

This work regards the study and implementation of techniques for filing and browsing suspect information, with use of a face recognition algorithm to help identification. Amongst the face recognition algorithms available, a version of PCA (Principal Component Analysis) was implemented. A multimedia database was created to help register individuals and occurrences, and the recognition algorithm was written to work with the data base. Tests suggest good recognition and suitability for database ordering.
\end{abstract}




\section{Introdução}

Instituições bancárias perdem milhões a cada ano através de fraudes em cartões e cheques, porque a única forma de validar a pessoa que está usando o cartão ou o cheque é através do número da senha ou pela assinatura [Per95b]. Grandes empresas têm os seus sistemas invadidos por hackers e seus dados roubados. Como resultado disso, vários estudos têm sido feitos para tentar resolver o problema através de medidas biométricas das pessoas. Sistemas biométricos são métodos automáticos para identificação de pessoas através de características fisiológicas ou comportamentais. Atualmente a maioria das pessoas são identificadas em passaportes, documentos de identidade e no trabalho através de fotos.

Vários progressos têm sido alcançados na área de identificação, como, por exemplo, com o uso de impressão digital. Várias instituições ao redor do mundo desenvolveram pesquisas nesse campo, incluindo o FBI. Sistemas de impressão digital são discretos e relativamente baratos. Eles são usados em bancos e no controle de acesso a áreas restritas [Rom97].

Impressões digitais são únicas para cada ser humano. Recentemente observou-se que a íris do olho, como a impressão digital, mostra padrões e texturas únicas para cada ser humano, e que permanece estável durante décadas de vida [Ve198].

Reconhecimento através da fala também oferece um meio natural e pouco importuno. O menos importuno de todos é o sistema de reconhecimento através de faces, que permite que o usuário seja identificado simplesmente passando na frente de uma câmera.

O reconhecimento de faces é umas das mais importantes funções do ser humano, o qual é capaz de identificar uma variedade muito grande de faces e aspectos psicológicos demonstrados pela fisionomia. A interação entre as pessoas depende da habilidade que elas têm em reconhecer sẹu interlocutor[Kru94].

Um dos aspectos importantes do reconhecimento de faces humanas é a sua complexidade. Seres humanos são capazes de identificar imagens distorcidas (caricaturas), imagens com pouca resolução (mosaico) e faces com detalhes ocultos (óculos de sol) de faces bem conhecidas. Esse reconhecimento acontece em maior ou menor grau, dependendo da capacidade do indivíduo e do nível de alteração das características 
conhecidas. Na maioria das vezes, seres humanos realizam a tarefa de reconhecimento de uma face sem esforço, de modo natural, e isso levou os pesquisadores descobrirem que o cérebro humano possui uma região de processamento dedicada ao reconhecimento de faces. $O$ entendimento do funcionamento do cérebro humano para essa tarefa foi importante para a elaboração de mecanismos que possibilitem que máquinas realizem o reconhecimento automático de faces [Rom97].

Diferentemente de outros objetos sujeitos a reconhecimento, as faces possuem sempre os mesmos elementos (boca, nariz, olhos, etc), facilitando um pouco a tarefa de identificação. $O$ grande problema do reconhecimento automático se deve às pequenas alteraç̃̃es que existem de uma face para outra, além das discrepâncias entre imagens diferentes de uma mesma face. $O$ reconhecimento deve levar em conta os contornos do rosto, a posição dos olhos em relação ao nariz, o formato do queixo, e outras variações.

Considerável esforço tem sido dedicado à resolução do problema de reconhecimento e caracterização de objetos e faces presentes em uma imagem. No início dos anos 80 , com os avanços alcançados pela microeletrônica e no desenvolvimento de arquiteturas paralelas de processamento, as técnicas digitais passaram a ser utilizadas para esse fim [Per95a]. Atualmente, a melhoria das técnicas computacionais inteligentes, como Sistemas Especialistas, Lógica Nebulosa, Redes Neurais, Algoritmos Genéticos e Principal Component Analysis (PCA- Análise do Componente Principal), tem permitido novas abordagens para esse problema, com mais precisão e de maior abrangência de aplicação.

O reconhecimento de faces é um dos problemas mais desafiadores no campo da visão computacional e do reconhecimento de padrões. Métodos seguros e robustos podem ser usados em uma grande variedade de aplicações, como, por exemplo, em sistemas de segurança de empresas e aeroportos, ou em sistema de identificação de suspeitos pela polícia [Gro94].

O campo denominado visão artificial procura "perceber" a informação contida numa imagem com o propósito de classificação, caracterização e reconstrução da mesma. A visão artificial é efetuada através de um conjunto de transformações, algumas delas em paralelo, que permitem a extração dos aspectos invariantes das imagens, a despeito da variabilidade do ambiente no qual elas estejam situadas. Tais invariâncias possibilitam o reconhecimento ou a caracterização da imagem, permitindo a interação do sistema de visão com as mesmas [Per95b].

Diversas denominações têm sido dadas a esse campo multidisciplinar, o qual aproveita conhecimentos relacionados com Processamento de Sinais, Inteligência Computacional, Neurofisiologia e outros, sendo que as mais utilizadas são: visão computacional, visão cibernética, visão de máquina, visão robótica, $\mathrm{e}$ visão por computador. De uma forma geral, todos esses nomes indicam o processo de cognição de uma imagem, que pertence à área do Reconhecimento e Análise de Padrões [Kru99].

No campo específico de apoio à identificação de suspeitos, as técnicas de reconhecimento de faces têm ganho cada vez mais espaço e se tomado um grande aliado para a elucidação mais rápida e precisa de 
casos policiais [Lee95b].

\subsection{Estrutura da Dissertação}

O presente trabalho trata da criação de um sistema multimídia para identificação de suspeitos com reconhecimento automático de faces, elaborado em parceria com a Polícia Militar de São Carlos. Este trabalho faz parte de um projeto de desenvolvimento de estratégias para apoio à investigação policial com o uso de recursos de processamento de imagem e visualização, em desenvolvimento junto ao ICMC/USP - São Carlos. O sistema multimídia permite arquivar todos os dados referentes aos suspeitos, tais como: dados pessoais e dados biométricos, bem como a foto da face do suspeito (visão frontal). $O$ sistema também permite o cadastramento de fichas de policiais, para uso interno da polícia. A ser integrado ao sistema multimidia, foi também desenvolvido um módulo de reconhecimento automático de faces, que pode ser usado para verificar se um suspeito já está cadastrado na base de dados, evitando assim falsidade ideológica ( $R G$ falsos). O sistema de reconhecimento automático também permite ordenar as imagens da base de dados por ordem de semelhança da foto pesquisada com as da mesma. Isso facilita o reconhecimento do suspeito pela vítima, evitando o cansativo processo de procura em centenas de fotos através de álbuns de fotografias convencionais.

A seguir, é dado um resumo do conteúdo desta dissertação.

No capítulo 2, são discutidos alguns aspectos do reconhecimento automático e sua relação com a aplicação de identificação de suspeitos.

No capítulo 3, são discutidos os principais algoritmos existentes para o reconhecimento de faces, e seus problemas. Apesar dessa discussão estar um pouco extensa, principalmente considerando que apenas um dos algoritmos foi implementado, foi escolhido manter o texto dos diversos algoritmos para documentar esse estudo em fases futuras do projeto em que este mestrado se insere.

No capítulo 4, é feita a apresentação do sistema multimídia para identificação de suspeitos com reconhecimento automático de faces desenvolvido. Além disso, são apresentados alguns resultados obtidos e indicados futuros passos para um maior desenvolvimento do sistema. 


\section{Reconhecimento Automático e Identificação de Suspeitos}

Este capitulo descreve algumas das possíveis aplicações do reconhecimento de padrões e de faces e seus requisitos. A descrição do reconhecimento de faces é concentrada nos temas relevantes ao processo de identificação de suspeitos em procedimentos policiais, que é o tema deste trabalho. A seguir será feita uma breve introdução ao reconhecimento de padrőes, uma vez que o reconhecimento de faces é considerada uma sub-área desse.

\subsection{Reconhecimento de Padrões}

Durante as duas últimas décadas houve um considerável crescimento do interesse em problemas de Reconhecimento de Padrões, com consequiente aumento da necessidade de métodos para o desenvolvimento de sistemas nessa área. O reconhecimento de padrões é uma área de pesquisa que estuda a operação e desenvolvimento de sistemas que reconhecem padrões e semelhança em dados. Ela inclui sub-áreas como análise discriminante, extração de características e estimativa de erro. O reconhecimento de padrões atua em importante áreas, tais como: análise de imagens, reconhecimento de caracteres, análise da fala, e identificação pessoal [Sme95].

As várias técnicas usadas para resolver problemas de Reconhecimento de Padrões podem ser agrupadas em duas abordagens gerais: a abordagem da decisão teórica ou discriminante e a abordagem sintática ou estrutural.

$\mathrm{Na}$ primeira abordagem, um conjunto de medidas de características é extraído de padrões. $\mathrm{O}$ reconhecimento de cada padrão, ou seja, a designação de uma classe padrão, é normalmente feita particionando o espaço das características. $O$ processo inclui não somente a capacidade de designar o padrão a uma classe particular, e classificá-lo, mas também a capacidade de descrever aspectos do padrão que o tornem inelegível para designá-lo para a outra classe [Woo96].

A abordagem sintática, por sua vez, ao enfatizar a descrição estrutural dos padrões, tenta fazer uma analogia entre a estrutura de padrões e a sintaxe de uma linguagem. A analogia é atraente por causa da 
disponibilidade de lingüística matemática como fundamentação teórica. Os padrões são especificados como sendo construídos de sub-padrões, assim como as frases e sentenças são construídas juntando palavras e as palavras são construídas juntando caracteres [Wo096].

$\mathrm{Na}$ área de identificação pessoal, pode-se utilizar o reconhecimento de padrões na identificação de informações extraídas de faces de indivíduos através da íris dos olhos e dos termogramas.

A tecnologia de reconhecimento através da íris é baseada no fato de que padrões aleatórios achados nas mesmas são únicos

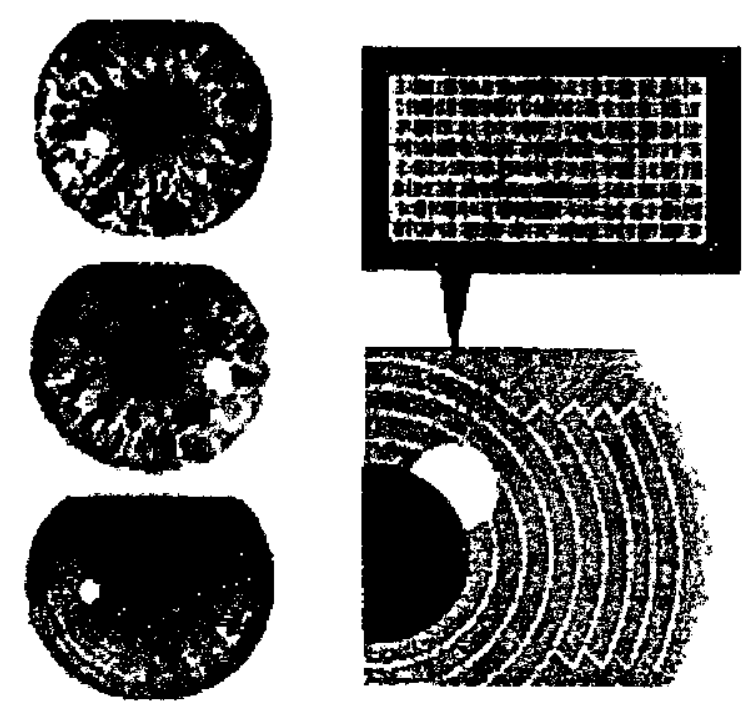

Figura 2.1: O padrao do tecido que forma a irts do olho humano 6 único para cada ser. Ele 6 estável durante toda a vida, tomando-se uma caracteristlca ideal para a identificaça blométrica [Vel98].
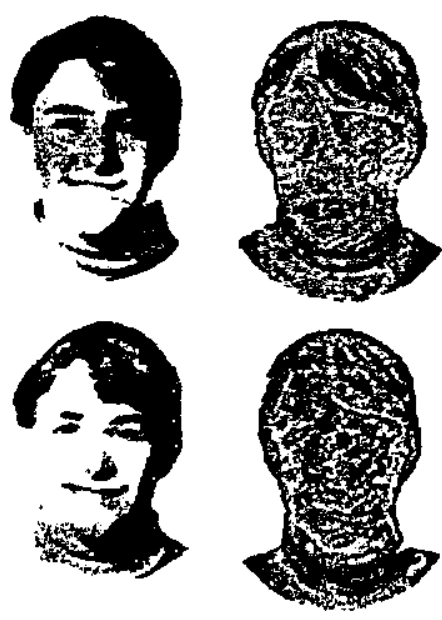

Figura 2.2: $O$ fluxo de sangue sob a peie cria um padrăo de emissăo de calor quo ó dlferente para cada pessoa, e que pode ser detectada por uma cåmera infravermelha. Os gêmeos dessa figura podem parecer Iguais para um olho humano, mas năo para o computador [Veig8]. antes dos 2 anos de idade, e se mantém constantes para o resto da vida [I\&t99] . A grosso modo, isso seria equivalente a um código de barras para seres humanos. Na população humana mundial não há dois padrões de íris iguais. Lentes de contatos e óculos não interferem nos padrões, não prejudicando assim o reconhecimento. Se comparada com a impressão digital, por exemplo, ela possui 1.078 padrões diferentes, contra 1.012 .

A taxa estimada de erro na identificação é de 1 em 1.2 milhões (figura 2.1) [Ve198].

Uma abordagem ainda em fase inicial, é a do reconhecimento de faces através de termogramas. Com uma câmera infravermelho é capturada a face de uma pessoa. Essa face é transformada em um mapa de emissão de calor, e esses mapas de padrões são comparados para se fazer o reconhecimento. As pesquisas ainda então na fase experimental e indicam que esses mapas térmicos são únicos para cada pessoa (figura 2.2) [Ve198]. 
Entre os métodos de reconhecimento de faces, o mais utilizado, entretanto, é o de caracterização da foto, a seguir descrita.

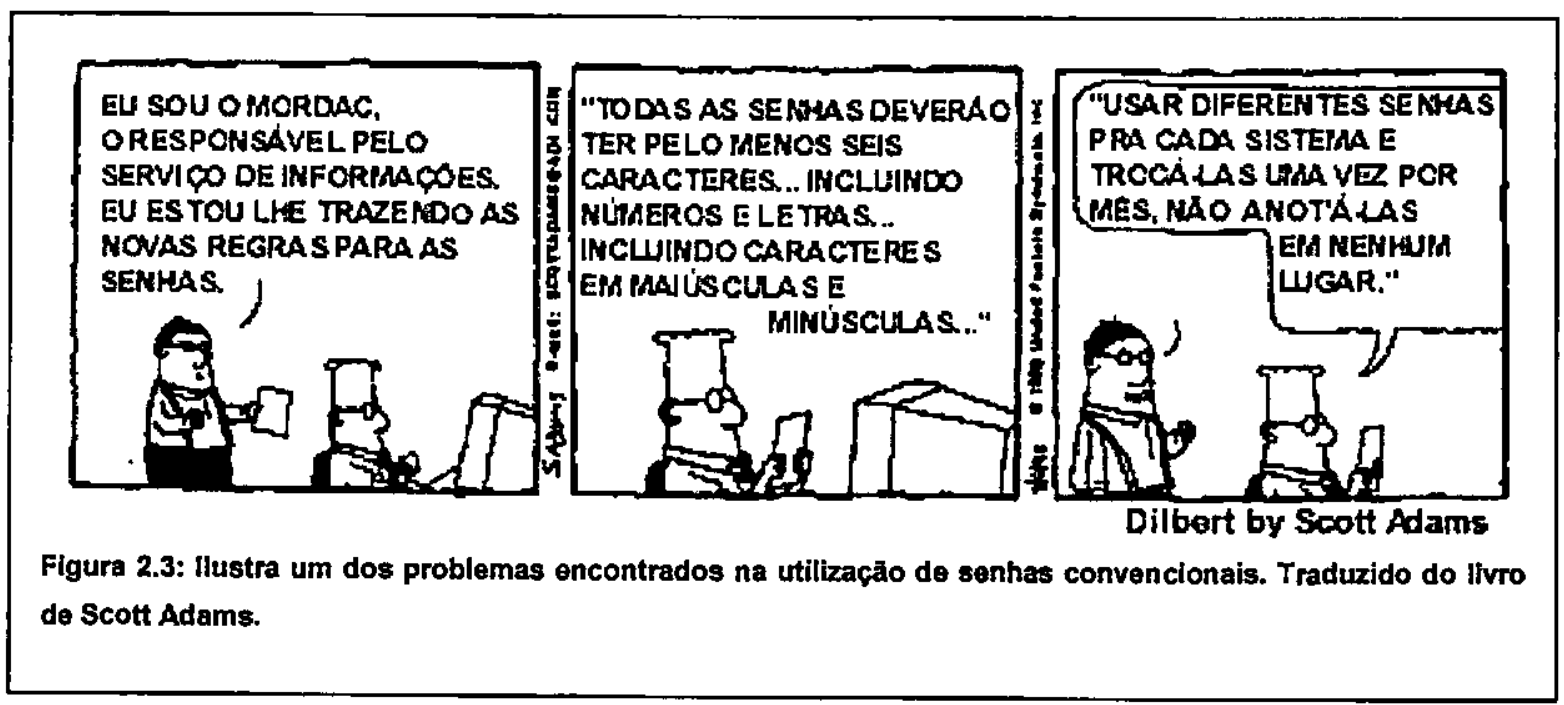

\subsection{Reconhecimento de Faces}

A unificação do controle de acesso é a promessa do reconhecimento de faces, uma tecnologia promissora no campo da identificação pessoal. Essa tecnologia já foi mostrada há alguns anos atrás nos filmes de ficção e nos de ação. A face humana é um exemplo de medida biométrica, que define características fisicas que tornam cada um de nós únicos, como nossa impressão digital, voz ou os complexos padrões que compõem a íris dos nossos olhos. Baseado nisso surgem várias tecnologias que buscam tornar,mas fácil e segura a identificação de pessoas.

Após 25 anos de pesquisa [Tim98], o reconhecimento facial está se tornando cada vez mais utilizado nas empresas comerciais e agora está ganhando um novo espaço no mercado de aplicações para computadores pessoais. Esse recurso pode ser usado para controlar o acesso a áreas restritas em empresas ou aeroportos, manter o sigilo de operações financeiras, e dar mais segurança às pessoas que utilizam cartões e senhas convencionais. Suas vantagens em relação a outras medidas biométricas são discutidas a seguir:

O reconhecimento por faces tem algumas vantagens sobre o reconhecimento por impressão digital e por íris que serão mostradas abaixo.

O reconhecimento pela impressão digital traz algumas desvantagens em relação ao reconhecimento por faces, quase todo ser humano possui uma face "boa" para o reconhecimento mas bem menos pessoas possuem uma impressão digital "boa". Algumas pesquisas feitas mostraram que $5 \%$ das pessoas não possuem uma impressåo digital que pode ser reconhecida num sistemas desses, o que é uma porcentagem alta. As razões para isso incluem: pele cortada, dedo com curativo, dedo com calo, pele seca, úmida, doente, dedo estreito, e sensor de leitura manchado ou engordurado pelo toque [Mir95]. 
A área da impressão digital é de $0,9 \times 1,3 \mathrm{~cm}$ enquanto que a área da face é de $12,8 \times 24,4 \mathrm{~cm}$, ou seja, o reconhecimento da face é muito mais resistente a cortes e contusōes.

O reconhecimento por íris possui em grau de acerto muito grande, praticamente $100 \%$, pois como já foi visto, a íris é impar para cada ser humano. O problema é que para se fazer a captura da íris de uma pessoa, em aplicações de identificação, a câmera tem que estar perfeitamente alinhada em relação à íris da mesma. Ou seja, é pouco prático. Já existe um sistema de três câmeras que fazem a procura pela íris numa face, sem que seja necessário o perfeito alinhamento, mas este sistema é ainda muito caro [Mir95].

Reconhecimento através da fala também oferece um meio natural e pouco importuno. O menos importuno de todos é o sistema de reconhecimento através de face, que permite que o usuário seja identificado simplesmente passando na frente de uma câmera.

O reconhecimento de faces é umas das mais importantes funções do ser humano, o qual é capaz de identificar uma variedade muito grande de faces e aspectos psicológicos demonstrados pela fisionomia. A interação entre as pessoas depende da habilidade que elas têm em reconhecer seu interlocutor [Spa93].

O reconhecimento automático de faces tem atraído muito interesse da comunidade científica desde os anos 60. Mas há indicios de trabalhos datados do final do século 19. Na sua explanação sobre identificação pessoal no Royal Institution em 25 de maio de 1888, Sir Francis Galton [Gre95], um cientista inglês, explorador e primo de Charles Darwin, explicou que ele "freqtentemente se irritava com a sensação de inabilidade para explicar verbalmente as semelhanças por hereditariedade e os tipos de características". Para se aliviar desse tipo de embaraço, ele "se deu ao considerável trabalho de fazer muitas experiências". Ele descreveu como prisioneiros franceses foram identificados usando quatro medidas primárias (comprimento da cabeça, largura da cabeça, comprimento do pé e comprimento do dedo médio do pé e das mãos respectivamente). Cada medida pode ter de um a três valores (largo, médio ou pequeno), dando um total de 81 classes primárias possíveis. Gaiton sentiu que seria vantajoso ter um método automático de classificação. Para esse propósito, ele projetou um aparato que ele chamou de seletor mecânico que poderia ser usado para comparar mediadas de perfil de faces em escolhendo as melhores medidas para descrever a forma do perfil, Gaiton relatou que a maioria das medidas que ele tentou foram razoavelmente eficientes.

Muitos trabalhos têm sido elaborados nesse campo, mas a comparação e descrição de vários métodos é na maioria das vezes uma tarefa muito complexa pois os resultados são obtidos usando diferentes conjuntos de imagens. Além disso, não há uma terminologia comum para descrever os métodos. De forma a descrever o problema tratado pelo presente trabalho, a seguinte terminologia será utilizada através dessa dissertação. A tarefa aqui, no tocante ao reconhecimento, consiste em distinguir uma face em um conjunto de imagens conhecidas. A face pode ou não estar contida no conjunto. A base de dados das imagens faciais é mista, consistindo de homens e mulheres de várias idades e grupos étnicos. No caso da 
utilização proposta aqui, não se quer ter como resposta "a imagem pertence a essa pessoa", mas sim a uma faixa de pessoas parecidas com aquela procurada, que será determinada através de um fator de tolerância. As imagens utilizadas são todas:

- na posição frontal (como em retrato $3 \times 4$ );

- com fundo liso;

- sem ocultação (isto é, sem óculos, chapéu, etc);

- sem inclinação drástica da cabeça para os lados;

- Incluindo uma única pessoa em "close".

O reconhecimento automático de faces encontra aplicações práticas em diversas áreas. Um sistema de localização e identificação de faces poderia ser usado para identificação de criminosos, ou na verificação de autenticidade onde a segurança é fator indispensável, caso dos sistemas bancários e de muitos sistemas computacionais. Na prática, qualquer sistema que exija códigos, senhas ou outros meios de acesso pode ser beneficiado pelo reconhecimento automático de faces. Recentemente, bancos e administradoras de cartão de crédito têm adotado a prática de imprimir a foto do cliente nos cartões e em talões de cheques, com o objetivo de diminuir o número de fraudes com decorrentes roubos. Esșa é uma demonstração clara da importância da face como chave de identificação (única, excluindo o caso de gêmeos idênticos) de uma pessoa.

Um sistema genérico de reconhecimento de faces deve abordar diversas questð̃es técnicas relativas tanto ao estímulo tratado (a face humana), quanto aos processos envolvidos na tarefa de reconhecimento em si.

São vários os processos associados ao reconhecimento automático de faces, os quais são apresentados a seguir [Per95b]:

1. Detecção: Dada uma imagem qualquer, identificar o local onde aparece(m) a(s) face(s);

2. Segmentação: Identificar as partes constituintes de uma face;

3. Representação: Selecionar as informações da face que serão utilizadas para representá-la;

4. Identificação: Verificar se uma face pertence ao conjunto de faces "conhecidas".

Deteç̧ão: no caso de sistemas genéricos de reconhecimento de faces, o primeiro passo é localizá-la(s) na imagem. Isso é válido para sistemas onde a entrada de dados é pouco controlada e bastante variável, tal como num possivel sistema de segurança onde a imagem é capturada por uma câmera. Nesse caso não é conhecido, a priori, o local da face na imagem capturada, dada a variedade de posicionamento das pessoas que utilizarão o sistema.

Algumas aplicaçð̃es poderão dispensar esse passo inicial provendo ao mecanismo de reconhecimento 
alguma informação sobre a localização da face na imagem.

Há duas abordagens para deteç̧ão de faces. Na primeira delas a face é tratada atomicamente. Um modelo geral representando os principais traços da face é utilizado como aproximação para a face que se deseja localizar. Esse modelo pode ser estático (quando informações prévias são conhecidas de antemão; exemplo: tamanho aproximado das faces em relação à imagem total ou o número de faces presentes na cena) ou deformável (métodos mais genéricos em que nenhuma informação a respeito da cena é previamente conhecida) [Bey93].

Na segunda abordagem, a face é localizada através de alguns de seus componentes, tais como olhos, boca e nariz. Da mesma forma que na abordagem anterior, a disponibilidade de informaçōes prévias definirá uma estratégia mais específica ou mais genérica.

Segmentação: essa é uma das etapas fundamentais em tarefas de processamento digital de imagens. Tecnicamente falando, a segmentação subdivide a imagem em suas partes (ou objetos) constituintes. A segmentação automática é considerada uma das mais difíceis tarefas de processamento digital de imagens [Per95b].

Em um sistema completo de processamento de imagens, a segmentação é uma etapa considerada intermediária (juntamente com a etapa de representação e descrição), antecedida pelas tarefas de aquisição e pré-processamento (consideradas de baixo nível ou "mecânicas" ) e precedendo tarefas (mais abstratas) de reconhecimento e interpretação. Esse esquema considera todos os passos envolvidos em processamento de imagens, mas nem todos os sistemas de reconhecimento compreenderão todas as etapas descritas. Alguns, por exemplo, poderão parar na etapa de segmentação ou de pré-processamento, caso as informações produzidas por esses passos sejam suficientes para o problema em questão.

No contexto do processamento de faces, a segmentação é comumente empregada antes da etapa de representação ou de extração de características. O objetivo nesses casos é localizar as partes constituintes da face para delas extrair propriedades e características que serão utilizadas na representação da mesma. A representação, por sua vez, será manipulada pelos algoritmos de reconhecimento.

Representação: existem duas abordagens clássicas para o problema da representação de faces: a abordagem geométrica e a pictorial. $\mathrm{Na}$ abordagem geométrica, estão em foco a forma e a relação espacial entre características faciais (olhos, boca, etc.). Os sistemas que adotam essa estratégia iniciam o processo de representação com a localização, na face, das características escolhidas (segmentação, descrita acima). Alguns dos pontos mais utilizados para essa tarefa são os cantos formados pela forma elipsoidal dos olhos e da boca, as laterais da face, contornos do queixo, "ponta" do nariz, dentre outros. A Figura 2.4 mostra um exemplo do uso dessa abordagem. Uma vez localizadas as caracterfsticas, o sistema pode capturar a relação espacial entre elas, formando um vetor cujas dimensões incluem distâncias, ângulos e curvaturas. Esses vetores de características (feature vectors) serão então utilizados pelos classificadores para calcular 
a similaridade entre um padrão de entrada e os padrões da base de dados.

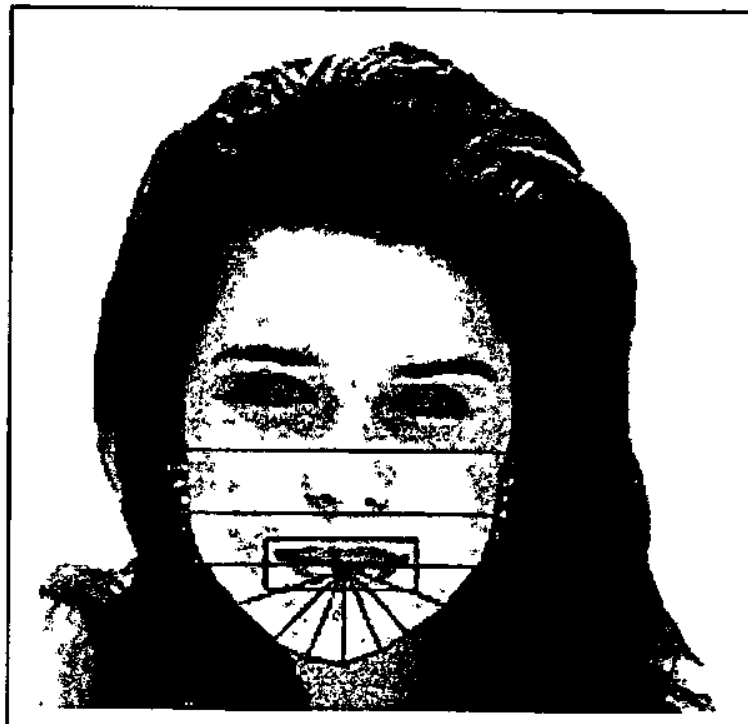

Figura 2.4: Apresentaçăo gráfica da representaçăo geométrica de uma face. O vetor de caracteristlcas contém os comprimentos dos segmentos de reta $\theta$ Angulos mostrados.

A abordagem pictorial utiliza representações baseadas na matriz de intensidades da imagem (também chamada de template). No caso mais simples, as faces são representadas por sua imagem 2D (em tons de cinza) ou por sub-imagens de componentes como olhos, boca e nariz. Técnicas mais sofisticadas empregam transformações sobre a imagem-base com $o$ intuito de realçar características (transformada de Karhunen Loève; MLP/backpropagation). Também é comum utilizar mais de um template por face para capturar diferentes ângulos de visão ou variações da face.

A escolha de um tipo de representação ou outro dependerá da aplicação em questão. A abordagem por templates apresenta um custo maior de

armazenamento do que os vetores de caracteristicas. A escolha da representação influenciará o esquema usado na identificação.

Uma dificuldade a ser superada em todas as técnicas é a escala entre as imagens. Antes de serem comparadas, ou antes de terem suas características extraídas, as faces devem estar na mesma escala. $O$ ajuste automatizado é feito pela escolha de um fator que normalize uma distância pré-determinada nas faces. Uma das medidas mais utilizadas é a distância entre as pupilas, em parte pela facilidade e precisão com que esses pontos são localizados na face.

Identificação: os paradigmas de reconhecimento de padrões, em geral, são baseados numa função de similaridade encarregada de associar e agrupar padrões de vetores em diferentes classes. $O$ objetivo da função de similaridade (por exemplo, a distância euclidiana) é estabelecer uma métrica entre a imagem apresentada e cada imagem a ser encontrada, utilizando, para tal, as representações adotadas. Uma heurística é responsável pela forma como as métricas obtidas serão interpretadas e consideradas. No caso de faces em vista frontal, há duas estratégias principais: uma configuracional (ou wholistic) e outra passoa-passo (ou piecemeal). Na primeira abordagem, a face (ou melhor, sua representação) é tratada por inteiro pelo processo de reconhecimento; a segunda abordagem analisa as representações de partes ou características isoladas da face.

Embora as estratégias utilizem caminhos diferentes, os princípios básicos são similares [Per95b]: 
1. Representação da face de entrada no mesmo espaço de representação utilizado pelas faces da base;

2. Utilização da função de similaridade para encontrar as melhores aproximações para o dado de entrada;

3. Análise dos resultados do passo anterior, descartando os resultados inexpressivos e destacando os melhores. É possivel que esse passo chegue à conclusão que não há nenhuma aproximação para o dado de entrada, ou seja, que o sistema não conseguiu encontrar nada na base que "parecesse" com a entrada.

Diversas métricas são utilizadas para computar o passo 2. Algumas das mais utilizadas são:

Distância Euclidiana: A mais comum de todas. Geralmente utilizada quando a representação adotada é a de vetores de características;

Conjunto Particionado: Também é utilizada quando a representação é baseada em feature vectors (vetores de características). Apoia-se no princípio de que vetores de dois padrões bastante diferentes diferem significativamente em pelo menos uma característica. Dessa forma o conjunto de faces conhecidas é reduzido progressivamente, rejeitando as faces que diferem em pelo menos uma característica. Tem por objetivo reduzir o conjunto para uns poucos ou um único elemento;

Algumas vezes é necessário combinar mais de um desses métodos, obtendo uma representação multidimensional que será utilizada pelas diferentes técnicas.

A seção a seguir dá um panorama da identificação de suspeitos e de sua associação com o reconhecimento de faces.

\subsection{Sistemas de Identificação de Suspeitos por Computador}

A identificação de suspeitos através de testemunhas ou vítimas é freqüentemente de importância central para a solução de crimes. Três métodos mais comumentes são usados para identificar suspeitos:

1. descriçð̃es verbais;

2. métodos de composição, tais como montagens por fotografia ou kits de identificação;

3. álbuns de suspeitos.

Faltam ds descrições verbais detalhes suficientes para que possam ser usados com precisão. Procedimentos de composição de retrato falado tem um relativo insucesso porque elas não geram uma imagem detalhada e precisa do suspeito. A tentativa através de álbuns de fotografia tem mais sucesso, porque as pessoas são hábeis em reconhecimento de faces [Lee93].

Mesmo assim, a tentativa através de álbuns tem alguns problemas fundamentais. A tarefa é desgastante, toma tempo, e confunde a testemunha à medida em que ela examina milhares de fotos. A probabilidade de selecionar um suspeito correto (acerto) diminui rapidamente depois das primeiras 100 a 200 fotos, enquanto que a possibilidade de se selecionar uma pessoa errada (alarme falso) aumenta rapidamente 
[Lee93].

Em resposta a tais dificuldades, têm crescido as tentativas de recuperação de imagens através de características faciais. Um conjunto de características é usado para se distinguir um subconjunto de fotos de um álbum numa base de dados. Nos sistemas de recuperação de características existentes, os usuários descrevem um suspeito, por exemplo, através de uma foto de alguém que se deseja encontrar ou em resposta a uma série de perguntas. Um exemplo de pergunta seria: numa escala de 5 pontos, baixo 1234 5 alto: Qual a altura dessa pessoa? O sistema combina a descrição da testemunha com aquelas das fotos do álbum na base de dados. As fotos são apresentadas para a testemunha ordenadas por grau de similaridade.

O propósito do trabalho de Lee [Lee93] foi o de estabelecer a viabilidade da tentativa de reconhecimento por características usando uma base de dados com fotografias de criminosos conhecidos.

O projeto de Lee baseia-se numa definição ampla de sucesso, incluindo:

1. sucesso de identificação;

2. escala de recuperação;

3. tolerância de desempenho;

4. qualidade das caracteristicas.

Sucesso de identificação é a habilidade das testemunhas em identificar suspeitos com sucesso através de suas fotos, e inclui tais medidas como acertos, erros, alarmes falsos, e não recuperação.

Escala de recuperação é a ordem em que a foto do suspeito se classifica quando as fotos da base de dados são organizadas em ordem de similaridade de acordo com a descrição da testemunha.

Tolerância de desempenho mede a habilidade de um sistema tolerar erros da testemunha em algumas características (tolerância a erros), e omissão de outras (tolerância a omissão), e ainda ter um desempenho aceitável (como o medido pela escala de recuperação).

Qualidade das características é uma medida que pode também ser chamada de medida de imprecisão, que acessa propriedades informacionais das próprias características: informatividade, ortogonalidade, suficiência, consistência, e observabilidade.

O desempenho do sistema é medido com maior precisão através da escala de recuperação. Apresentação antecipada das fotos-alvo marcadamente melhora o desempenho na identificação. Os desempenhos do sistema e do usuário, por outro lado, são confusos em termos de sucesso de identificação. Portanto, o objetivo imediato do trabalho de Lee foi a minimização da escala de recuperação.

Para alcançar isso, ele seguiu sete estágios no projeto e desenvolvimento:

1. geração de características; 
2. seleção de características;

3. construção da base de dados;

4. projeto do programa de recuperação;

5. simulações por computador;

6. testes empiricos.

Geração de caracteristicas: para gerar uma grande quantidade de características em potencial, ele pegou uma amostra de 25 fotos P\&B (preto e branco).

Comparação em pares: Esse passo consistiu num processo onde cada amostra de fotos era comparada com as outras 24. Para cada par distinto de fotos, uma característica era observada e caracterizada no primeiro indivíduo mas não no segundo.

Seleção de características: Lee utilizou 5 critérios para selecionar as características dessa pesquisa: informatividade, ortogonalidade, suficiência, consistência, e observabilidade. Para otimizar o desempenho do sistema ele selecionou características que eram, com base em estudos piloto, o máximo informativas, mutuamente ortogonais, observáveis, memorizáveis e codificadas consistentemente por diferentes pessoas; e o número de características do sistema minimizado, mas ainda discriminante entre as fotos. $\mathrm{Da}$ pesquisa ele selecionou 90 características faciais (por exemplo, cabelo liso $\mathrm{x}$ cabelo encaracolado, careca $\mathrm{x}$ cabeludo, pescoço fino $\mathrm{x}$ pescoço grosso, etc).

Construção da base de dados de fotografias: a base de dados consistiu de 640 fotos oficiais de criminosos conhecidos. As fotos foram tiradas sob condições padrão - vista frontal do rosto a partir do ombro. Os suspeitos eram todos brancos, masculinos, e de idades entre 18 e 33 anos.

Cada foto foi codificada com 90 características faciais, numa escala de 5 pontos (ex: nariz estreito - 123 45 - nariz largo).

Desenvolvimento do sistema de reconhecimento de características: o sistema possui um formulário a ser preenchido com as 90 características faciais que foram classificadas anteriormente (em escala de 5 pontos).

Similaridade entre a descrição da testemunha e a da base de dados é medida por uma métrica Euclidiana, isso é, soma-se os desvios elevados ao quadrado entre a descrição da característica da testemunha e a da base de dados, e extrai-se a raiz quadrada da soma. Pesquisas preliminares sugerem que a métrica Euclidiana minimiza a escala de recuperação em relação a outras métricas.

\section{Utilizando o Sistema}

Método: 10 "vítimas"- foram testadas, 5 homens e 5 mulheres de idades variando de 19 a 30 anos. Entre elas estavam incluídos estudantes universitários bem como trabalhadores da comunidade. 
Procedimento: as testemunhas recebiam uma foto de um provável suspeito e observavam-na por um curto período de tempo. Depois de responder o questionário de 90 caracteristicas faciais (escala de 1 a 5 ), as vítimas pesquisavam as fotos da base de dados, uma por uma, na ordem de classificação. Pedia-se a ela para identificar o suspeito. Adivinhação não foi desencorajada. Além disso, se a vítima não lembrasse de uma característica, essa deveria ser mantida em branco.

Aparato: o sistema de recuperação por computador foi preparado para operar inicialmente sem julgamento de certeza. Depois de completados os testes, os julgamentos de certeza foram usados para eliminar qualquer foto da base de dados que diferisse maximamente (isso é, de 4 a 5 pontos na escala). As fotos restantes da base de dados foram ordenadas da mais similar para a menos similar à descrição feita pela testemunha.

Resultados: todas as 10 testemunhas identificaram corretamente seus criminosos. A classificação média de recuperação dos alvos foi 9,70 (ou seja, entre as 10 primeiras). A pior performance foi uma classificação em trigésimo.

A porcentagem média de características omitidas foi $8,9 \%$. O desvio médio entre a codificação da testemunha e a da base de dados foi 0,78 .

O sistema possui um ótimo desempenho, pois todas as fotos dos suspeitos "verdadeiros" foram ordenadas muito antes da centésima foto, aumentando em muito a probabilidade da testemunha selecionar o suspeito correto.

Classificação de recuperação para pesquisas simuladas de 10000 fotografias.

$\mathrm{P}$ (omissão)

\begin{tabular}{|c|c|c|c|c|c|c|}
\hline & & .10 & .30 & .50 & .70 & .90 \\
\cline { 2 - 7 } & .05 & 1 & 1 & 1 & 2 & 177 \\
\cline { 2 - 7 } & .15 & 1 & 1 & 26 & 69 & 722 \\
\cline { 2 - 7 } & .25 & 14 & 71 & 119 & 401 & 1487 \\
\cline { 2 - 7 } & .35 & 389 & 789 & 1090 & 1670 & 2580 \\
\hline
\end{tabular}

Tabela 2.1: A tabela mostra o número de fotos recuperadas de acordo com a porcentagem de omissăo de características e de acordo com a porcentagem de erro estipuladas para as testemunhas [Lee93].

Simulações por computador: para avaliar o efeito do tamanho da base de dados, e das taxas de omissão e dos erros variantes no desempenho do sistema, Lee simulou tanto grandes bases de dados de fotos como o comportamento da testemunha procurando um suspeito. Ele construiu e simulou uma base de dados com 10.000 fotografias com descrições do mesmo tipo daquelas usadas na base de dados com 640 fotos. $O$ comportamento das testemunhas foi simulado omitindo aleatoriamente algumas características, e cometendo erros proporcionais aos cometidos por seres humanos, no teste anterior. Para cada combinação 
de probabilidades de omissão e erro, 200 tentativas de pesquisas do suspeito foram conduzidas e os suspeitos foram selecionados aleatoriamente. $O$ índice de erro variou de 5 a $35 \%$ enquanto que o índice de omissão variou de 10 a $90 \%$.

Os resultados indicam que o sistema tem um alto grau de tolerância a erros e omissōes das testemunhas, além de habilidade para manipular grandes bases de dados.

Outros três trabalhos realizados por Eric Lee e outros [Lee94], [Lee95a] e [Lee95b] vêm comprovar que o desempenho na identificação de suspeitos por testemunhas através de álbum de fotografias, diminui à medida em que a testemunha examina mais fotografias.

O trabalho de Eric Lee, descrito acima, e os outros três citados, sugerem uma série de diretivas para a implementação de um sistema de identificação de suspeitos por computador, tomando menos tediosa $\mathrm{e}$ mais rápida a identificação correta do suspeito pela testemunha, agilizando, por consequaencia, o processo de investigação policial. Tais diretivas devem fazer parte de qualq̨uer sistema de apoio à identificação de suspeitos e deverão ser consideradas no desenvolvimento do presente trabalho.

Uma outra ferramenta útil no processo de identificação de suspeitos é o Retrato Falado, apresentado a seguir.

\subsection{Sistemas de Retrato Falado}

O Retrato Falado é um método muito usado pela polícia em todo o mundo para a identificação de suspeitos e possíveis infratores da lei. $O$ uso do retrato falado, em conjunto com fotografias de infratores, representa uma das ferramentas mais utilizadas pela polícia para conseguir uma identificação positiva. Não é uma técnica a ser aplicađa isoladamente, mas uma primeira tentativa de solução que produzirá subsídios para outras técnicas de investigação criminal. O exemplo descrito abaixo mostra um resumo das fases do processo da criação do retrato falado da identificação de um possível suspeito de assalto a mão armada a uma loja de conveniência (resumo) [Per95b]:

Uma balconista jovem de 22 anos liga para a polícia relatando um roubo em uma loja. Quando os dois policiais chegaram ao local ela descreveu que um homem entrou na loja, e quando o último cliente saiu, o ladrão sacou a arma e ordenou que ela entregasse todo o dinheiro do caixa. Depois ele mandou que ela se deitasse no chão de barriga para baixo. Em seguida ele fugiu.

Ela descreveu suas características como sendo um homem negro, alto, magro, de 1,98 $\mathrm{m}$ de altura, mais ou menos 20 anos. Ela achava que ele não tinha barba mas alguns pelos no rosto. Disse também que ele usava boné, jaqueta preta de nylon, onde uma pequena arma preta estava escondida. Ele segurava a arma na mão direita e pegou o dinheiro com a esquerda.

No dia seguinte, ela, com o auxílio de um perito, montou um retrato falado do criminoso. No final, ela 
descreveu o retrato falado como não sendo parecido com o ladrão, mas era o melhor que ela poderia descrever.

Após dois dias, a mulher retornou voluntariamente à delegacia para ver algumas fotos. Eram dez fotos de homens negros com idades variando entre 20 e 35 anos. Após algum tempo examinando as fotos, a testemunha disse que não estava bem certa, mas que um dos homens sem barba ou bigode lembrava algo do criminoso. Depois disse que uma outra foto também apresentava alguma semelhança, mas não tanto quanto o primeiro. A segunda foto possuía alguma barba. Depois, o primeiro suspeito identificado conseguiu apresentar um bom álibi.

Dois meses depois, o suspeito da segunda foto foi identificado como o autor de um outro roubo a uma loja de conveniências na noite anterior a esse roubo descrito. Foi preso e submetido a uma identificação visual juntamente com outros presos. O suspeito preso possúa 2,03 metros, 31 anos e possuía um pequeno bigode. A balconista reconheceu o assaltante como sendo o mesmo preso pelo crime cometido no dia anterior. Meses depois, numa corte, ela voltou a reconhecer positivamente o suspeito e disse, sob juramento, que tinha 'absoluta certeza' de que ele era o assaltante.

O cenário descrito acima possui a maioria dos elementos humanos e procedimentos encontrados em crimes. Particularmente, podemos identificar comportamentos específicos da testemunha e dos policiais, operações que envolveram a memória humana, o desenrolar dos procedimentos empregados na solução do crime, como eles estão interligados entre si, e como dependem da testemunha.

É notória a importância da testemunha no transcorrer da investigação policial até o julgamento do caso. A testemunha é consultada a cada passo, e suas respostas, mesmo duvidosas, encaminham o passo seguinte da investigação. Não há dúvidas que a testemunha é essencial para descobrir o autor de um crime, ainda mais se for estimulada de maneira adequada para a informação que dela se deseja obter. Também é notório que fotos podem auxiliar o procedimento de identificação.

Os procedimentos aos quais as testemunhas são submetidas, podem ser classificados em dois tipos:

1. procedimentos de recuperação (recall);

2. procedimentos de reconhecimento (recognition).

Os procedimentos de recuperação agem na tentativa de resgatar representações mantidas na memória da testemunha, enquanto que os procedimentos de reconhecimento, como o próprio nome diz, agem por comparação de representações externas com as representaçőes da memória da testemunha. A produção de um retrato falado é um exemplo de procedimento de recuperação e a análise de fotografias é um exemplo de procedimento de reconhecimento.

A divisão entre reconhecimento e recuperação reflete também a discrepância existente entre a habilidade de reconhecer e a habilidade de descrever uma face. Muito já foi dito sobre a capacidade do ser humano 
de reconhecer faces. Essa é uma tarefa que as pessoas realizam quase que continuamente e com uma incrivel flexibilidade. Em contrapartida, essas mesmas habilidades não podem ser estendidas para a capacidade de descrever faces. Quem já passou pela experiência de ter que descrever uma face, mesmo familiar, sabe como é difícil expressar verbalmente, de forma objetiva, suas características. A dificuldade não depende do grau de familiaridade da face, mas da complexidade inerente a esses estímulos.

São vários os procedimentos empregados durante uma investigação criminal que utilizam a memória da testemunha como possivel fonte de informação, seja através do reconhecimento ou da recuperação. Esses procedimentos são comuns a todos os departamentos ou delegacias de polícia e são ilustrados na figura 2.5 e descritos a baixo [Per95b].

Descrição Verbal: Geralmente requisitada logo no início das investigaçōes. A testemunha é convidada a relembrar detalhes do crime (hora, local, arma do crime) e do criminoso (roupas, postura, aspecto físico geral $e$, principalmente, a face). A descrição pode ser livre, quando a testemunha narra os fatos sem a interferência do policial, ou dirigida, quando o policial direciona a narração.

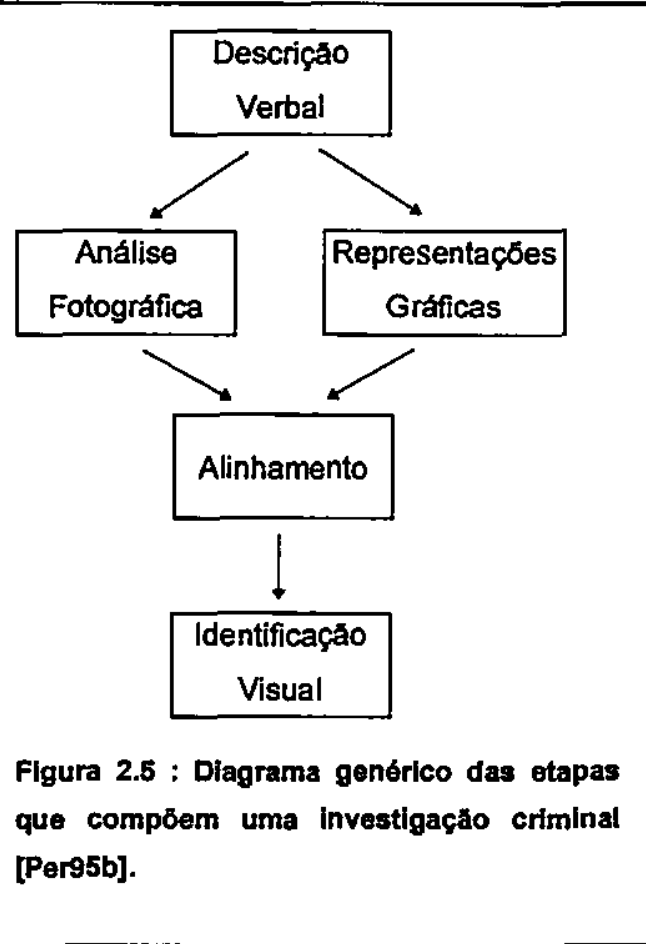

Representações Gráficas: O objetivo dessas técnicas é o de obter uma representação gráfica da face do suspeito. Geralmente envolvem a descrição da testemunha assistida por um técnico.

Análise Fotográfica: Quando o policial tem uma lista de suspeitos, ele pode submeter a testemunha a uma análise das fotografias dos mesmos. Essas fotos são selecionadas do arquivo de fotografias do departamento de polícia a partir dos indícios fornecidos anteriormente pela testemunha e também pela experiência do profissional.

Alinhamento: Apresentação de um número de suspeitos (em tomo de 5 ou 6) perfilados lado a lado. A testemunha observa o grupo na tentativa de identificar o criminoso entre eles. Além da face, outras informações tambèm estão disponíveis para a apreciação da testemunha, tais como: altura, postura e aspecto fisico geral. Em alguns casos, quando a legislação permite, pode-se pedir que os suspeitos falem ou se movimentem. À testemunha é reservado o direito de rejeitar o alinhamento por não conseguir identificar nenhum dos presentes.

Identificação Visual: Procedimento de reconhecimento no qual o suspeito é apresentado sozinho. A testemunha dá uma resposta do tipo "sim" ou "não". Essa situação é comumente empregada durante o julgamento como um instrumento legal de identificação de um criminoso perante o tribunal. Outras etapas 
de identificação servem apenas para orientar a investigação.

As duas primeira técnicas, descritas acima, são procedimentos de recuperação, embora a testemunha também realize reconhecimento, notadamente no segundo caso. As demais são tidas como procedimentos de reconhecimento.

Há diversas pesquisas envolvendo os procedimentos acima citados: aferição da eficiência de cada método, influência exercida por variáveis externas como sexo e idade, a ordem com que os procedimentos devam ser empregados a fim de preservar ao máximo as informações da testemunha e a legalidade desses métodos como instrumentos lícitos para a investigação e o julgamento são algumas das questões pesquisadas.

\section{Sistemas de Composição de Retrato Falado}

Os primeiros sistemas de composição de retratos falados foram criados por volta de 1880 por um jovem francês chamado Alphonse Bertillon (1853-1914), considerado o inventor da antropometria [Pet77]. Antropometria é a ciência e a técnica que usa as medidas do corpo humano para extrair conclusões sobre a condição nutricional dos indivíduos e dos grupos populacionais [Ben96]. Conta-se que Bertillon não concordava com as precárias metodologias empregadas na época para identificação de criminosos, constituídas apenas por relatos transcritos. Ele passou então a recortar fotografias de criminosos, isolando cada característica facial. Esse "banco" de características passou a funcionar como base para a montagem das faces descritas pelas testemunhas.

Esse tem sido o princípio adotado pelos kits de composição disponíveis comercialmente: montar a face a partir de um conjunto de componentes. A diferença fica por conta do número de características empregadas e da representação adotada: desenhos ou fotografias. A maioria dos kits assume a presença de um operador que assiste a testemunha na tarefa de montar o retrato. Dentre os principais kits existentes, sem o emprego do computador, constam o Identikit e o Photofit [Lee94]. Entretanto, o método que foi mais utilizado no mundo inteiro e ainda empregado em muitos países é o de desenho manual [Per95b].

Com o avanço tecnológico, surgiram vários sistemas de retrato falado baseados em computador. Dois deles são o E-FIT [Asp95] e o CompuSketch [Vis91]. O CompuSketch é um dos sistemas de composição de retratos falados utilizados pela Polícia Federal Brasileira, a exemplo do Departamento de Polícia Federal de Pernambuco, e da Polícia Militar de São Carlos. O CompuSketch possui dois modos de utilização. No primeiro, mais burocrático, o perito responde a questionários de perguntas relacionadas ao criminoso e ao crime em geral. Todos os dados relativos ao crime que possam ser utilizados durante as investigações criminais são registrados. No final, uma versão do retrato é montada com base nas informações fornecidas, principalmente aquelas relativas aos caracteres físicos faciais do criminoso. $O$ segundo modo de utilização do CompuSketch, chamado QuickSketch, pula a etapa de questionários e passa diretamente para o editor do retrato. $O$ perito então aborda a testemunha, fazendo as perguntas que 
achar apropriadas. O retrato é formado por desenhos de partes da face: cabelo, olhos, boca, nariz, orelhas, sobrancelhas e contorno geral do rosto.

Um problema que pode acontecer com um retrato falado, conforme descrito anteriormente, é que às vezes a testemunha não reconhece o retrato final como sendo o do suspeito, mesmo tendo ela descrito todas as características necessárias para a elaboração do retrato falado. Na figura 2.6 pode-se ver um retrato falado desenhado por computador e a imagem real da pessoa.

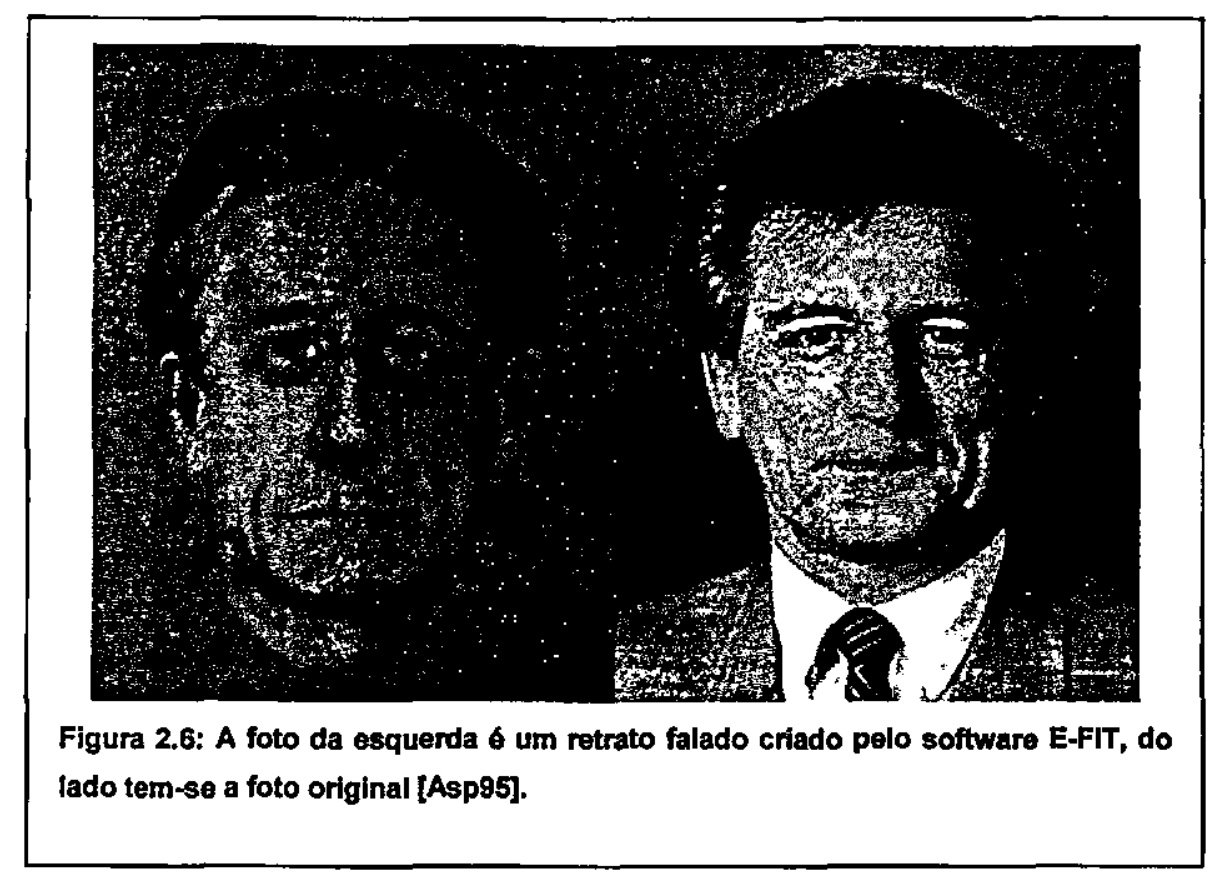

Há quatro fatores fundamentais relacionados à estrutura e uso de ferramentas de composição de retratos falados (face recall tools):

1. interferências externas;

2. representações adotadas;

3. representatividade dos componentes escolhidos;

4. estratégias para composição do retrato.

Interferências Externas: pode a exposição da testemunha a dezenas ou centenas de padrões de componentes de face prejudicar sua memória? Não existem evidências que mostrem as dificuldades unicamente associadas a sistemas de composição de retratos; resultados dependem do estilo e sensibilidade do operador no momento de abordar a testemunha.

Representações Adotadas: basicamente são dois os tipos de representações utilizados pelos kits/sistemas de composição de faces: fotografias ou desenhos. Quanto mais realista for a representação adotada, maior é a precisão da identificação. Isso privilegia os kits baseados no Photofit, que utiliza fotografias, em lugar 
de desenhos, na representação de seus componentes.

Representatividade e variaçđo dos componentes: diz respeito a quais características da face devem ser utilizadas na composição do retrato. À faixa de variação que cada uma destas características.

Estratégias para a composição do retrato: a maioria dos kits/sistemas de composição de retratos falados encoraja a testemunha a relembrar ou selecionar as características da face individualmente. Análises de descriçðes espontâneas, entretanto, evidenciam que as pessoas, em geral, utilizam atributos mais globais como idade, expressão e caráter. Há também evidências que mostram como os kits atuais comprometem a performance de pessoas que se utilizam dessas estratégias globais na descrição de uma face.

Além das dificuldades mencionadas acima, é preciso ter em mente que o retrato falado é apenas um dos procedimentos empregados na investigação de um crime. Ele pode, e deve, ser combinado com outras informaçőes.

As etapas que compðem a investigação de um crime ocorrem, em geral, na ordem anteriormente apresentada pela figura 2.5 .

As entrevistas iniciais servem para obter um perfil genérico do criminoso que direcionará, de certa forma, as etapas seguintes. Uma análise de fotografias ou um alinhamento, por exemplo, podem ser montados com base nas descrições fornecidas pela testemunha e nas representações gráficas obtidas. A etapa da análise de fotografias, em particular, poderia utilizar o retrato obtido como um dos critérios para a seleção das fotografias utilizadas.

Retratos falados são utilizados para reduzir o universo dos suspeitos de um crime. Não é uma técnica a ser aplicada isoladamente, mas uma primeira tentativa de solução que produzirá subsídios para outras técnicas de investigação criminal.

A análise ou reconhecimento de fotografias de faces, por sua vez, é uma atividade mais natural e fácil de ser realizada que a descrição de uma face, além de produzir os resultados mais efetivos. $O$ avanço tecnológico atual permite não somente o uso de ferramentas computacionais para catálogo de todas as informações de reconhecimento, como também o desenvolvimento de ferramentas potentes de auxílio à deteç̧ão e indexação de indivíduos e seus dados. Tal avanço vem permitir uma melhoria na técnica de investigação e conseqüente aumento de produtividade na localização de suspeitos e captura de criminosos.

\subsection{Análise de Aplicações}

Em muitos casos, cartões magnéticos e cartões de chips, bem como senhas, não são métodos seguros de controle de acesso. Cartð̃es podem ser roubados ou perdidos, senhas podem ser esquecidas ou ser descobertas [Sie96]. 
Um sistema realmente seguro deve ter habilidade de conferir se a pessoa autorizada a entrar numa determinada área, por exemplo, é a que está fisicamente presente. Isso é possível implementando algum método que analise as características das pessoas. Um método promissor é o de reconhecimento de faces porque um sistema usando esse método é fácil de ser usado e ao mesmo tempo muito seguro. Há muitas áreas de aplicações para os sistemas VACS (Visual Access Control System): segurança de empresas, aeroportos, sistemas de computador, banco 24 horas, identificação de suspeitos, etc.

Um exemplo de segurança seria o uso de um sistema de reconhecimento de faces em bancos 24 horas, que requerem sempre um alto grau de segurança no acesso às contas dos clientes. No caso, além do cliente ter que utilizar o cartão e sua senha pessoal, há uma pequena câmera defronte ao painel do sistema que captura sua foto e compara com a base de dados de fotos de seus clientes. Desse modo fica impossível a utilização de cartões e senhas roubados. A identificação, nesse caso, é maior que $99 \%$, o que garante poucos inconvenientes tanto para o cliente como para o banco. Um sistema desse tipo, chamado FaceVACS, é utilizado por uma banco alemão [Sie96].

O reconhecimento de faces deve também ser apto a reconhecer pequenas alterações na fisionomia da pessoa, como por exemplo, um corte de cabelo diferente, uso de óculos, ou diferentes express ̃̃es faciais. Essas "pequenas alterações" devem ser tratadas pelo procedimento de tolerância, já que raramente o sistema vai conseguir capturar uma face idêntica à cadastrada na base de dados. A tolerância é necessária pois normalmente a comparação não é feita entre as imagens, mas entre as características das imagens, as quais devem ser iguais dentro de um certo limite. Esses limites podem ser ajustados. Dependendo da aplicação, às vezes é melhor rejeitar um reconhecimento, mesmo que seja a pessoa certa, do que dar autorização indevida a uma pessoa não cadastrada.

Existem vários esquemas conhecidos para essas aplicações de reconhecimento, e o algoritmo empregado nesses esquemas variam de acordo com:

1. o grau de confiabilidade desejado;

2. tempo de espera para o reconhecimento;

3. o tamanho da base de dados e requisitos da aplicação quanto à tolerância a treinamento.

No caso de sistemas de segurança de empresas onde a população é relativamente pequena, e o sistema pode ser treinado para uma identificação confiável, um algoritmo adequado seria o de redes neurais (veja próximo capítulo), pois a resposta do sistema tem que ser "sim" ou "não" para a comparação feita entre as faces. Não pode haver dúvidas e o tamanho pequeno da população permite um tempo de processamento rápido.

Um dos sistemas comerciais existentes para esse e outro tipo de aplicações semelhantes é o ZN-Face, que utiliza de redes neurais e leva menos de 3 segundos para fazer a identificação em um Pentium-PC de 
90Mhz [Boc96]. Outro sistema comercial, também utilizado para este tipo de aplicação é o TrueFace que é compatível com plataformas Win95, NT e Sun Solaris, e leva menos de 2 segundos para fazer a identificação [Mir95].

$\mathrm{Na}$ figura 2.7 pode-se ver um diagrama genérico das fases que compõem o reconhecimento automático de faces em sistemas de segurança.

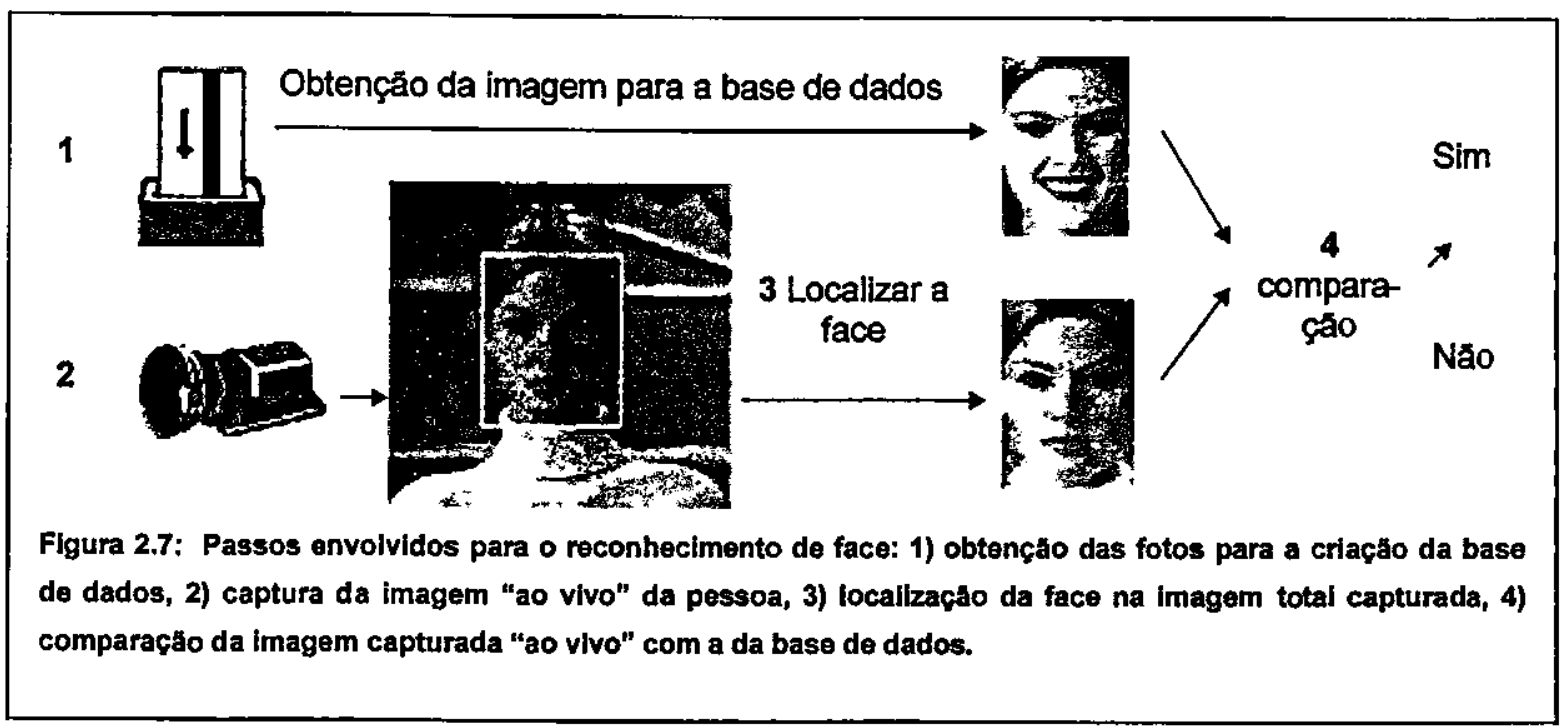

No caso do sistema de identificação de suspeitos desenvolvido neste trabalho, não há a necessidade de $100 \%$ de certeza de reconhecimento, como teria, por exemplo, no caso de um sistema de identificação em real time para segurança industrial. Tratando-se de procedimentos policias, que é o caso desse sistema, são três as abordagens que podem ser feitas durante um reconhecimento:

1. Reconhecer se uma foto já faz parte da base de dados de fotos do sistema. Isso é muito útil para a polícia saber se um suspeito já está ou não cadastrado no sistema, pois muitas vezes esses indivíduos utilizam de RGs falsos e são sempre tratados como réu primário.

2. Oferecer uma ordenação das fotos da base de dados por semelhança à foto conhecida. Isso é de suma importância para o processo de análise fotográfica. Normalmente, a vítima procura a foto do suspeito num álbum de fotografia. $O$ problema é que esse processo é muito cansativo e pouco eficiente como visto na seção 2.3. Com o auxílio do sistema de reconhecimento, as fotos da base de dados são ordenadas de modo que a vítima não precisa olhar o álbum todo, apenas algumas fotos, agilizando $\mathrm{e}$ tornando mais eficiente o processo.

3. Reconhecimento de uma face baseada em características introduzidas pelo procedimento do retrato falado. Com base nas características fornecidas para a elaboração de um retrato falado, é feita uma pesquisa na base de dados para saber se há alguma face que se assemelhe ao retrato falado. Essa abordagem não foi implementada neste trabalho; ela será apenas discutida na conclusão. 
O algoritmo de reconhecimento escolhido para essa aplicação foi o PCA (apresentado com mais detalhes no capítulo 3), pois ele facilita o manuseio de bases de dados maiores se o critério de busca não for rígido, como é o nosso caso.

Serão discutidos no próximo capítulo alguns algoritmos existentes para o reconhecimento automático de faces. 


\section{Algoritmos para Reconhecimento de Faces}

O reconhecimento automático de faces possui dois problemas que devem ser levados em conta antes da elaboração do sistema [Alm96]:

1. Deve-se achar um conjunto de características que não variem com o tamanho, rotação, translação, iluminação, expressão facial, e com disfarces;

2. É necessária uma classificação mínima de erros para comparar as características obtidas de uma imagem facial desconhecida com uma imagem conhecida, vinda de um banco de dados.

Deve-se ter em mente que a captura de uma imagem para um banco de dados pode ser feita de várias maneiras. $O$ correto seria sempre se ter o mesmo fundo para imagem, de preferência um fundo liso que desse contraste com a face da pessoa. Só que em algumas circunstâncias, isso não pode ser controlado, muito menos a qualidade da iluminação e o uso de aparatos, como óculos de sol, boné, chapéus, etc. Dependendo do uso que irá ter o sistema de reconhecimento de faces, esses itens podem ser controlados ou não. $O$ ideal seria ter sempre um fundo liso, com a face da pessoa sempre na mesma posição, e com a mesma iluminação, mas no caso de sistemas de segurança (em tempo real) isso é praticamente impossível. Já em sistemas de reconhecimento que não são em tempo real, algumas características da foto da face podem e devem ser ajustadas. Tendo em mente esses fatos, deve-se pensar em como fazer uma normalização das imagens antes de executar o algoritmo de reconhecimento propriamente dito. E ver também qual é o melhor algoritmo para o sistema que será desenvolvido. Um algoritmo que funciona muito bem para um sistema pode não apresentar bons resultados para outro sistema.

Outro fator que deve ser levado em conta é que se o reconhecimento automático de faces deve ser feito em tempo real ou não. O reconhecimento em tempo real é possivel para sistemas de segurança como os de empresas e aeroportos, onde a população de imagens a ser classificada é pequena.

Os sistemas baseados em medidas de características de faces têm, até agora, utilizado duas visões da face [Oli95]: a visão frontal e a visão lateral, mas normalmente com estratégias separadas. Os sistemas que usam uma visão lateral da face excluem características disponiveis em uma visão frontal, o que restringe 
suas listas de características. Entretanto, eles levam em consideração relevos como nariz, queixo e testa, não disponíveis na visão frontal. Sistemas baseados em imagens de visão frontal possuem muito mais características, geralmente acrescentando mais medições geométricas. Contudo esses sistemas "não possuem" informações sobre relevos faciais. Apesar disso, com técnicas de processamento de imagens, pode-se até calcular a altura dos relevos (nariz, boca, etc.), com o sério inconveniente de que todas as imagens têm que estar com as mesmas condições de iluminação para que tal medida seja confiável.

Basear um procedimento de reconhecimento somente em visões frontais ao invés de visões laterais é uma boa escolha, já que uma visão frontal pode conter um conjunto mais rico de características disponível, além do fato da maioria dos documentos registrarem imagens de faces somente com visões frontais, tais como passaporte e registro geral (R.G.). Para satisfazer requisitos de reconhecimento dentro de populações grandes, é necessário um conjunto grande de características. Isso não é conseguido somente fazendo mais medições geométricas. É evidente que o reconhecimento de faces pode estar baseado somente em visões laterais, porém o conjunto de características disponíveis não será tão rico quanto o necessário para a aplicação.

Existem várias abordagens para algoritmos de reconhecimento de faces. Os primeiros algoritmos para reconhecimento foram centrados em vetores de características geométricas (ver seção 3.4) seguidos pelos métodos de template matching (apresentado na seção 3.1), que são baseados em métodos de processamento de imagens para comparação de padrões.

Duas classes de algoritmos bastante utilizados para esse fim são baseados em Análise de Componente Principal (Principal Component Analysis - PCA), apresentada na seção 3.2, e em Redes Neurais, apresentada na seção 3.3 .

A seção 3.4 resume técnicas alternativas de representação e reconhecimento de faces.

\subsection{Template Matching}

O método de template matching é somente efetivo quando as imagens investigadas possuem o mesmo tamanho, a mesma orientação e a mesma condição de iluminação das imagens na base de dados. Esse método opera de modo a realizar correlações diretas entre segmentos de imagens [Cyg96][Ban97].

Há várias variações do algoritmo de template matching. $\mathrm{O}$ que será apresentado aqui é o que faz uso de uma biblioteca pré-estabelecida de templates e compara esses com imagens que se deseja reconhecer.

O sucesso do template matching para o reconhecimento de padrões depende da robustez da biblioteca de padrões. Quanto mais templates houver na biblioteca da mesma face, com pequenas variações de posições, melhor será a taxa de acerto no reconhecimento [Cyg96][Bru93].

A determinação automática de similaridade local entre templates de características em todas as locações 
da área de pesquisa (melhor enquadramento - best fit) tradicionalmente tem sido feita utilizando métodos de correlação cruzada ou reconhecimento de padrões [Nas96].

Nesse esquema uma métrica de comparação é utilizada para cada template e os valores mais altos obtidos correspondem à face desejada.

$O$ algoritmo de template matching usa, via de regra, um produto interno normalizado pixel-a-pixel como métrica para comparação. A equação usada para calcular esse valor é mostrada na equação 3.1 . Nessa equação, $\mathrm{A}$ e $\mathrm{B}$ referem-se às matrizes bi-dimensionais que representam a face $\mathrm{e} o$ template respectivamente.

$$
M=\frac{\langle A, M\rangle}{\sqrt{\langle A, A\rangle\langle B, B\rangle}}
$$

A notação $<\mathrm{X}, \mathrm{Y}\rangle$ acima mostra a função do produto interno. $\mathrm{O}$ produto interno fornece um método para calcular a projeção de um vetor em outro (ou, nesse caso, uma imagem em outra). Para as duas matrizes A e B de tamanho NxM o produto interno pode ser calculado pela equação 3.2:

$$
\begin{aligned}
& <A, B>=\sum_{i=0}^{=N} \sum_{j=0}^{j=M} A_{i, j} \cdot B_{i, j} \\
& =\mathrm{A}_{0,0} \cdot \mathrm{B}_{0,0}+\mathrm{A}_{0,1} \cdot \mathrm{B}_{0,1}+\ldots \mathrm{A}_{\mathrm{N}, \mathrm{M}} \cdot \mathrm{B}_{\mathrm{N}, \mathrm{M}}
\end{aligned}
$$

Isso mostra que para quaisquer duas imagens contendo somente valores positivos, a comparação métrica irá sempre estar entre 0 e 1 , onde 0 representa imagens completamente ortogonais e 1 representa imagens completamente correlacionadas. Para aplicar a equação 1, ambas as imagens devem ter o mesmo tamanho. Se não tiverem, elas devem passar por um pré-processamento onde ocorre a normalização da imagem capturada em relação ao template pré-estabelecido.

Apesar de ser um método efetivo em condições ideais, o template matching exige características rígidas de similaridade de condições entre captura de imagens, o que pode ser inadequado para muitas aplicações.

Será mostrado a seguir um outro método clássico de reconhecimento de faces, usando Análise de Componente Principal.

\subsection{Análise do Componente Principal}

A PCA (Principal Component Analysis ou expansão Karhunen-Loève - KL) é uma das abordagens mais populares para o problema de reconhecimento de faces. Em geral, esse método é utilizado para análise de dados multivariados e tem como objetivo procurar um subconjunto de direções principais num conjunto de dados de qualquer distribuição estatística. A transformação de um conjunto de dados inicial num espaço de componente principal minimiza a correlação cruzada de uma única amostra de dados 
[Gro94][Too93][Sir87].

Em suma o que o PCA faz é reduzir a dimensão de um conjunto ou espaço para que esta nova base descreva melhor um "modelo" típico do conjunto. No caso de reconhecimento de faces, os "modelos" são o conjunto de faces a serem treinadas [Rom97][Mog95][Swe95].

KL é um ótimo método linear para reduzir redundância em um conjunto de dados. PCA gera um conjunto de eixos ortogonais de projeção conhecida como componente principal (auto-vetores), dos dados de entrada, distribuídos em ordem decrescente de variância. A transformada de $\mathrm{KL}$ é um método estatístico bem conhecido para extração de características e projeção de dados multivariados e tem sido usada amplamente em reconhecimento de padrões, processamento de sinais, processamento de imagens e análise de dados. Através de KL, pontos em uma entrada espacial de dimensão $n$ são projetados em um espaço de dimensão $m, m \leq n$ [Law94][Kir90][Val94].

A PCA é aplicada a um conjunto inicial de faces e expandida através dos auto-vetores (eigenvectors) obtidos, e seu cálculo segue os seguintes passos [Gro94]:

1. Cálculo da média das imagens de um conjunto, onde:

$s=$ conjunto de dados de dimensão $\mathrm{N}$, geralmente no caso de reconhecimento de faces, é uma matriz quadrada;

$\mathbf{m}=$ vetor resultante (médio);

$x=$ imagem;

$$
\mathbf{m}=\frac{1}{s} \sum_{j=1}^{s} \mathbf{x}_{j}
$$

2. Cálculo dos vetores diferença $\mathbf{d}_{\mathrm{j}}$ :

$$
\boldsymbol{d}_{j}=\boldsymbol{x}_{j}-\boldsymbol{m}
$$

O passo seguinte é o cálculo dos auto-vetores (eigenvectors) $u_{\mathrm{k}}$ e auto-valores (eigenvalues) $\lambda_{\mathrm{k}}$ da matriz de covariância $\mathbf{C}$, a qual é dada pela expressão abaixo:

$$
\mathrm{C}=\frac{1}{S} \sum_{j=1}^{s} \mathbf{d}_{j} \mathbf{d}_{j}^{T}
$$

Há vários métodos para o manuseio numérico da matriz de covariância e para cálculo dos auto-vetores e auto-valores. No presente trabalho, que implementou o PCA, foi usado o método das potências. Esse método será descrito em detalhes no capítulo 4.

Após resolver esse problema dos auto-vetores, qualquer dado $\times$ pode ser projetado nesse auto-espaço gerado por $\mathbf{u}_{\mathrm{k}}$ da seguinte forma: 


$$
\omega_{k}=\mathbf{u}_{k}^{T}(\mathbf{x}-\mathbf{m})
$$

onde $\omega$ são as coordenadas de $\mathbf{x}$ no auto-espaço.

Da mesma forma, qualquer dado $\mathbf{x}$ pode ser expandido como uma combinação linear de $u_{k} \omega_{k}$

$$
\mathbf{x}=\mathbf{m}+\frac{1}{s} \sum_{k=1}^{s} \omega_{k} \mathbf{u}_{k}
$$

$\omega_{k}$ descrevendo a contribuição de cada auto-vetor.

A redução da dimensionalidade pode agora ser obtida ordenando os auto-vetores $\mathbf{u}_{\mathbf{k}}$ de acordo com o valor absoluto dos auto-valores $\lambda_{\mathrm{k}}$ correspondentes, e tomando apenas os maiores s-r para a expansão de dados na equação (3.3).

$O$ vetor $\Omega^{T}=\left(\omega_{1}, \omega_{2}, . . \omega_{s-r}\right)$ pode ser interpretado como um vetor característica que descreve propriedades estatísticas do conjunto de dados.

Pode-se afirmar que a análise de cluster (agrupamento) descrita acima também pode ser imaginada como um agrupamento de várias dimensóes do conjunto de dados com características altamente correlacionados. Portanto um subconjunto menor pode ser produzido. $O$ uso dessa abordagem em reconhecimento de faces é apresentado a seguir.

\section{Codificação de Imagens Usando a Transformação de KL}

A PCA é considerada um método popular para codificação de imagens, por exemplo, para remover correlaçóes de dados altamente correlacionados como imagens faciais. A figura 3.1 mostra um conjunto de 20 imagens faciais, e a figura 3.2 mostra os eixos principais desse conjunto de dados. No exemplo ilustrado, foram usadas imagens ao nível de pixel como vetores de dados de dimensão $64 \times 64$. $O$ eixo principal resultante $\mathbf{u}_{\mathrm{k}}$ pode também ser visualizado como imagens de mesmo tamanho de pixels. Na figura 3.2 é indicado que os diferentes auto-vetores enfatizam as variações locais do conjunto em valores de cinza de dados de imagem. As imagens são ordenadas de acordo com o tamanho do auto-valor associado. No canto superior esquerdo pode-se ver a imagem média.

Usando a equação (3) pode-se reconstruir qualquer imagem do conjunto de dados pelas médias de um conjunto limitado de auto-vetores derivados. Isso corresponde a um esquema de codificação que é ilustrado nas figuras 3.3, 3.4 e 3.5, as quais mostram a eficiência da codificação quando usando diferentes números de auto-vetores. 


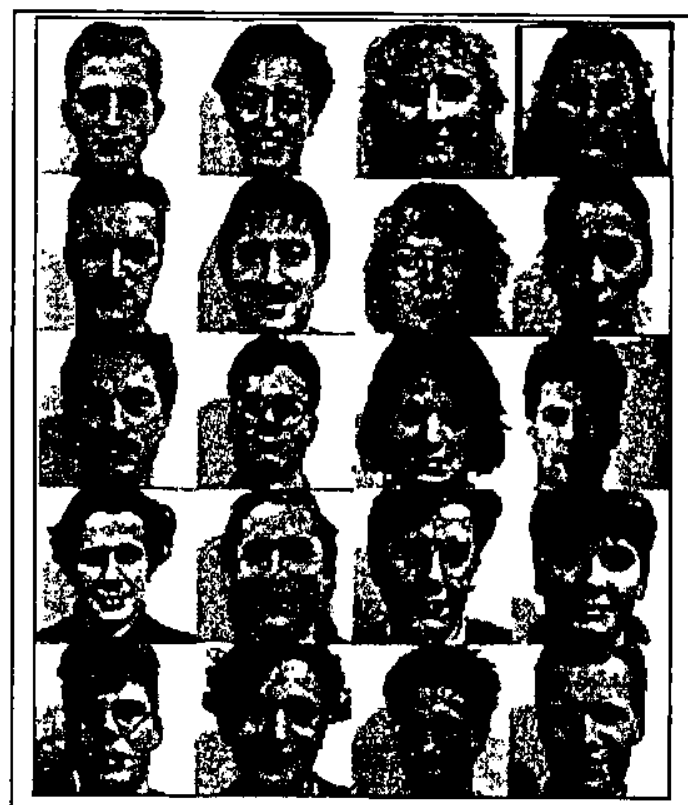

Figura 3.1: Conjunto inicial de 20 imagens facials [Gro94].

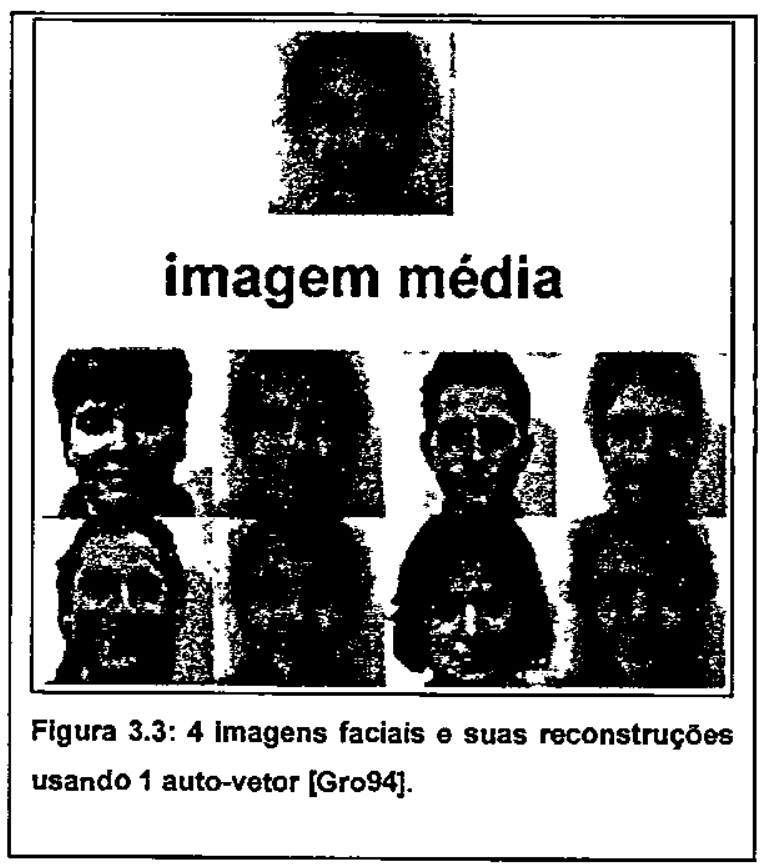

Embora a interpretação visual das fotografias de auto-vetores mostrados na figura 3.2 de algum modo

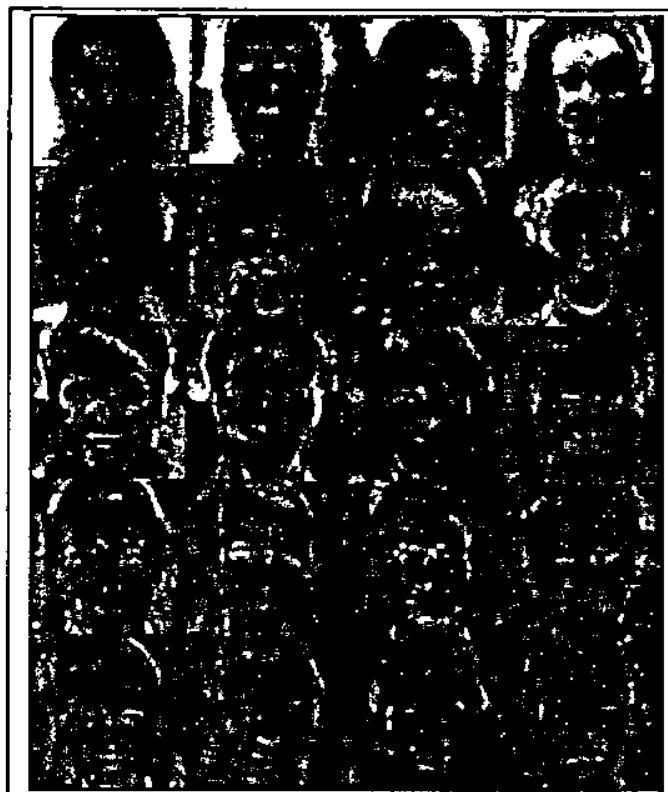

Figura 3.2: Vetor médio (canto superior esquerdo) e auto-vetores do conjunto de dados [Gro94].

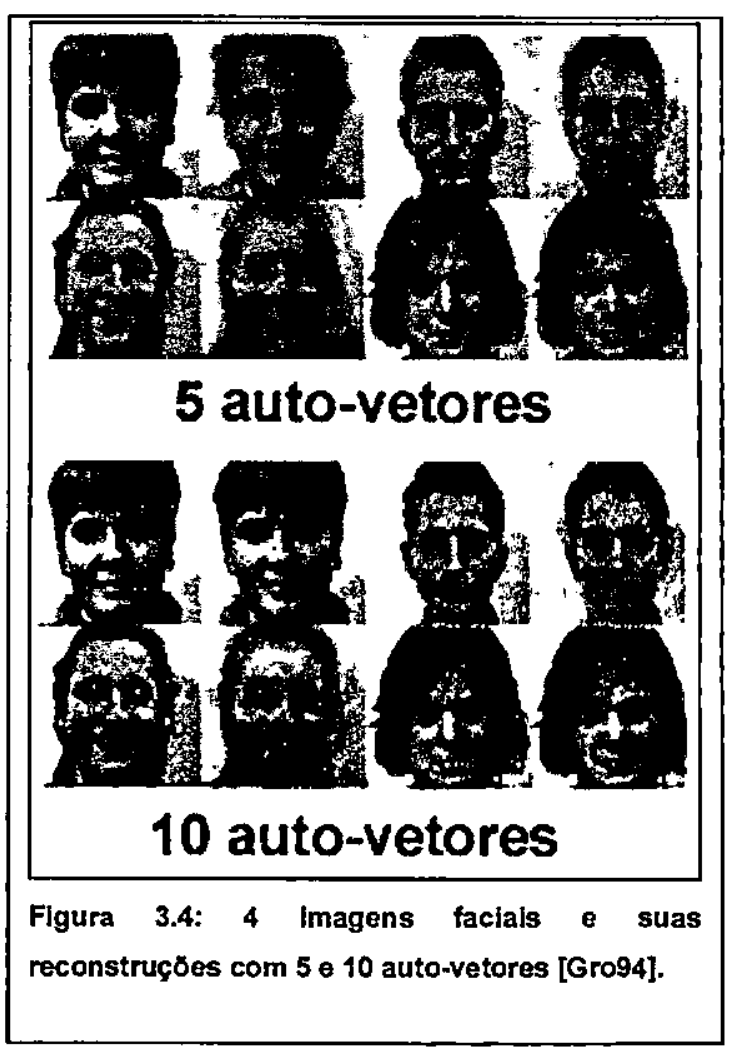

mostra a correspondência entre as regiões enfatizadas por vetores particulares e por características faciais simbólicas como cabejo, olhos ou nariz, é necessário afirmar que apenas propriedades estatísticas são visualizadas. Isso também deve ser observado quando se estiver estimando a qualidade da reconstrução e codificação. 


\section{Uso Prático de PCA na Procura de Características Faciais}

Os passos do uso da análise de componente principal para procurar características faciais é mostrada na figura 3.6. No passo inicial, um conjunto de faces, partindo de um banco de faces a serem incluídas, é projetado num sub-espaço definido pelos seus autovetores mais importantes. As características dos vetores derivados desse procedimento servem como um treinamento básico para qualquer esquema de classificação supervisionado. Por razões de robustez, usualmente imagens faciais diferentes de uma mesma pessoa são utilizadas. Uma vez "treinada" a classificação, já se pode conseguir discriminar qualquer nova e desconhecida imagem por projeção e classificação.

Supondo-se que esse método irá providenciar uma

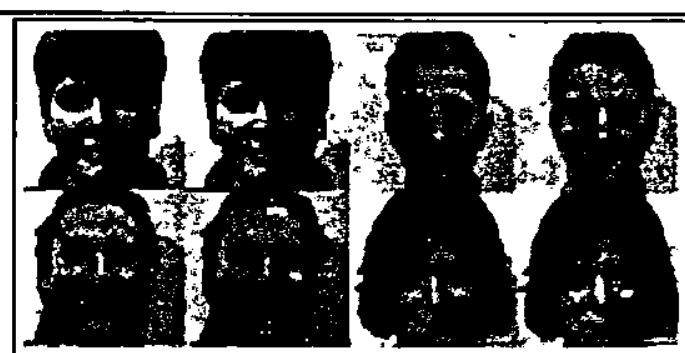

15 auto-vetores

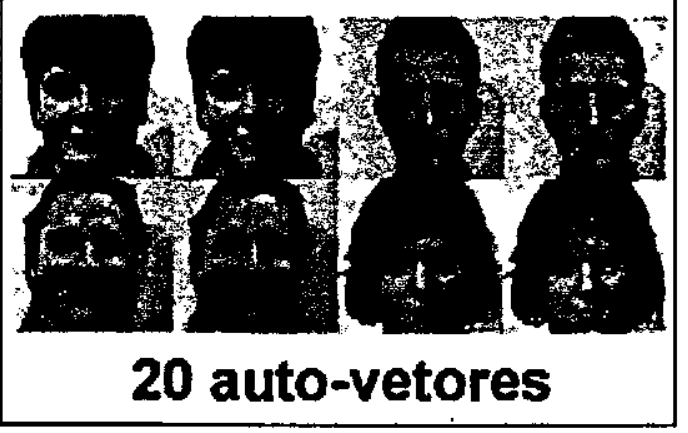

Figura 3.5: Imagens faciais e suas reconstruçőes com 15 e 20 auto-vetores [Gro94]. ótima representação das características faciais de diferentes pessoas, um simples classificador euclidiano deve ser suficiente. Esse processo é descrito abaixo e ilustrado na figura 3.6 :

De acordo com o conceito de PCA descrito acima, é calculado para cada pessoa $\mathrm{I}(\mathrm{I}=1, . ., \mathrm{Q})$ a projeção $\Omega_{\mathrm{ij}}$ $=\left(\omega_{i j}{ }^{(1)}, ., \omega_{i j}{ }^{(K)}\right), j=1, . ., P$ (onde $P$ é o número de fotos da mesma pessoa na base de dados), e sua média global das imagens faciais:

$$
\bar{\Omega}=\frac{1}{P} \sum_{j=1}^{P} \boldsymbol{\Omega}_{i j}
$$

Projetando a nova imagem facial no auto-espaço, temos:

$$
\Omega_{\text {novo }}
$$

Feito isso, calcula-se a distância euclidiana $\varepsilon_{\mathrm{i}}$ com:

$$
\varepsilon_{i}=\left\|\boldsymbol{\Omega}_{\text {novo }}-\overline{\boldsymbol{\Omega}}_{i}\right\|
$$

Em seguida acha-se o mínimo para todas as imagens da base:

$$
\bar{\varepsilon}=\min _{i}\left[\varepsilon_{i}\right]
$$


e para a melhor comparação define-se um limitante $\tau$ para rejeitar faces desconhecidas, se $\bar{\varepsilon} \geq \tau$ Um aspecto fundamental para a utilização de PCA é a escolha de uma amostra válida numa população grande.

O classificador euclidiano não é o melhor classificador possível, uma vez que a representação da base por PCA não é ótima.

Assim, melhores classificadores foram projetados para melhorar a robustez do método, entre eles, aqueles utilizando redes neurais.

O uso de redes neurais para o reconhecimento de faces é apresentado a seguir.
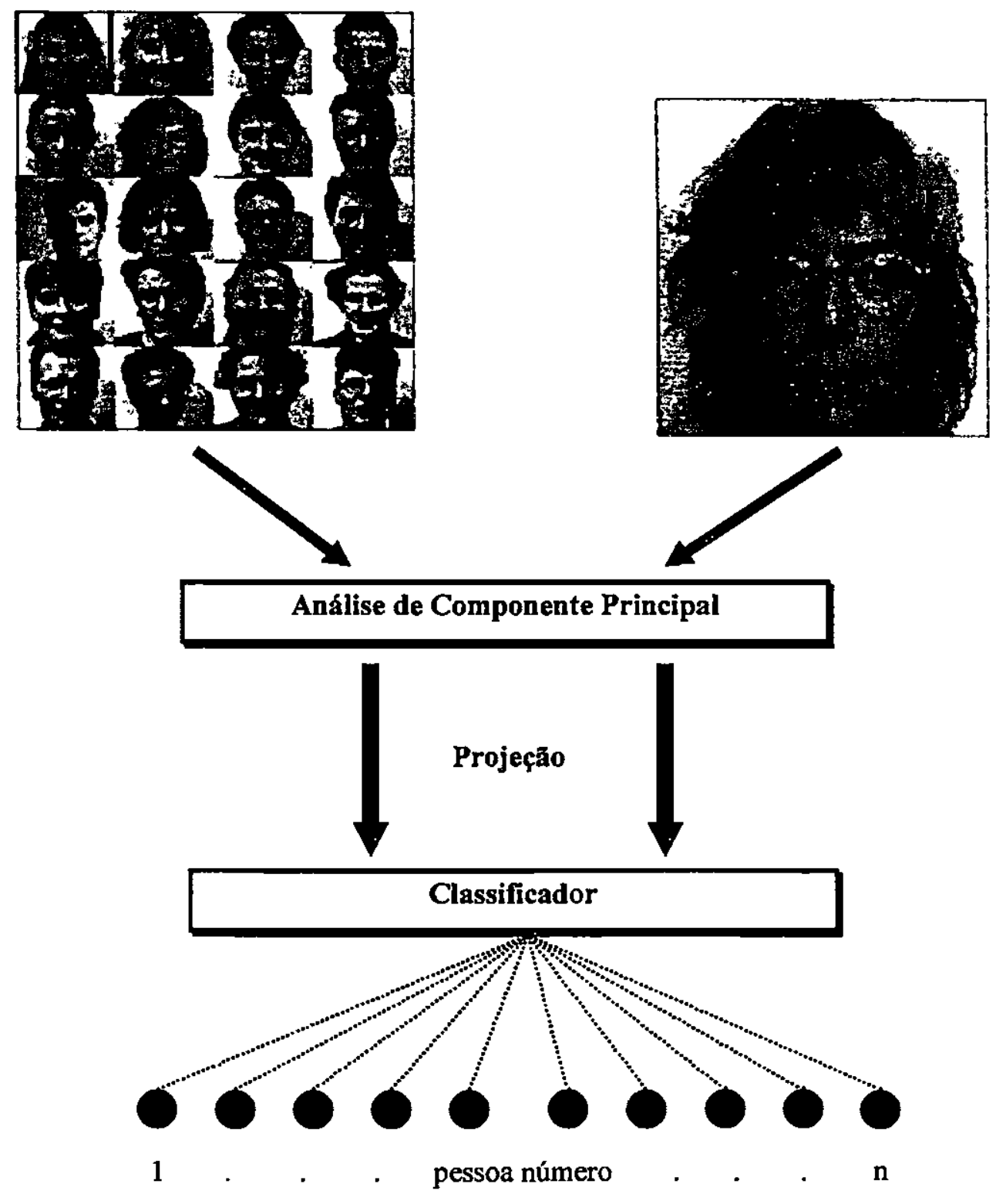

Figura 3.6: Esquema geral para reconhecimento de faces usando PCA [Gro94]. 


\subsection{Redes Neurais}

O neurônio natural, célula fundamental do sistema nervoso dos mamiferos, é o ponto de partida para a tentativa de construção de máquinas que simulem o funcionamento do cérebro humano. $O$ termo Redes Neurais é utilizado para descrever um número de diferentes modelos destinados a imitar algumas das funções do cérebro humano [Dav91].

O desenvolvimento de um modelo que simule o cérebro (utopia no presente e futuro recente) passa por uma caracterização completa dos neurônios, células base de toda a computação cerebral. Em seguida, deve-se interconectá-los numa arquitetura adequada ao problema em tratamento; por fim, deve-se dotar essa estrutura de algum procedimento que mude o comportamento dos neurônios a fim de que "aprendam" e levem a rede a gerar alguma resposta satisfatória para a questão levantada. Atualmente já existem vários paradigmas de interconexão de neurônios e algoritmos de aprendizagem, modo como é chamado o procedimento capaz de "ensiná-los" . Cada paradigma que surge pretende dar solução a uma classe de problemas em particular. Hoje em dia os modelos baseados em redes neurais (ou conexionistas) são empregados com bom desempenho em diversas áreas de aplicação, notadamente em reconhecimento de padrões, compressão de dados, predição de séries numéricas e aproximação de funções [Was89].

Redes neurais são cada vez mais empregadas no reconhecimento de padrões, devido à complexidade do problema, que dificilmente pode ser abordado em termos algorítmicos [Dav91]. Através de um processo de treinamento, as redes neurais passam a ser capazes de reconhecer padrões, mesmo que os dados utilizados nesse treinamento sejam não-lineares, incompletos ou até mesmo contraditórios. $\mathrm{A}$ habilidade de manipular esses dados imprecisos faz com que as redes neurais sejam extremamente eficazes em tarefas onde especialistas não estão à disposição ou um conjunto de regras não pode ser facilmente formulado [Per95a].

Redes neurais são compostas por diversas unidades computacionais paralelas, interconectadas parcial ou totalmente. Cada uma dessas unidades ("neurônios artificiais") efetua um certo número de operaçб̃es simples e transmite seus resultados às unidades vizinhas com as quais possui conexão. No caso da visão por computador, tanto a dificuldade de estabelecer algoritmos de reconhecimento quanto a natureza dos dados com os quais se trabalha, indicam as redes neurais como uma solução promissora. Deve-se levar em conta também o poder computacional dos computadores de hoje, já que redes neurais exigem grande capacidade de processamento. Ela é mais recomendada quando houver uma pequena população, como no caso de seu uso em sistemas de segurança de empresas, controlando o acesso de funcionários e visitantes a certas áreas [Jia94].

Um dos algoritmos de treinamento mais difundidos em redes neurais é o backpropagation [Dav91][Val94], que permite obter ótimos resultados em diversas aplicaçôes, inclusive em reconhecimento de padrões. Esse algoritmo representa a solução matemática para os problemas 
encontrados pelo modelo perceptron [Dav91].

Multi-layer perceptron (MLP) são redes neurais feedforward treinadas com 0 algoritmo de backpropagation. O MLP (figura 3.7) são redes supervisionadas, portanto requerem uma resposta desejada para serem treinados [Mur95]. O MLP, que aprende como transformar os dados de entrada na resposta desejada, é amplamente utilizado na classificação de padrões. Com uma ou duas camadas escondidas (hidden layers), ele pode implementar, virtualmente, qualquer mapeamento de entrada-saída [Neu96]. A maioria das aplicações de redes neurais envolve o MLP.

O primeiro passo no uso do algoritmo de backpropagation é o seu treinamento, que envolve três passos (figura 3.7) [Ray96]:

1. feedforward da entrada. Durante o feedforward, cada neurônio de entrada (chamado $\mathrm{X}_{\mathrm{i}}$ ) passa seu sinal através de um elo de conexão, (chamado de $\mathrm{V}_{\mathrm{ij}}$ ) para os neurônios escondidos (hidden layer) apropriados (chamado de $Z_{j}$ ). Cada neurônio escondido calcula sua ativação e envia seu sinal através da conexão apropriada (chamada $W_{j k}$ ) para os neurônios de saída (chamado $Y_{k}$ ). Os neurônios de saída calculam suas ativações para formar o feedforward de saída da rede neural.

2. propagação para trás (backpropagation) do erro. O erro para cada neurônio de saída é calculado comparando com o vetor alvo das saídas desejadas. Esse erro é então propagado para as camadas inferiores da rede obtendo a ponderação dos erros da camada superior. Os pesos pelos quais cada erro serão multiplicados são determinados pelo peso da conexão dos dois neurônios em questão.

3. ajuste apropriado para os erros. Os erros calculados acima serão usados para ajustar os pesos das várias conexões. $\mathrm{O}$ ajuste dos pesos $\mathrm{W}_{\mathrm{jk}}$ (do neurônio escondido $\mathrm{Z}_{\mathrm{j}}$ para o neurônio de saída $\mathrm{Y}_{\mathrm{k}}$ ) é determinado pelo erro no neurônio $Y_{k}$ e a ativação do neurônio $Z_{j}$. Similarmente o ajuste dos pesos $V_{i j}$ (do neurônio $X_{i}$ para o neurônio escondido $Z_{j}$ ) é determinado pelo erro associado com o neurônio $Z_{j}$ e a ativação do neurônio $X_{i}$.

Esses três passos são repetidos até os erros dos neurônios de saída serem considerados satisfatórios.

Uma das funções de ativação usadas em redes MLP/backpropagation é uma função semi-linear do tipo "sigmoide" ou "S-shaped" (figura 3.8). 


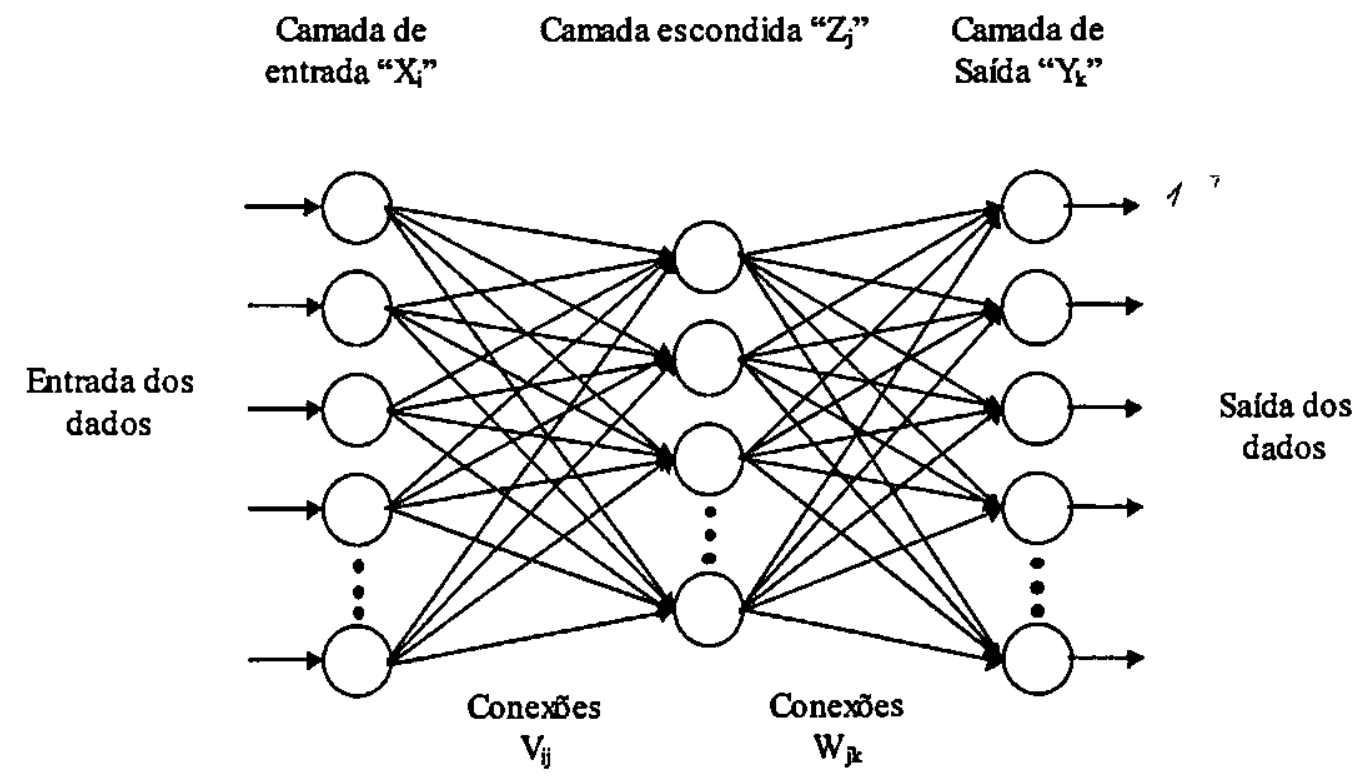

Figura 3.7: MLP/Backpropagation de tris camadas [Ray96].

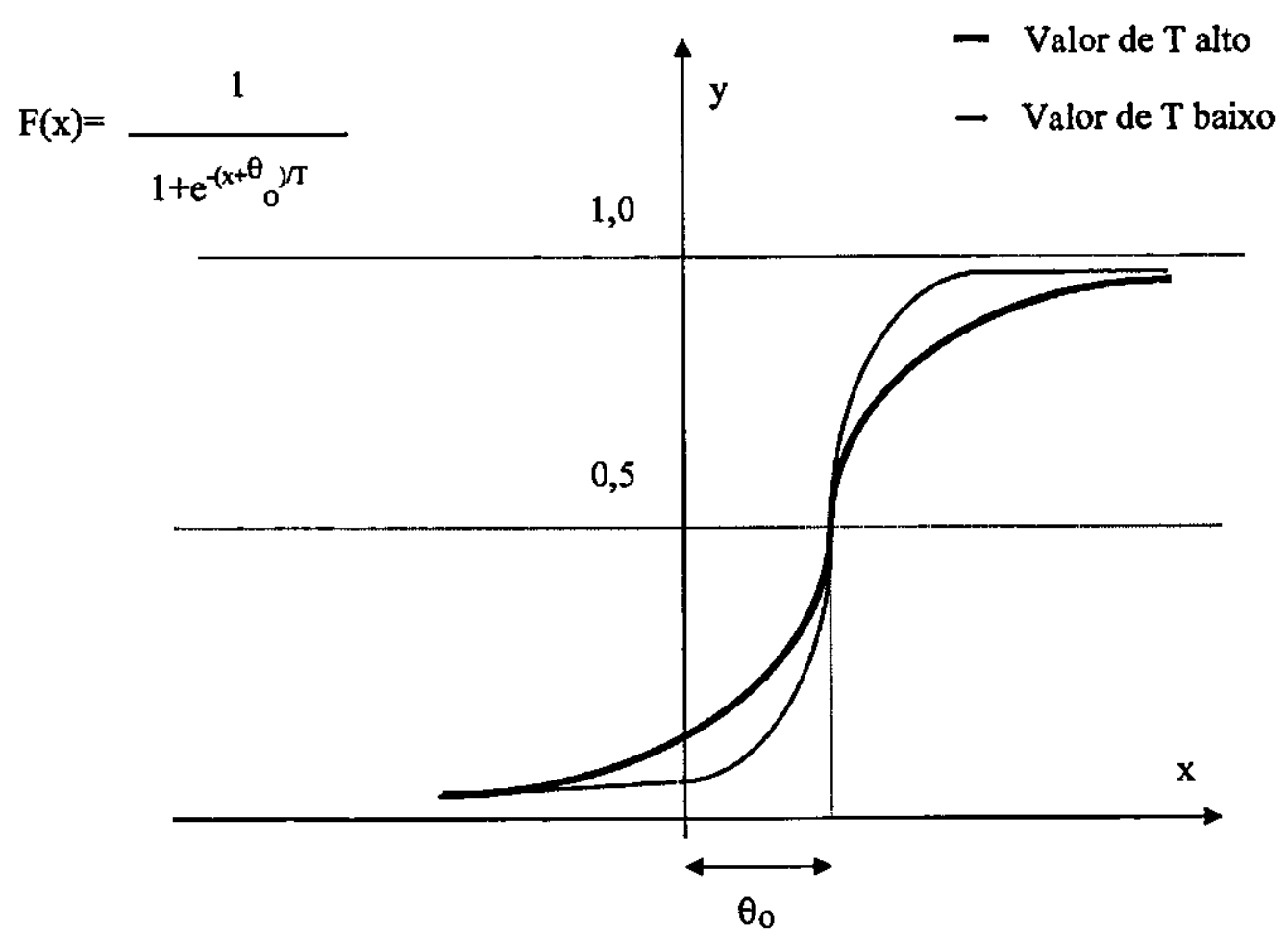

Figura 3.8: Funçảo Sigmóide [Per95b].

A função de ativação sigmoidal possui os seguintes valores: $(T=0,25)$ com saída entre $(0,1)$ e taxa de aprendizagem de 0.1. Essa função é sempre positiva e limitada superiormente por $1 \mathrm{e}$ inferiormente por 0. 
O $\theta_{0}$ é chamado limiar de ativação. A função produz valores "altos" para entradas acima desse limiar e valores "baixos" para valores abaixo desse limiar. Na implementação, o termo $\theta_{0}$ é implementado como mais um peso de uma entrada sempre em 1.

Após o treinamento do algoritmo de backpropagation, o sistema está pronto para ser usado. Um dos usos de redes neurais em reconhecimento, consiste em utilizar a rede para identificar um retrato montado. A "função" identificação, portanto, recebe como entrada uma imagem que é o retrato recém-editado e produz como resposta os identificadores das faces (da base de dados de faces) mais semelhantes. As classes mais semelhantes são aquelas cujos neurônios mais se aproximaram do valor 1 quando o retrato foi apresentado na rede e propagado até a camada de saída.

Nessa fase de uso da rede, cada neurônio da camada de safda produz um valor entre 0 e 1. Quanto mais próximo de 1 for o valor do neurônio de uma classe, maior a correlação entre o retrato falado e essa classe. $O$ retrato será rejeitado caso nenhum neurônio apresente um valor de saída acima de um limiar estabelecido. As classes cujos neurônios apresentem os valores mais próximos de 1, e acima do limiar, serão selecionadas.

\subsection{Outras Técnicas}

Esta seção discute outras técnicas que podem ser empregadas para o reconhecimento automático de faces.

\section{Características Geométricas}

Uma face pode ser reconhecida mesmo quando os detalhes das características dos indivíduos (como olhos, nariz e boca) não estão bem definidos. As informações remanescentes são, nesse caso, puramente geométricas e representam o que restou de uma imagem com uma resolução não muito boa. A idéia é extrair a posição relativa e outros parâmetros de características distintas como os olhos, boca, nariz $\mathrm{e}$ queixo. A extração de características é fácil, pois as faces possuem simetria bilateral e o layout de faces variadas são bem similares. Por outro lado, esses mesmos fatores, tomam mais dificil a etapa de reconhecimento de uma face [Bru92][Bru93][Jia95].

Para se ter um bom reconhecimento utilizando essa técnica, deve-se levar em conta os seguintes:

1. a amostragem da face deve ser a melhor possível;

2. deve existir pequena alteração de iluminação entre as fotos;

3. devem existir apenas pequenas alterações das expressões faciais;

4. deve-se colher a maior quantidade possível de informações faciais.

Um algoritmo genérico para o reconhecimento por características geométricas seria:

1. realizar a normalização da imagem; 
2. realizar as projeções horizontal e vertical da imagem;

3. encontrar as regiões onde estão a boca, nariz, etc;

4. realizar a classificação.

As projeções horizontal e vertical compõem uma técnica muito útil para a extração de características e são definidas respectivamente como:

$$
H(y)=\sum_{x=x 1}^{x^{2}} I(x, y) \quad V(x)=\sum_{y=y 1}^{y 2} I(x, y)
$$

onde $\mathrm{I}(\mathrm{x}, \mathrm{y})$ é a imagem e $[\mathrm{x} 1, \mathrm{x} 2] \mathrm{x}[\mathrm{y} 1, \mathrm{y} 2]$ é a área onde a projeção irá ser realizada.

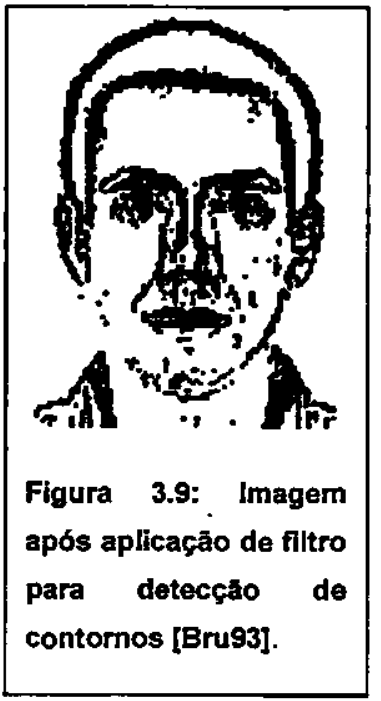

Uma outra saída, mais precisa, encontrada para a elaboração de uma projeção horizontal e vertical seria a de primeiro, junto com a fase de normalização, aplicar um filtro de deteç̧ão de contornos na imagem, como sugere a figura 3.9. Feito isso separa-se o mapa das arestas em horizontal e vertical através do gradiente (figura 3.10) e em cima desse mapa usam-se as equações acima apresentadas. $O$ gradiente horizontal (imagem esquerda da figura 3.10) é usado para detectar as bordas esquerda e direita da face e do nariz, e o gradiente vertical (imagem direita da figura 3.10) é usado para detectar o topo da cabeça, olhos, base do nariz, boca e queixo. Uma vez que os olhos são localizados através de template matching, as outras caracteristicas são mais fáceis de achar devido ao layout conhecido de uma face.

A boca e o nariz são localizados usando estratégias similares. A posição vertical é inferida usando padrões antropométricos. A primeira estimativa da posição real é obtida procurando-se por picos da projeção horizontal do gradiente vertical para o nariz e por vales de projeção horizontal de intensidade para a boca.

Os picos e vales são então taxados usando sua relevância e a distância da localização esperada (altura e profundidade são ponderados por um fator Gausiano). Os que tiverem valores mais altos são a posição vertical do nariz e da boca. Tendo estabelecido a posição vertical, a busca é limitada a uma pequena região.

A delimitação horizontal do nariz é feita procurando-se por picos (na projeção vertical do mapa de arestas horizontal), na região de busca, onde a altura está acima do valor médio dos picos dessa região. As bordas do nariz são estimadas

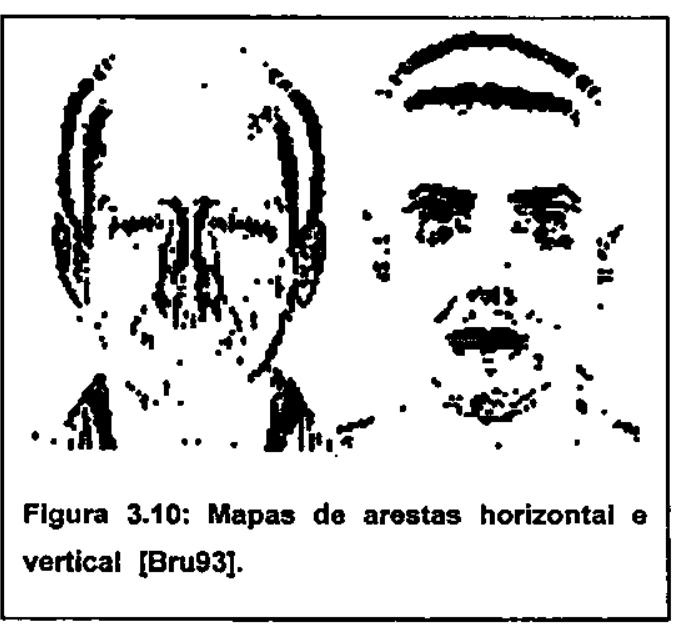


pelos picos da esquerda para a direita. A altura da boca é calculada usando-se a mesma técnica, mas aplicada à componente vertical do gradiente. $O$ tamanho da boca é calculado limitando a projeção vertical do mapa de arestas vertical pelo valor médio (figura 3.11).

As sobrancelhas são localizadas de modo similar ao descrito acima e os contornos faciais são calculados seguindo o contorno do mapa de intensidade de gradiente de projeção elíptica da imagem da face (figura 3.12). Após encontradas as características faciais, o próximo passo seria o reconhecimento propriamente dito, que é feito aplicando-se um classificador de vizinhança (nearest neighbor).

Um dos problemas mais críticos dessa técnica é a normalização. A extração de características deve ser de
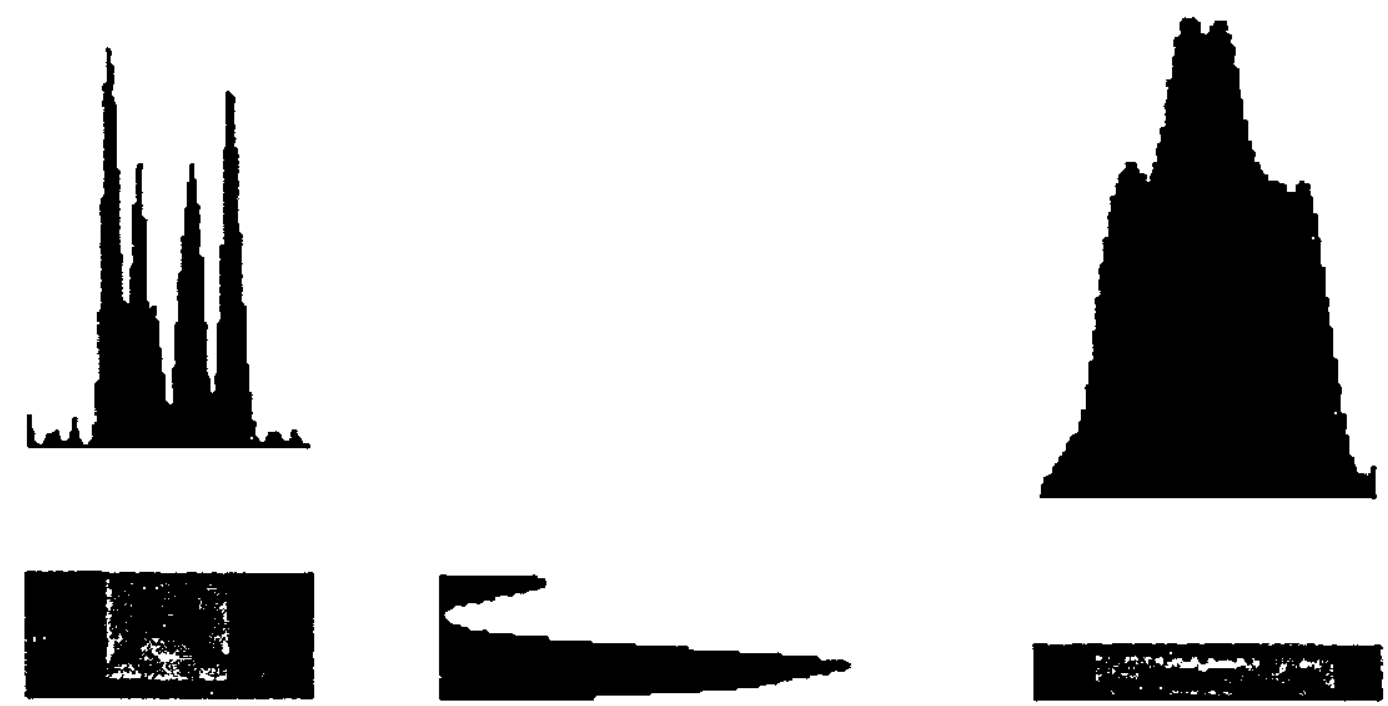

Figura 3.11: Restriçøes horizontal e vertical para o nariz e restriçāo horizontal para a boca [Bru92].

algum modo normalizado para que diferentes posições, escalas e rotações da imagem plana não prejudiquem o reconhecimento. A escala e a rotação são normalmente feitas com base na distância inter-ocular e na direção do eixo de um olho para o outro.

Um olho padrão (sem sobrancelhas), é utilizado como template (ver seção 3.1) para localizar os olhos na imagem a ser normalizada. Para resolver o problema de variações de escala deve-se criar alguns outros templates a partir da imagem padrão do olho (pode-se, para o caso de 5 templates, utilizar valores como: $0.7,0.85,1,1.15$ e 1.3$)$.

Uma vez feita a detecção dos olhos, a imagem é normalizada. A

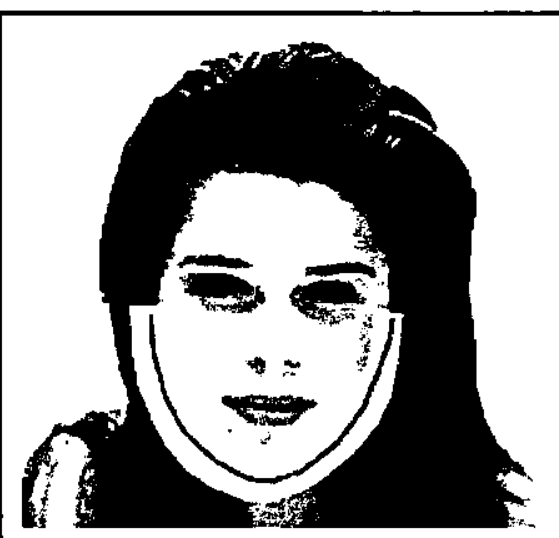

Figura 3.12: Perfil eliptico do contorno do rosto. normalização só dá bons resultados em imagens que possuem rotação inferior a 15 graus. 
O reconhecimento de faces utilizando essa técnica é sugerido para pequenas bases de dados ou como um pré-processamento para estratégias mais complexas de reconhecimento de faces [Bru93].

A vantagem dessa técnica sobre as de template matching são: uma representação mais compacta $(<22$ bytes) e alta velocidade de comparação.

\section{Transformada de Walsh}

A transformada de Walsh pode-se usada para a extração de perfis de faces a partir de uma visão frontal para fornecer uma medida para o reconhecimento automático de faces. As características de perfil são extraídas por uma projeção de intensidade a partir de uma região vertical da face e são descritas pelo espectro de potência de Walsh, o qual possui boa habilidade para distinguir as diferenças de perfis de faces distintas [Jia94][Jia95].

A característica de perfil de uma face é potencialmente disponivel a partir de uma fotografia frontal da face dentro de uma região central vertical da imagem da face. Dessa forma, uma região retangular vertical que vai da testa ao queixo é definida como sendo a região característica dessa face. Essa região é bem caracterizada em uma imagem, já que a posição dos olhos pode ser estabelecida com uma boa resolução. A variação de intensidade nessa região é utilizada para representar a característica de perfil de uma face.

A distribuição de intensidade de uma imagem pode ser representada por uma projeção de intensidade $f(x, y)$ ao longo da direção w na linha $z$ é definida como $\mathrm{p}_{\mathrm{w}}(\mathrm{z})$ :

$$
p_{w}(z)=\int_{z} f(x, y) d w
$$

O perfil é detectado pela projeção tomada ao longo da direção perpendicular ao eixo vertical do perfil. Essa projeção reflete a relação entre os picos e vales de intensidade e a variação de posições relativas, o que corresponde às características individuais de cada face. A figura 3.13 mostra as projeções de perfil para três fotos.

A transformada de Walsh é eficiente para realizar uma projeção de perfil pois é baseada em componentes sequenciais, o que é apropriado para decomposição e estudos de sinais digitais.

Para o reconhecimento de faces efetivo, pode-se utilizar o espectro de potência de Walsh para calcular a diferença entre duas faces (a face a ser reconhecida e a da base de dados). Essa diferença chamada $d$, é expressa, para imagens com resolução de 128x128x8 [Jia94]:

$$
d=\sum_{i=1}^{128} \frac{\left|x_{i}-y_{i}\right|}{\sqrt{x_{i} y_{i}}}
$$

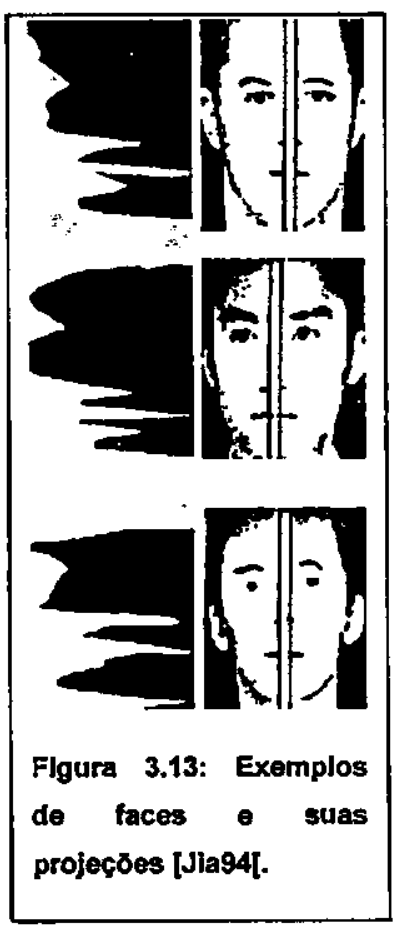


onde $x_{i}$ e $y_{i}$ são os elementos de características da face da imagem $\mathrm{X}$ e Y.

O gráfico da figura 3.14 ilustra o resultado da comparação de uma imagem a ser classificada (primeira imagem da figura 3.13) com outras imagens da base de dados. $O$ eixo horizontal do gráfico mostra o número das faces e o eixo vertical mostra o inverso da diferença, isso é, quanto maior o valor da comparação maior a chance de ser a imagem certa.

Pelo gráfico nota-se que a imagem correta é a número sete, onde o valor da comparação foi 10. A imagem número 8 é a da mesma pessoa

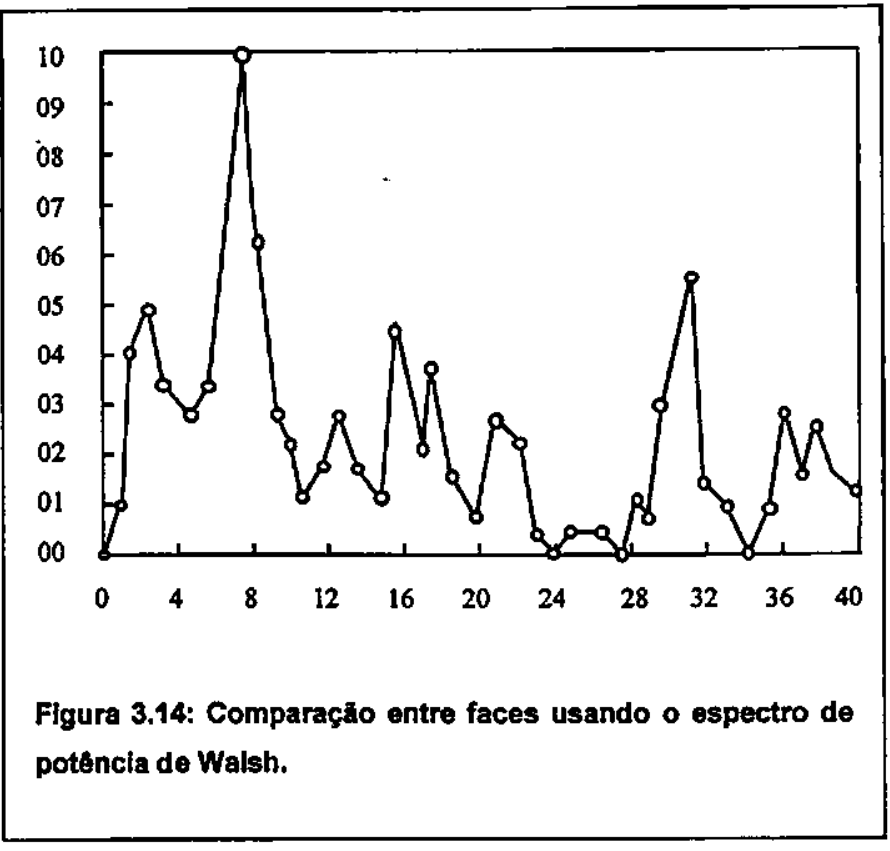
com posição e fisionomia um pouco

diferente. A imagem número 31 corresponde a imagem do meio da figura 3.13. Note que ambas imagens (a de cima e a do meio) possuem o mesmo número de picos e vales (e também possuem tamanhos similares), mas com formatos diferentes.

Os resultados apresentados em [Jia94] mostram que as características de perfil representadas pelo espectro de potência de Walsh são confiáveis quanto à identificação e à detecção de diferenças entre faces, obtendo uma boa tolerância a efeitos de rotação e iluminação.

\section{Hidden Markov Models (HMM)}

O método HMM é baseado em comparar padrões de imagem com uma sequiência de estados duplamente embutidos de modos estocásticos. HMMs são geralmente usados para modelagem estocástica de séries de vetor tempo não estacionárias. Como tal, eles têm a óbvia e imediata aplicação em processamento de fala, particularmente em reconhecimento onde o sinal de interesse é naturalmente representado como uma seqũência variável no tempo de estimativas espectrais. HMM fornece um modelo estatístico para um conjunto de seqüências observadas [Sam94].

Para se usar HMM para reconhecimento, uma seqüência de observação é obtida de um sinal de teste e suas semelhanças com cada HMM gerando esse sinal é computada.

HMMs têm sido usado principalmente em aplicações de reconhecimento de fala, uma área onde eles foram estudados em profundidade e onde eles são agora uma técnica bem estabelecida. HMMs modelam as propriedades estatísticas de sequências de observação 1D e os dados de fala são naturalmente 1D ao longo do eixo de tempo. Uma curta notação para um HMM pode ser dada por [Sam93a][Sam93b]: 


$$
\lambda=(\mathrm{A}, \mathrm{B}, \pi) \text {, onde: }
$$

A é a matriz de probabilidade de estado de transição, B é a matriz de probabilidade de símbolo de identificação e $\pi$ é o estado inicial da distribuição.

A técnica de HMM tem sido extensivamente usada com sucesso em aplicações de reconhecimento de voz, onde a mesma palavra falada duas vezes pela mesma pessoa pode resultar em sinais diferentes. A habilidade de HMM em manusear essa variabilidade, fez com que alguns pesquisadores experimentassem o seu uso no reconhecimento de faces. A natureza unidimensional (1D) dos sinas vocais no eixo do tempo é conveniente para uma análise usando HMM, a qual requer uma sequiência de observações 1D.

O problema de reconhecimento de faces está enfocado a partir de uma perspectiva de reconhecimento de padrões estatísticos. Intuitivamente, uma face pode ser dividida em um certo número de regiões tais como, boca, olhos, nariz, etc. e se isso puder ser localizado confiavelmente, então as técnicas de comparação de padrões comuns poderiam ser aplicadas para cada região individualmente para computar uma distância métrica total. Entretanto, localização precisa é muito difícil na prática. Além disso, demarcação precisa das regiōes é confusa já que não é claro, por exemplo, onde termina a região da boca e começa a região do queixo.

Uma solução potencial para o problema mencionado acima é associar regiões faciais com estados de densidade contínua de HMM Isso permite que as fronteiras entre as regióes sejam representadas por transiç̃̃es probabilisticas entre estados e a imagem real dentro de uma região a ser modelada por uma distribuição gaussiana multivariada. No caso geral HMM precisaria ser 2D. Para isso é assumida que uma aproximação de primeira ordem pode ser usada onde as regiões faciais são, ou restritas a faixas horizontais, ou modeladas por pseudo-topologia 2D. Em ambos os casos HMM simples (1D) podem ser usadas [Sam94].

As imagens são bi-dimensionais (2D), mas elas podem ser convertidas para sequiências espaciais 1D. Uma sequência espacial pode ser obtida fazendo a amostragem de uma imagem através de uma "janela deslizante" (figura 3.16). Isso converte a imagem em uma sequência $1 \mathrm{D}$ de fatias de dados onde cada elemento da sequêencia é um vetor feito de um certo número de amostragens (dependendo do tamanho da "janela deslizante"). O tamanho da janela e a direção da amostragem podem variar.

Se for realizado um treinamento para várias imagens faciais frontais $(W)$ de várias pessoas $(F)$, onde 0 tamanho da base de dados é dado por $\mathrm{WxF}$, a técnica de amostragem mostrada na figura 3.15 permite converter cada imagem em uma seqüência de vetores $\mathrm{O}=\mathrm{O}_{1} \mathrm{O}_{2} \ldots \mathrm{O}_{\mathrm{T}}$, os quais são espacialmente ordenados de cima para baixo.

Usando essa técnica, cada imagem é amostrada em uma sequêencia de linhas de blocos que se sobrepøem. A sobreposição permite que o modelo capte características independentemente da sua posição vertical. Cada bloco de linha representa um vetor de observação (de tamanho X x L, onde L é o número de linhas 
em cada bloco) que resulta em uma sequência $1 \mathrm{D}$ de vetores de observação, $\mathrm{O}=\mathrm{O}_{1} \mathrm{O}_{2} \ldots \mathrm{O}_{\mathrm{T}}$, onde $\mathrm{T}$ pode ser calculado por:

$$
T=\frac{Y-L}{L-V}+1
$$

e $\mathrm{V}$ é quanto houve de sobreposição (expresso em número de linhas) entre os blocos sucessivos.

A sobreposição durante o processo de amostragem tem as seguintes funções principais:

1. A sobreposição determina como a semelhança de alinhamento de uma caraterística é, e é esperado que uma grande sobreposição aumentaria a semelhança em preservar o alinhamento.

2. Dado um tamanho de imagem fixo e uma altura de janela, a sobreposição determina a sequência $\mathrm{T}$ de observação como pode ser visto na equação xyz.

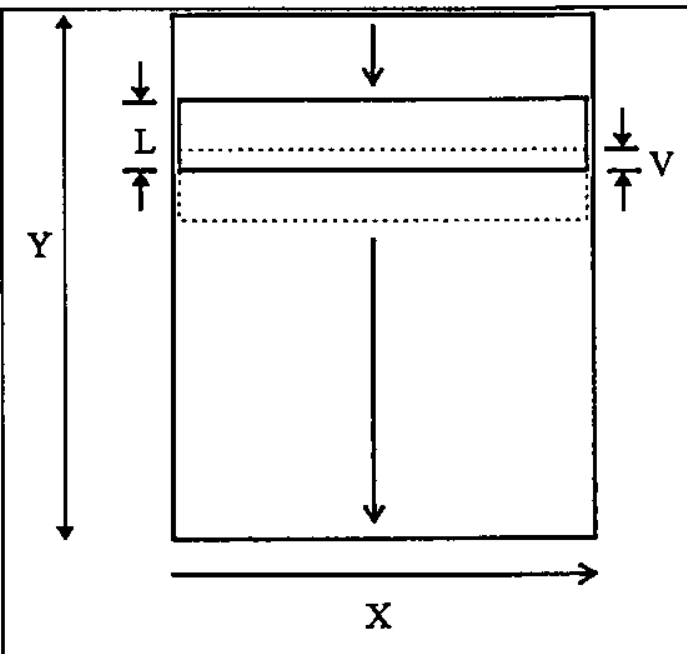

Figura 3.15: Técnica de amostragem [Sam93a].

Um grande valor de $\mathrm{M}$ produz um grande $\mathrm{T}$ porque as regiões faciais são super-amostradas portanto aumentam o comprimento do treinamento e observações de dados de teste. A precisão do modelo depende do número de observaçães $\mathrm{T}$ nos dados de treinamento. Se $\mathrm{T}$ for pequeno a precisão será limitada, já que não existe ocorrências suficientes de eventos modelo.

A sequência obtida pode alimentar um HMM que irá então dividi-la em um número de estados, cada estado representando uma banda facial. Esse termo indica o bloco horizontal (de tamanho L) o qual tem significado estatístico suficiente para resultar em uma atribuição HMM de um estado para representá-lo. Deseja-se estabelecer então uma correspondência entre bandas de estatísticas faciais e bandas de características. Assumindo que cada face está numa posição frontal vertical, as bandas de características devem ocorrer nessa ordem: testa, seguida pelos olhos, seguidos pelo nariz, etc. (veja figura 3.16).

A ordenação dessa forma sugere o uso de um HMM da esquerda para a direita onde somente transições entre estados adjacentes serão permitidos. A figura 3.17 mostra o diagrama de estado correspondente.

Pode-se treinar um HMM para cada pessoa da base de dados e obter um HMM da esquerda para a direita

$$
\lambda^{(\mathrm{k})}=(\mathrm{A}, \mathrm{B}, \pi), 1 \leq \mathrm{k} \leq \mathrm{F} \quad \text { onde, }
$$

F é o número total de pessoas diferentes na base de dados;

A: mede a probabilidade de ir de uma banda facial para outra. Após o treinamento, $A(k)$ irá armazenar as ocorrências de transições de uma banda para outra através da face e a espessura das várias bandas (isso 
pode ser visto ordenando os termos $a_{i i}$ os quais representam a probabilidade de ficarem na mesma 1 testa banda facial).

B: mede a probabilidade de observar um vetor de características em particular, retornando o que se deseja encontrar em uma banda facial específica. Após o treinamento, $\mathrm{B}^{(\mathrm{k})}$ irá armazenar o vetor de características da distribuição por pessoas através das várias bandas.

$\pi$ : todas as sequências de observação se iniciam no

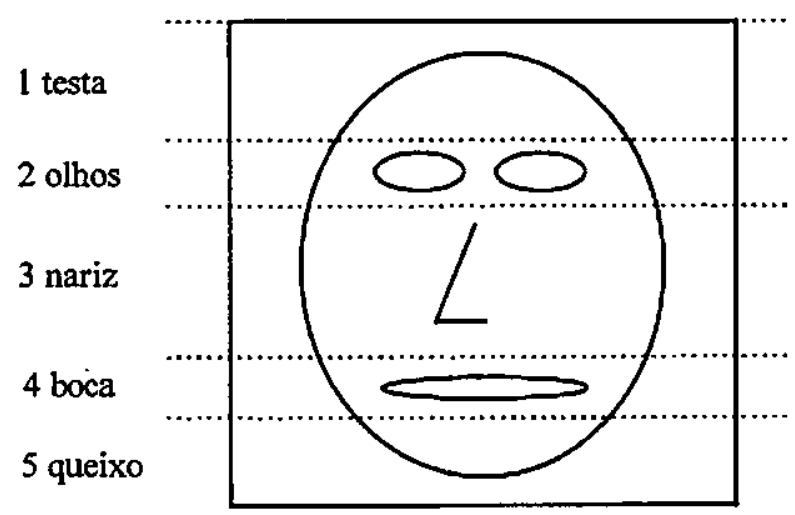

Flgura 3.16: Bandas faciais para HMM do 5 estados [Sam93a]. topo e por essa razão, com o presente modelo, esse parâmetro não dá qualquer informação discriminatória $\left(\pi_{1}=1\right.$ e $\left.\pi_{\mathrm{i}}=0, \forall \mathrm{i} \neq 1\right)$.

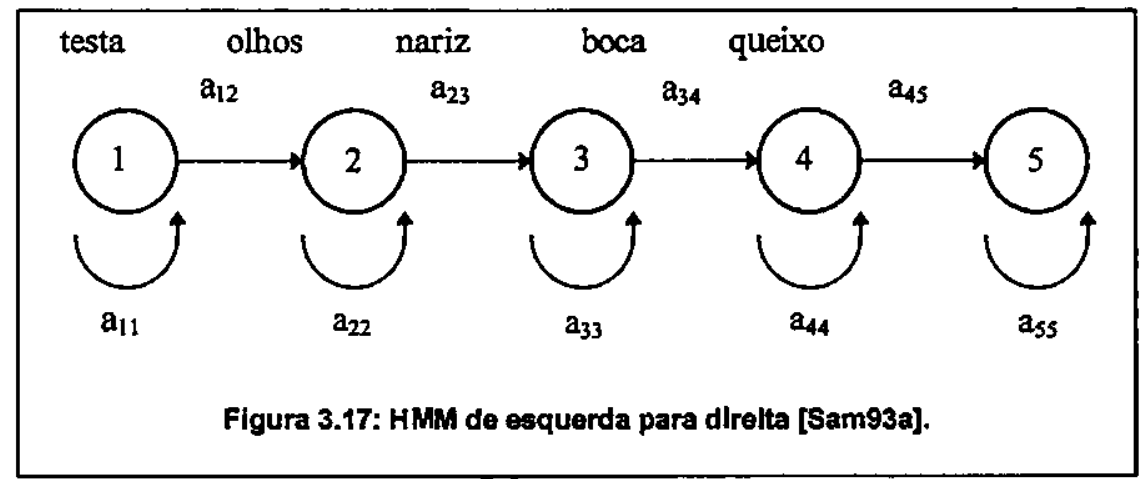

A identificação de uma pessoa desconhecida é feita convertendo-a para uma sequência de observação ID (O) usando a técnica de amostragem ilustrada acima. Essa seqüência é comparada a cada seqüência (treinada) da base de dados e é calculado um modelo de probabilidade:

$$
\operatorname{Pr}\left[\mathrm{O} \mid \lambda^{(\mathrm{k})}\right], 1 \leq \mathrm{k} \leq 20
$$

O valor mais alto retornado corresponde à pessoa desconhecida.

O classificador apresentado irá sempre classificar a imagem desconhecida pela maior comparação. Isso pode resultar em um erro caso essa imagem não esteja na base de dados. Por isso ele é mais indicado para sistemas de segurança de empresas onde a base de dados é formada por todos funcionários e com certeza a imagem desconhecida está na base de dados. Para sistemas de identificação de suspeitos, seria necessário a inclusão de um limite associado ao valor da probabilidade, para que não fosse mostrado apenas a "melhor comparação", mas sim as "melhores comparações" dentro desse limite. 


\section{Sistema Híbrido (Convolutional Neural Network)}

Esse sistema combina amostragem local de imagens, um mapa de redes neurais auto-organizacional e uma rede neural convolucional [Law94]. O mapa auto-organizacional (SOM) produz uma quantização da imagem amostrada em uma topologia espacial onde as entradas são próximas do espaço original e próximas também do espaço de saída, desse modo resultando uma redução de dimensionalidade e invariância para pequenas alterações nas imagens amostradas. A rede neural convolucional fornece uma invariância parcial para translação, rotação, escala e deformação. A rede convolucional extrai recursos maiores sucessivamente num conjunto hierárquico de camadas. Os resultados usando a transformada de Karhunen-Loève (KL) no lugar do mapa auto-organizacional foram de 5,3\% de erro versus 3.8\%, e um multi-layer perceptron (MLP) no lugar da rede convolucional foram de $40 \%$ de erro versus $3.8 \%$. $O$ método é capaz de uma classificação rápida, e requer somente uma rápida normalização e préprocessamento.

O diagrama alto nível da figura 3.18 mostra os blocos do sistema.

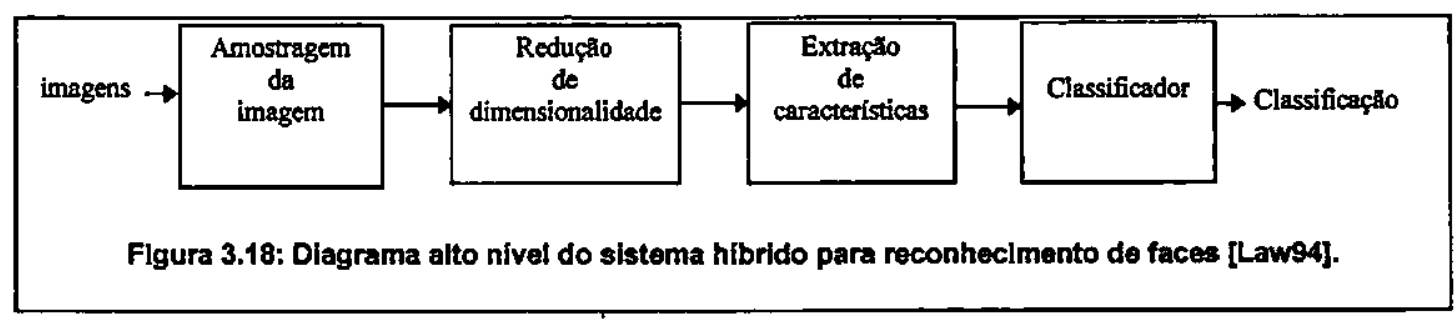

A figura 3.19 mostra o diagrama do sistema para reconhecimento de faces e os métodos alternativos discutidos acima. O classificador de estilos MLP representa o estilo final MLP totalmente conectado à camada da rede convolucional. A decomposição é mostrada (linhas tracejadas) onde é facilitada a troca de uma ou mais camadas por diferentes tipos de classificadores. O classificador de vizinhança (nearestneighbor) é potencialmente interessante pois ele torna possível a adição de novas classes com um tempo extra de treinamento mínimo. O MLP pode substituir a rede convolucional inteira. Pode-se também utilizar um SOM ou KL para realizar a redução de dimensionalidade, e enviar a saída para o classificador baseado em rede convolucional ou em MLP.

O sistema trabalha da seguinte maneira:

1. Para as imagens no conjunto de treinamento, uma área fixa (por exemplo $5 \times 5$ ) é sobreposta à imagem inteira como mostra a figura 3.20 e amostras das imagens locais são extraídas a cada sobreposição. Cada sobreposição à região é movida de 4 pixels.

2. Um mapa auto-organizacional (SOM) (por exemplo, com três dimensర̃es e 5 nós por dimensão com $5^{3}=125$ nós no total) é treinado com os vetores do passo anterior. O SOM quantiza os vetores de entrada das 25 dimensões em 125 valores ordenados topologicamente. As três dimensర̃es do SOM podem ser imaginadas como três características. A substituição do SOM por KL projeta os vetores de 
um espaço de 25 dimensões para um espaço tridimensional.

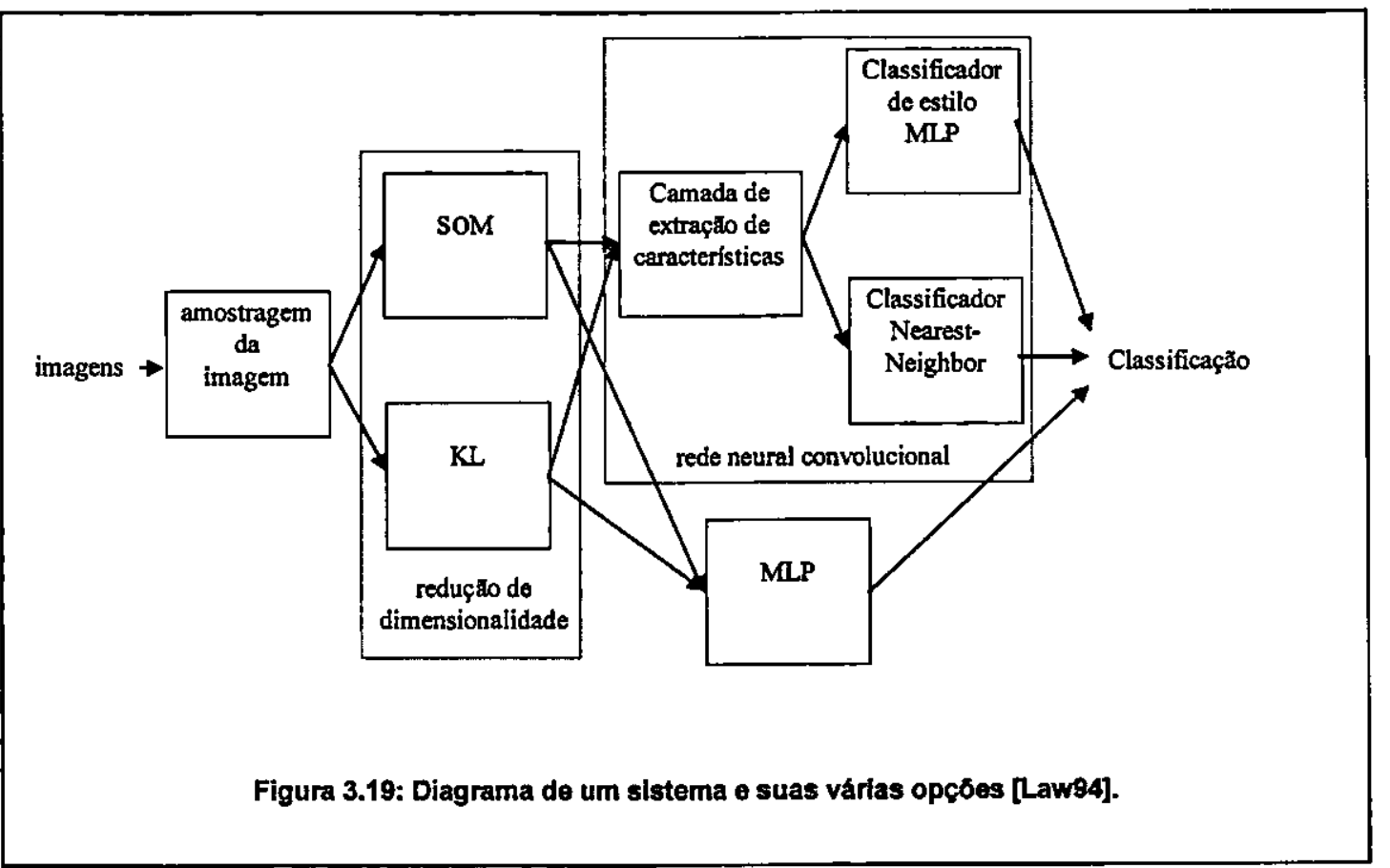

3. A mesma região do primeiro passo é sobreposta em todas as imagens do conjunto de treinamento e de testes. As amostragens das imagens locais são passadas através do SOM a cada passo, desse modo criando novos conjuntos de treinamento e testes na saída do espaço criado pelo mapa autoorganizacional. Cada imagem de entrada é agora representada por 3 mapas, cada qual correspondendo a uma dimensão no SOM. O tamanho desses mapas é igual ao tamanho da imagem de entrada (92x112) dividida pelo tamanho da área (para uma área de tamanho 4, os mapas são 23x28).

4. Uma rede neural convolucional é treinada com o novo conjunto de treinamento criado. Também foi usado, para comparação, um MLP no seu lugar [Law94].

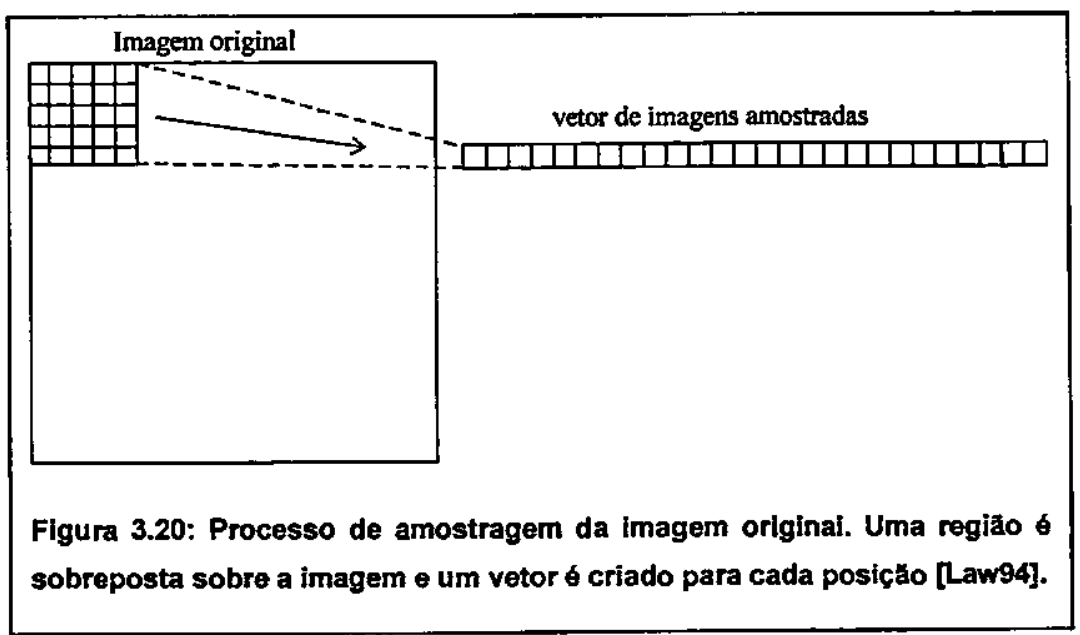




\section{RBF (Radial Basis Function)}

Um outra técnica que pode ser usada em sistemas de reconhecimento de faces é o RBF networks. Esse método, comparado com o de back-propagation (BF) padrão, é muito superior. Esse método também é baseado em redes neurais e usa, como entrada, imagens faciais parciais (por exemplo, olhos, nariz, orelhas, etc). Essa é uma técnica interessante, pois o sistema é capaz de reconhecer uma imagem sem precisar ver a face inteira [Sat97].

O foco central do estudo desse método, é no uso de imagens de orelhas para o reconhecimento, porque elas não são influenciadas pelas expressões faciais e a influência do envelhecimento é praticamente desprezível.

A técnica funciona do seguinte modo:

Primeiro é feito a captura das imagens parciais através de uma câmera de vídeo (figura 3.21). A captura deve ser feita com uma luz uniforme e a uma distância padrão

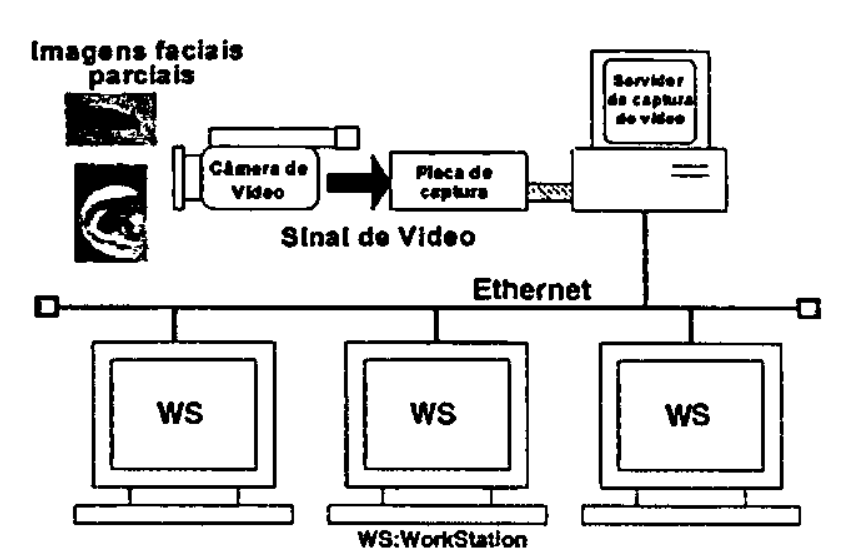

Figura 3.21: Configuraçăo de um sistema para captura das imagons parciais da face.

(figura 3.22). Seis imagens por pessoa são obtidas, elas são todas em tons de cinza e com dimensão $\mathrm{n} \times \mathrm{m}$ (tipo de um mosaico), como mostrado na figura 3.23. A figura 3.24 mostra um exemplo de olho e nariz.

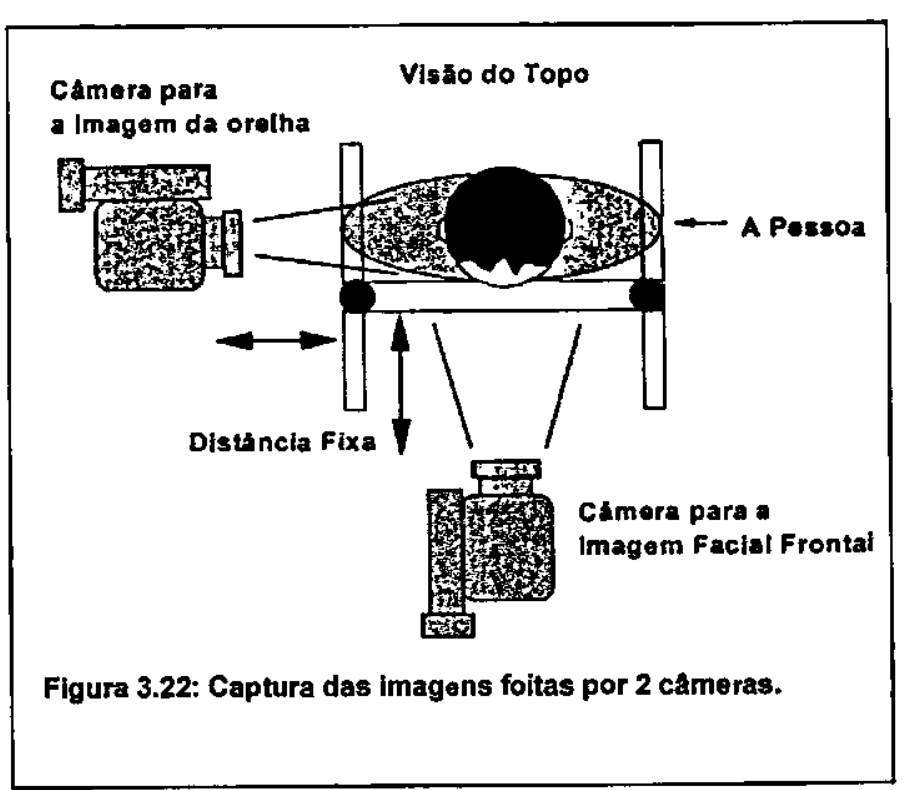
Uma vez digitalizadas e processadas as imagens, essas irão abastecer a entrada do RBF onde irá ocorrer o treinamento. Uma vez o sistema estando treinado ele está pronto para iniciar o reconhecimento. Quando uma nova imagem parcial é capturada, ela é processada para o mosaico estabelecido e é entrada no sistema para o seu reconhecimento.

Testes comparativos entre o RBF e o BF, mostram que o RBF possui uma taxa de acerto muito maior, outra vantagem desse método é o valor obtido com a taxa de rejeição (no caso da imagem a ser reconhecida, não fazer parte da base de dados) de quase $100 \%$ de acerto. 
A figura 3.25 mostra um diagrama de blocos das etapas de reconhecimento utilizando-se esse método.
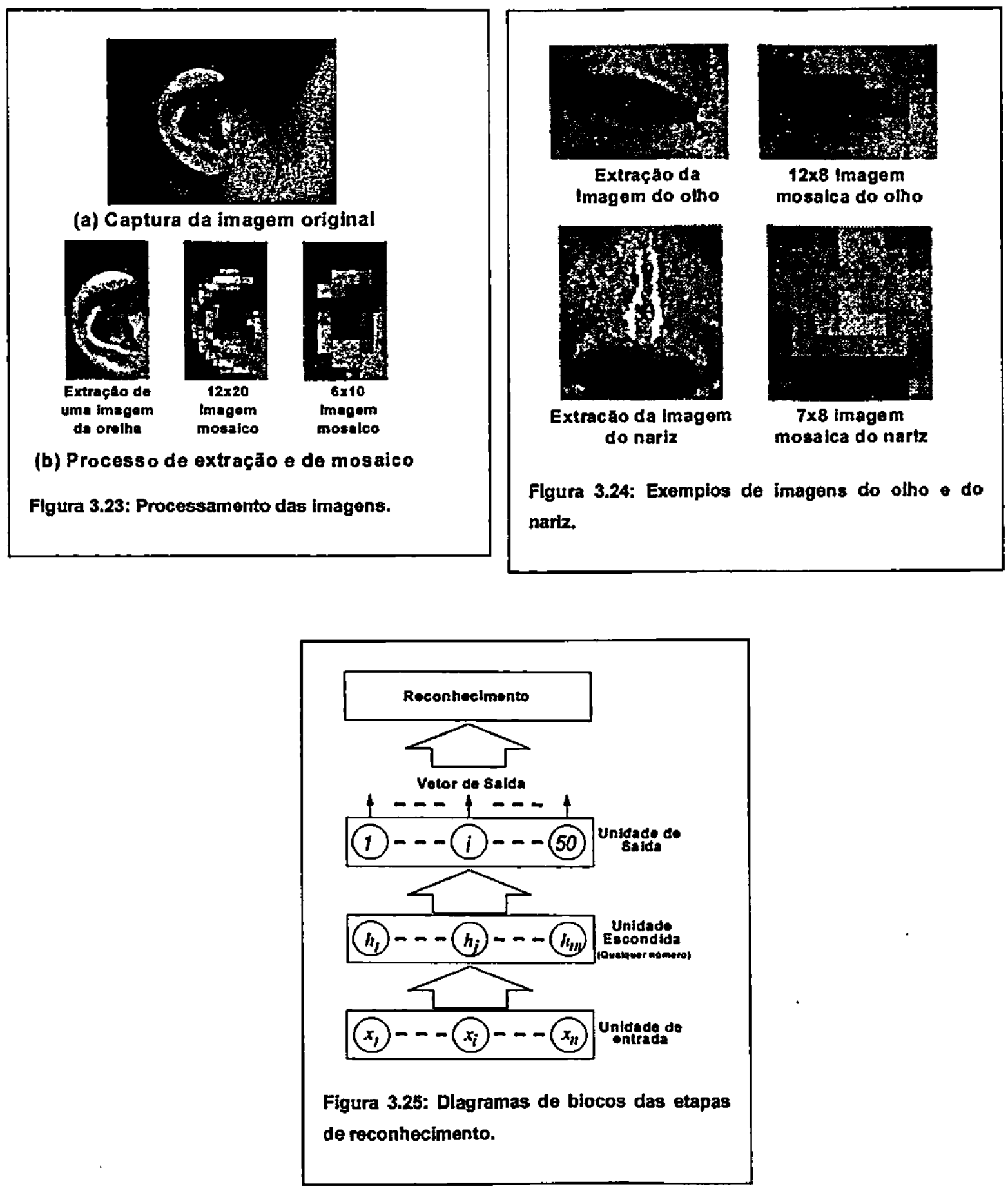

\section{Problemas Relacionados com o Reconhecimento Automático de Faces}

Como apresentado anteriormente, o reconhecimento automático de faces tem vários problemas que devem ser levados em conta antes da elaboração de um sistema como [Bey93][Sch93]:

1. todas as faces possuem as mesma caracteristicas e basicamente a mesma configuraçâo geométrica;

2. faces podem apresentar diferenças de fisionomias (rindo, sério, triste, alegre, etc.); 
3. existem diferenças de luminosidade das imagem da base de dados e a que será classificada;

4. existem diferenças de posicionamento, rotação e escala entre as imagens da base de dados e a que será classificada.

Todos esses problemas devem ser considerados, dependendo da aplicação a que o sistema de reconhecimento irá ser empregado. Sistemas de segurança exigem regras rígidas, pois o reconhecimento deve ser preciso, enquanto que sistemas como o de identificação de suspeitos são mais tolerantes a esses problemas, pois apenas apoiam o trabalho de investigação.

A maioria desses problemas podem ser minimizados pela etapa de normalização que ocorre antes do reconhecimento propriamente dito [Sch93].

Há várias opções para resolver os problemas apresentado acima, no caso das vária fisionomias, pode-se em vez de se utilizar apenas uma imagem de cada pessoa para o banco de dados de imagens, pode-se utilizar várias imagens, com fisionomias diferentes. Isso diminui a taxa de erro que possa ocorrer durante a identificação da imagem correta pelo sistema.

Para o problema de diferenças de luminosidade, há vários algoritmos de processamento de imagens que podem ser aplicados, para tentar igualar os níveis de contraste e brilho com o de uma imagem padrão préestabelecida.

E finalmente com relação ao posicionamento, rotação e escala da imagem. Primeiro deve-se localizar onde estão os olhos na imagem, depois traçar uma reta entre os dois olhos e rotacionar a imagem até que esta reta fique plana. Para se ter todas as imagens com o mesmo tamanho (escala) é preciso medir a distância entre os olhos das imagens da base de dados e deixá-la com a mesma distancia de uma imagem padrão (pré-estabelecida). E por fim o posicionamento das imagens pode ser feito levando em consideração a posição dos olhos nas imagens[Bru93].

No presente trabalho de mestrado, foi desenvolvido um sistema para cadastramento de dados e fotos de indivíduos, para ser usado no auxílio à identificação de suspeitos. Adicionalmente, foi implementado o reconhecimento de faces utilizando PCA, considerado adequado para esta aplicação, para ser usado tanto na identificação de pessoas que já tenham sido cadastradas, quanto para o apoio à ordenação das fotos no momento da tentativa de reconhecimento por testemunhas. O próximo capítulo faz uma breve descrição do sistema multimídia proposto para identificação de suspeitos, e do algoritmo implementado, além de alguns resultado obtidos e comentários sobre trabalhos futuros e conclusões. 


\section{Sistema Multimídia para Identificação de Suspeitos com Reconhecimento Automático de Faces}

Apesar da dependência que os procedimentos policiais possuem da realização do retrato falado, esse método apresenta uma série de deficiências, conforme mencionado no capítulo 2.

Há alguns anos atrás não havia ainda tecnologia, ou essa tecnologia custava muito caro, para se poder usar sistemas computacionais complexos em sistemas de segurança ou de identificação. Muitos estudos foram feitos nessa área, mas todos esbarravam em dois problemas fundamentais: capacidade de processamento e espaço para armazenamento. Um sistema completo de segurança, com reconhecimento de faces em tempo real, precisa processar milhares de informaçóes por segundo, e tem que possuir uma taxa de erro muito próxima de zero.

Apesar dessas limitações ainda estarem presentes, o avanço tecnológico atual veio não só permitir criar sistemas de segurança várias vezes mais complexos e rápidos, mas também permitir o uso de ferramentas computacionais para catálogo de todas as informações de reconhecimento, para a deteç̧ão e indexação de indivíduos e seus dados, e ordenação de fotos através de outras fotos ou características automaticamente. Tal avanço causa uma melhoria significativa na técnica de investigação policial e conseqüente aumento de produtividade na localização de suspeitos e captura de criminosos.

O trabalho descrito neste capítulo foi desenvolvido em colaboração com a Polícia Militar de São Carlos, e faz parte de um ambiente integrado multimídia para auxílio à manutenção e indexação de informações referentes à identificação de suspeitos, com uso do reconhecimento automático de faces.

O projeto DETECT, do qual esse sistema faz parte [Alm96] visa prover um ambiente para otimização do reconhecimento e localização de suspeitos através do desenvolvimento de algoritmos de identificação de características e associação de informações. Em sua versão final o sistema deverá contar com catálogos de informações variadas sobre indivíduos (retrato falado, fotos, voz, características individuais, "modusoperandi", impressão digital, etc.), pesquisa e associação inteligente dessas informações, detecção automática de características a partir de imagens, e apoio à identificação de suspeitos. $O$ sistema multimídia para identificação de suspeitos desenvolvido neste trabalho, corresponde ao arcabouço básico 
do projeto DETECT, e inclui:

- Um mecanismo de cadastramento de informações referentes a suspeitos e policiais, incluindo suas características fisicas.

- Um algoritmo de reconhecimento automático, capaz de apoiar a identificação de uma foto em particular e a ordenação de um conjunto de fotos.

Nos casos em que a vítima ou testemunha tem que reconhecer fotos, a intenção é ordenar a base de fotos, colocando as "mais parecidas" primeiro, melhorando assim as possibilidades de localização rápida, conforme parâmetros estabelecidos por Eric Lee, em trabalho descrito no capítulo 2.

Parte do projeto DETECT tem relevância também em aplicações generalizadas de reconhecimento de pessoas por características faciais, como sistemas de segurança e controle de acesso a edifícios, como descrito no capítulo 2. A implementação em particular do algoritmo de PCA, escolhido para a etapa do reconhecimento, também tem implicações em outras áreas, como análise de dados multivariados e visualização de informação.

Este capitulo apresenta a implementação referente ao projeto, descrevendo o sistema de cadastramento de dados de policiais e suspeitos (seção 4.1), e o reconhecimento automático com ordenação em uma base de fotos (seção 4.2). Alguns testes realizados do algoritmo de reconhecimento implementado são apresentados na seção 4.3. Comentários sobre a integração do cadastramento com o reconhecimento são feitos na seção 4.4. A seção 4.5 discute conclusões e trabalhos futuros dentro do sistema multimídia e do projeto DETECT.

\subsection{O Sistema de Banco de Dados para a Aplicação Policial}

A linguagem escolhida para implementação da base de dados foi o FoxPro da Microsoft. Foi escolhida essa ferramenta por se tratar de uma linguagem fácil de ser implementada e que possui muitos recursos potentes. Um outro ponto forte do FoxPro é o fato dele ser cross-plataform, isto é, um projeto desenvolvido para o MacOS, sistema-alvo no caso da polícia de São Carlos, pode ser levado para outra plataforma onde a linguagem exista, como por exemplos o Windows, sem praticamente qualquer alteração de código, bastando apenas recompilar o projeto e fazer alguns ajustes na interface (como por exemplo, tipo de fonte). Isso é um requisito importante, uma vez que este projeto deverá executar inicialmente num computador Macintosh Quadra 950. Foi usada a versão 2.6 do programa por ela ser a última versão que trabalha nos Macintosh anteriores ao PowerPC, isto é, nos Macs que usam a família de processadores da Motorola 680XX, que é o caso do microcomputador Macintosh Quadra. 


\section{Conceitos de Banco de Dados}

Os computadores foram amplamente utilizados durante quinze anos antes que um SGBD (Sistema de Gerenciamento de Banco de Dados) se tornasse largamente difundido. O Webster's Ninth New Collegiate Dictionary registra a origem do termo 'banco de dados' em 1967. Até então, os programas de aplicações tratavam da organização dos seus próprios dados.

Um banco de dados é um conjunto de dados relacionados [Elm94]. Os SGBD's geralmente possuem uma das três categorias: hierárquica, em rede ou relacional.

O modelo relacional é poderoso e ainda assim simples, flexível e natural. Os dados são armazenados em tabelas conceituais nas quais as linhas são instâncias e as colunas atributos, refletindo algum tipo de associação definida pela aplicação. Por exemplo, uma lista telefônica deve ter colunas para nome, endereço e número do telefone com uma linha para cada nome. O seu problema é a redundância, pois tabelas relacionais são mais esparsas que outras estruturas de dados e várias tabelas podem ser necessárias para apoiar um conjunto de dados simples.

O FoxPro é relacional e armazena dados em tabelas e relaciona as tabelas com chaves de índices, mas o mecanismo de armazenamento é mais direto que outros SGBD relacional típicos. Cada tabela no FoxPro, existe como um arquivo separado com um ponteiro que descreve as colunas e os números das linhas, seguidos por linha após linha de tamanho fixo dos próprios dados. Esse modelo é chamado arquivo plano porque as instâncias de dados nunca contêm elos que metaforicamente sairiam do plano bidimensional da tabela. Embora seja mais fácil pensar em tabelas como compostas de linhas e colunas, o FoxPro define sua própria terminologia. Tabelas são arquivos, simplesmente porque cada tabela é armazenada num arquivo diferente, geralmente com a extensão '.DBF'. Bancos de dados são compostos de um ou mais desses arquivos, sendo incorreto se referir a um arquivo como banco de dados, a não ser que esse corresponda a um único arquivo no banco de dados. Colunas, na terminologia do FoxPro, são campos, porque eles correspondem a campos de entrada de dados num formulário de tela. Como os campos têm características diferentes (por exemplo, alguns são números, outros cadeias de caracteres, etc), eles também são chamados atributos. As linhas da tabela são os registros. Em outros sistemas de desenvolvimento de bancos de dados, os registros são chamados de tuplas [Vos91][Lon93].

Em 1970, E. F. Codd foi o primeiro a descrever o modelo relacional. O modelo relacional é uma abstração matemática, projetado para facilitar a manipulação de banco de dados e criar linguagens de manipulação de dados. É também o modelo de interface com o usuário, porque tabelas de dados são fáceis de entender. Entretanto, o modelo relacional não é um método de armazenagem ou de acesso, porque ele não dita regras sobre como os dados que formam uma base são armazenados. $O$ FoxPro armazena e apresenta os dados usando um modelo tabular, mas muitos outros sistemas comerciais armazenam dados no estilo em rede enquanto apresentam esses dados como tabelas. Em outras palavras, 
o método de armazenamento e o método de apresentação podem ou não ser isomórfico

A álgebra relacional é um conjunto de oito operações que leva em consideração uma ou duas tabelas com operandos e produz uma outra tabela como resultado. Quatro das operações (união, intersecção, diferença e produto cartesiano) são emprestadas da teoria dos conjuntos. Como todos os operadores consideram tabelas como operandos e produzem tabelas como resultados, pode-se realizar cadeias de operações da mesma forma que se produz uma cadeia de operações em expressões aritméticas, como por exemplo $(\mathrm{A}+4 * \mathrm{~B}-2)$.

A álgebra relacional é completa porque os seus oito operadores podem questionar, atualizar e manter tabelas relacionadas sem extensão adicional. Entretanto essa é uma construção matemática. Para tomá-la palpável, necessita-se de uma implementação real, tal como uma linguagem tipo query estruturada (SQL - Structured Query Language).

Linguagens de banco de dados reais possuem dois componentes: linguagem de definição de dados (DDL - Data Definition Language) e linguagem de manipulação de dados (DML - Data Manipulation Language). A DDL cria tabelas e gerencia nomes de coluna (campo) e atributos. Pode-se usá-la também para especificar atributos de banco de dados, tabelas e indices, incluindo armazenamento físico, preferências de método de acesso e segurança através de senha. O DML trata basicamente queries e atualizações, mas trata também adição e subtração de amostras de dados [Elm94].

A linguagem FoxPro é mais do que uma DML ou uma DDL: é uma linguagem de desenvolvimento de aplicaçð̃es com edição em tela-cheia, processamento de exceção, variáveis escalares, e conceitos de fluxo de controle não facilmente manipuláveis nas DDL/DML's. Com ela consegue-se tanto a criação de tabelas, como atribuição de privilégios de acesso com seus diálogos de interação.

O FoxPro pertence a uma categoria de SGBD chamada Xbase, que utiliza um formato padrão para armazenamento e indexação dos dados e possui estrutura de linguagem similar. Esse termo genérico se refere a linguagens como o FoxPro, o Dbase, Clipper, FoxBase+ e Arago. O Xbase originou-se de um SGBD para grande porte chamado JPLDIS (Jet Propulsion Laboratory Database-Management and Information Retrieval System - Sistema de Gerenciamento de Bases de Dados e de Recuperação de Informaçāo do Laboratório de Jato-Propulsão) desenvolvido em 1972 [Lon93].

O FoxPro permite criar um sistema completo, com arquivos de imagem, janelas, emissão de relatórios, menus e tudo mais que uma aplicação convencional possui. Uma aplicação, pode ser implementada em módulos, e depois todos esses módulos podem ser unidos num editor de projetos e compilado para um arquivo executável para ser distribuído entre os clientes.

Um projeto em FoxPro engloba uma variedades de arquivos necessários para a criação da aplicação final, são eles: 
- Arquivos de Programa (PRG)

- Arquivos de Programa de Tela (SPR)

- Arquivos de Programa de Menu (MPR)

- Arquivos de Banco de Dados (DBF)

- Arquivos de Índices (NDX, CDX)

- Arquivos de Variáveis de Memória (MEM)

- Arquivos de Tela (SCX)

- Arquivos de Menu (MNX)

- Arquivos de Query (QRY)

- Arquivos de Formulário de Relatório (FRX)

- Arquivos de Formulário de Etiqueta (LBX)

- Arquivos de Biblioteca (FLL)

- Arquivos de Formato (FMT)

$O$ projeto também mantém todas as referências a cada um dos arquivos, as dependências e os relacionamentos. É o programador que tem que especificar todos os componentes de um projeto que são necessários para a aplicação final. O Gerenciador de Projetos então assegura que a aplicação gerada é baseada nos últimos arquivos-fonte. Por exemplo, quando se modifica um dos arquivos de programa num projeto e se cria uma aplicação, o Gerenciador de Projeto recompila cada arquivo alterado, se necessário, antes de incluí-lo na aplicação. A figura 4.1 mostra os componentes de um projeto no FoxPro.

\section{Organização do Sistema de Banco de Dados para Aplicação Policial}

O sistema de banco de dados desenvolvido é simples e é responsável por cadastrar tanto informaçð̃es de policiais como de suspeitos. Ele possui dois arquivos dbfs (suspeitos.dbf e policiais.dbf) onde são armazenadas todas as informações referentes ao cadastro de suspeitos e de policiais, dois outros arquivos $\mathrm{dbf}$ (fotol.dbf e foto2.dbf), onde são armazenadas as fotos dos suspeitos e dos policiais, e um outro arquivo $\mathrm{dbf}$ (ordem. $\mathrm{dbf}$ ) onde é retornado o resultado das pesquisas por fotos semelhantes. As figuras 4.2 e 4.3 ilustram os relacionamentos entre os arquivos da base de dados.

Por uma questão de organização dos textos, as telas e os detalhes do sistema foram colocados em apêndices desse texto, e são aqui referenciados. A descrição detalhada de cada arquivo da base de dados com os seus respectivos campos (tamanho, tipo) é apresentada no apêndice II. As imagens das faces armazenadas nos arquivos foto1.dbf e foto2.dbf são imagens gráficas coloridas (no caso de policiais) e 
P\&B (preto e branco) no caso dos suspeitos. Essas imagens estão no formato PICT (formato proprietário do sistema operacional do Mac). As imagens não possuem uma resolução fixa em pixels, pois o sistema automaticamente re-escala a imagem para o tamanho adequado quando essa for visualizada na base de dados. A área útil em pixels da janela de visualização é $200 \times 180$ e a resolução necessária para processamento é de $64 \times 64$. Portanto seria bom haver um pre-processamento das imagens para que elas não fiquem maiores que o necessário, evitando desperdício de espaço de armazenamento, já que serão armazenadas milhares de fotos.
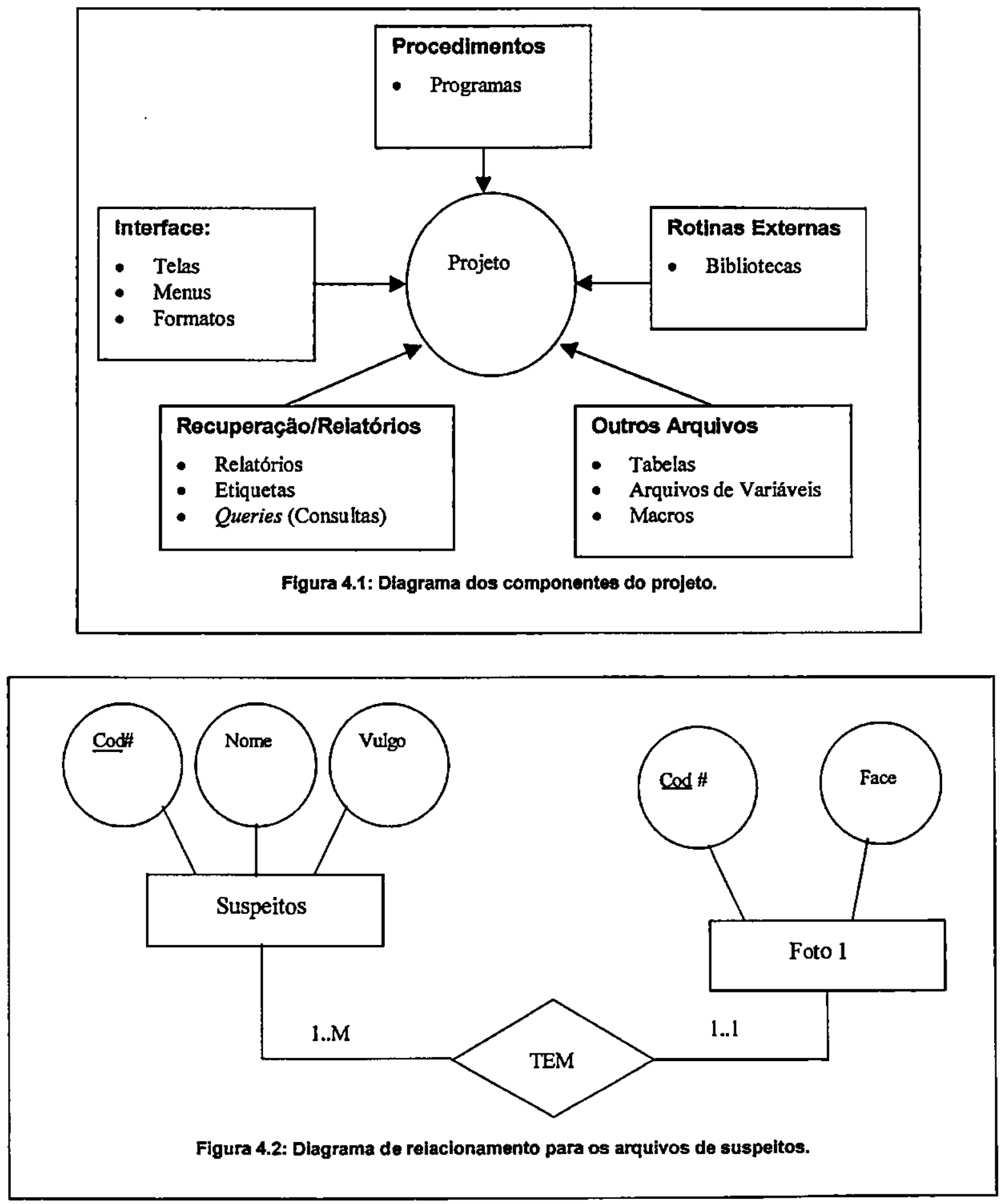


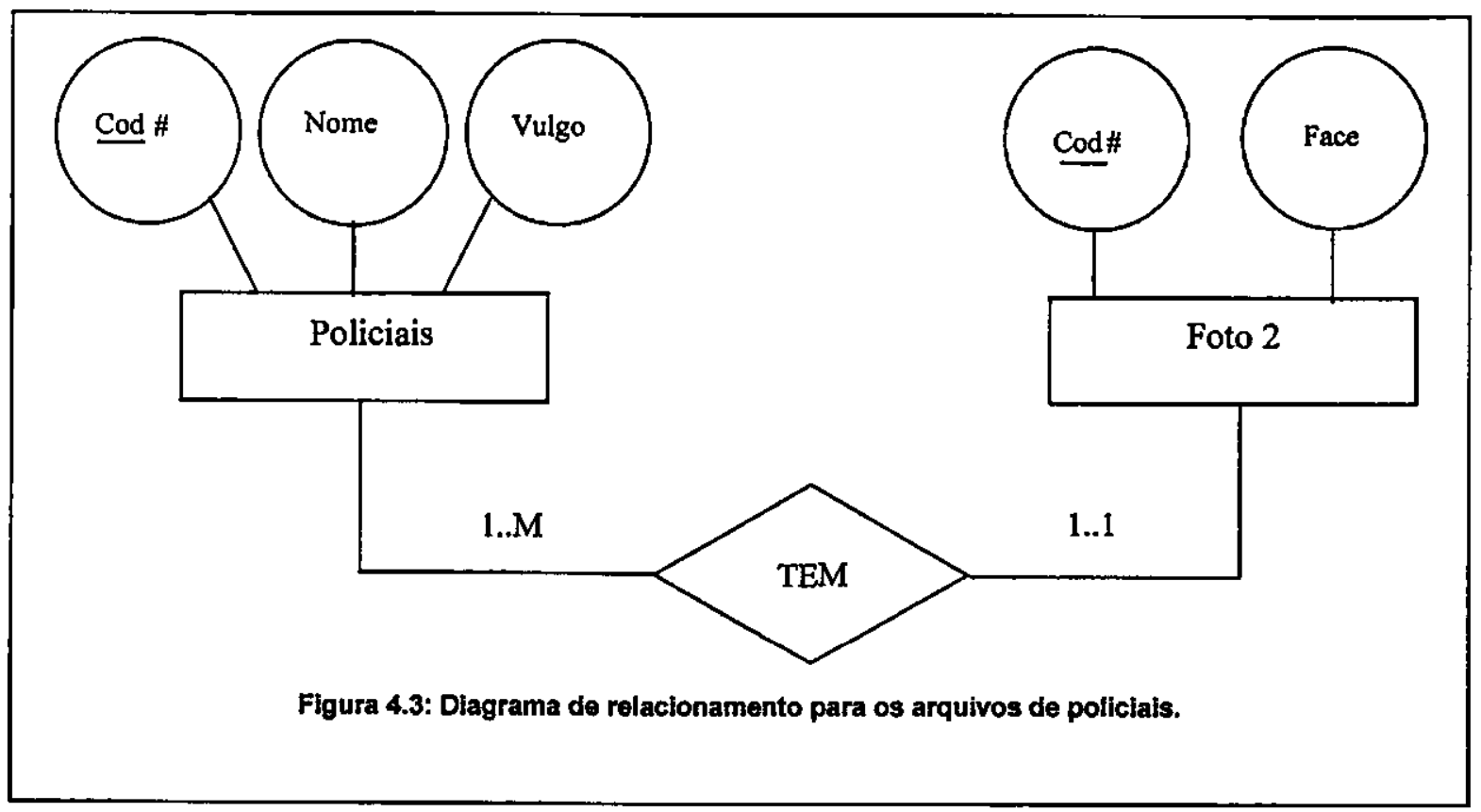

As imagens utilizadas pelo programa de reconhecimento de faces não são armazenadas em conjunto com a base de dados do FoxPro, mas em arquivos gráficos formato PGM ASCII (Portable Graymap Format) com 256 tons de cinza ( 8 bits - P\&B). A sintaxe desse tipo de arquivo é a seguinte [Gom94]:

- Um "numero mágico" para a identificação do tipo do arquivo. No caso do PGM ASCII esse número é "P2".

- Uma linha que inicia com \# e um texto de comentário, que pode ser o nome do programa que criou a imagem ou o nome do arquivo.

- Dimensões x e y da imagem, separadas por um espaço em branco.

- O valor que representa o branco máximo da imagem. Na maioria dos casos esse valor é 255.

- Valores que variam entre 0 (preto) e 255 (branco), que representam as tonalidades da imagem. Os valores são armazenados com um espaço entre eles. Cada valor representa um tom de cinza. Para se formar uma cor ou tom de cinza no sistema RGB, adotado pelo PGM, são necessários três componentes: $\mathbf{R}$ (vermelho), $\mathbf{G}$ (verde) e $\mathrm{B}$ (azul). No caso do cinza os três componentes são iguais, e somente um é armazenado. Ele varia de 0 a 255 perfazendo assim os 256 tons de cinza. Para se obter, por exemplo, um cinza escuro, usa-se a tripla $(50,50,50)$ no sistema RGB e armazena-se somente o valor 50 no arquivo PGM [Gom94].

As imagens PGM possuem como nome o código do suspeito da base de dados. Desse modo pode-se fazer a associação entre os dados do sistema multimídia e a foto que será utilizada para o reconhecimento 
de imagem. Na versão atual do programa, cada suspeito possui apenas uma foto, mas nada impede que futuramente cada suspeito possua um número maior de fotos (por exemplo, um suspeito pode ter uma foto frontal sério, uma outra rindo, outras com pequenas rotações na cabeça). Em alguns casos, quanto mais fotos existirem do mesmo suspeito, maiores as chances de reconhecimento. Essa característica, entretanto, não é de suma importância para o caso tratado aqui, pois neste projeto quer-se apenas ordenar os suspeitos mais parecidos, ao invés de dar certeza do reconhecimento. No entanto, essa característica pode melhorar a aplicabilidade da técnica.

\section{Interface do Sistema}

O apêndice I mostra as telas do Sistema Multimfdia, com as opçðes de menus, as janelas do sistema e as fichas para cadastro tanto de suspeito como de policiais. Tentou-se criar um sistema que fosse o mais amigável possível e seguindo padrões definidos de HCI (Human-Computer Interaction -Interação Homem-Máquina) [Pre94].

A tela 7 do mostra a ficha para o cadastro de suspeitos. Nessa ficha tem-se os dados pessoais, bem como as características físicas e a foto. A maioria dos dados presentes nessa ficha foram retirados das fichas que são preenchidas manualmente pelos policias no ato de uma ocorrência. Em algumas características físicas, há um número do lado esquerdo da opção, como, por exemplo, na tela 13. Esses códigos são os mesmos usados pelos polf́cias quando é feito um BO (boletim de ocorrência policial). Foram inseridas algumas novas características para as fichas policiais existentes. Isso foi feito para tentar cobrir todas as brechas existentes nas fichas impressas. Nas características novas que foram inseridas, tais como tatuagem, deficiência e cicatriz, não foi utilizado nenhum código. A tela 9 mostra as opç̃es disponíveis para a altura do suspeito, com 5 opções fixas, ao invés da altura em metros, para diminuir a taxa de erro quando for feita a descrição do suspeito, levando-se em conta os estudos realizados por Eric Lee, descritos no capitulo 2.

Na tela 23 tem-se a interface do primeiro sistema de busca e indexação. Nesse módulo é feito o reconhecimento da imagem a ser pesquisada na base de fotos. Essa imagem deve estar no formato PGM ASCII com uma resolução de $64 \times 64$ pixels em tons de cinza. A pesquisa irá retornar uma sequueencia de imagens (tela 24) ordenadas por ordem de similaridade com a imagem pesquisada. Com o auxilio dos botões "volta" e "próxima", pode-se navegar pelas imagens. Nem sempre a foto do suspeito (supondo que ela esteja na base de fotos) deverá aparecer como sendo a primeira da pesquisa. Isso pode variar devido a vários fatores, tais como diferente iluminação, posição ou ângulo entre a foto a ser pesquisada e as fotos da base de fotos, ou detalhes visuais, como peruca e maquiagem. $O$ algoritmo de reconhecimento é responsável pela ordenação das fotos da base. Ele foi implementado usando a técnica de PCA (ver seções 4.2 e 4.3) e está ainda por ser integrado ao sistema multimídia.

Um outro sistema de busca é o de característica $\mathrm{x}$ característica (tela 25). Nesse módulo, a vítima ou 
testemunha irá responder algumas questões referentes ao suspeito, tais como cor da pele, altura, peso, se possui cicatriz, cor dos olhos e dos cabelos, etc. Com base nessas características descritas, serão apresentadas as fotos dos suspeitos que mais se assemelham com a descrição da vítima. Essa pesquisa é muito útil, por que facilita e agiliza o processo de identificação, já que a vítima não tem que olhar todas as fotos do álbum de suspeitos da polícia, mas sim só as que satisfazem as características descritas por ela. Essa funcionalidade do sistema ainda não implementada, estando a interface pronta e os dados organizados para uma futura implementação.

A seguir será descrita a implementação do algoritmo para reconhecimento de faces baseado em PCA.

\subsection{Algoritmo para Reconhecimento Automático de Faces}

Para a implementação do módulo de reconhecimento de faces foi escolhido o PCA (descrito no capítulo 3). O PCA foi escolhido por não haver necessidade do reconhecimento ser em tempo real, e por não se necessitar de uma precisão muito grande no reconhecimento. No caso deste projeto, como já dito antes, deseja-se ter uma lista de fotos mais parecidas, e não $100 \%$ de acerto, como seria o caso para um sistema de segurança. Ou seja, deseja-se uma lista de pessoas que mais se assemelhem com a da imagem pesquisada. Não é necessário que a imagem correta seja a primeira da lista, mas sim, que ela esteja entre as primeiras, para agilizar o processo de reconhecimento do suspeito pela vítima.

A implementação do código foi realizada em Borland C++ [Bor98] (em Windows) e em seguida será transportado para o Macintosh e recompilado utilizando o programa CodeWarrior 9 da Metrowerks [Cod97]. Para permitir essa migração, durante a etapa de implementação do código fonte em ambiente Windows, foi tomado o cuidado de não utilizar nenhuma função exclusiva do Borland $\mathrm{C}++$; as funções matemáticas necessárias foram todas implementadas diretamente, para não haver problema de incompatibilidade quando da migração para o ambiente Macintosh.

Para melhor entendimento, o processo de funcionamento do PCA será divido em passos, conforme a sua ordem de execução.

\section{Pré-processamento}

Para o reconhecimento, o primeiro passo a ser realizado é a construção de uma base de dados de imagens no formato PGM (descrito acima). As imagens devem ser formatadas em 8 bits, preto e branco, com resolução de $64 \times 64$ pixels, frontais, e pré-processadas para ter um fundo neutro e brilho/contraste parecidos. A captura dessas imagens pode ser feita através de scanner, máquina fotográfica digital ou uma câmera de vídeo, acoplada ao computador. A melhor qualidade se obtém tirando uma foto do suspeito com uma máquina fotográfica convencional, utilizando filme preto e branco, e depois 
digitalizando essa imagem para computador com o auxílio de um scanner de mesa. A resolução ótica do scanner não precisa ser muito grande, já que a imagem irá ter apenas $64 \times 64$ pixels. Recomenda-se digitalizar a imagem com uma resolução de $100 \mathrm{dpi}$, para não ocupar muito espaço em disco.

Quanto mais definidas e melhor processadas forem as imagens, mais preciso será o reconhecimento. Portanto, esse passo é muito importante e depende da habilidade e paciência do operador. Existem vários programas que permitem fazer esse pré-processamento, sendo que um dos mais utilizados é o Photoshop, da Adobe [Ado98], que está na versão 5 e está disponível para Windows e Macintosh. Um outro programa shareware muito bom para este tipo de processamento e que já exporta a imagem no formato PGM é o PaintShop Pro, da Jasc Software [Jas98]. A vantagem desse último em relação Photoshop está na capacidade de já gravar as imagens processadas no formato PGM ASCII, o que não é o caso do Photoshop.

\section{Cálculo da Média}

O passo seguinte para se iniciar o cálculo do algoritmo de PCA é calcular a média de todas as imagens que compõe a base de fotos. A média é calculada somando-se a intensidade pixel a pixel das imagens e dividindo pelo número de imagens que compõe a base da fotos. A intensidade média obtida deve então ficar entre 0 e 255. A fórmula abaixo ilustra esse cálculo:

$\mathrm{S}=$ número de imagens da base de dado;

m = vetor resuitante (médio);

$x=$ cada imagem da base de fotos;

$\mathbf{m}=\frac{1}{s} \sum_{j=1}^{s} \mathbf{x}_{j}$

A figura 4.4 ilustra a aparência de um vetor calculado pela fórmula acima, com base nas fotos da figura 4.7. Esse vetor possui 4096 posiçð̃es (64x64 - resolução da imagem). Para facilitar os cálculos matemáticos,

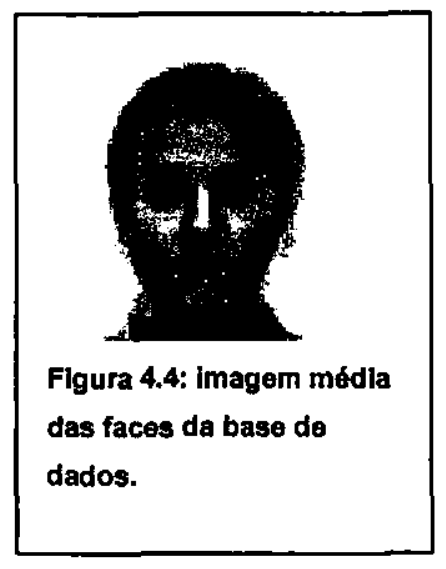
do ponto de vista de implementação, a matriz $64 \times 64$ característica da foto foi transformada em um vetor de 4096 posições. A indexação é dada pela seguinte ordem: elemento 0 é $\mathrm{x}_{0} \mathrm{y}_{0}$, elemento 1 é $\mathrm{x}_{1} \mathrm{y}_{0}$, elemento 2 é $\mathrm{x}_{2} \mathrm{y}_{0}, \ldots$, elemento 64 é $\mathrm{x} 0 \mathrm{yl}$ e assim por diante, até o último elemento (4095) que é $\mathrm{x}_{63} \mathrm{y}_{63}$. A figura 4.5 mostra graficamente como é feita essa conversão. Uma vez calculada o vetor médio, 0 próximo passo é calcular a diferença entre as imagens da base de fotos e sua média. Essa diferença vai ser usada para calcular a matriz de covariância. 


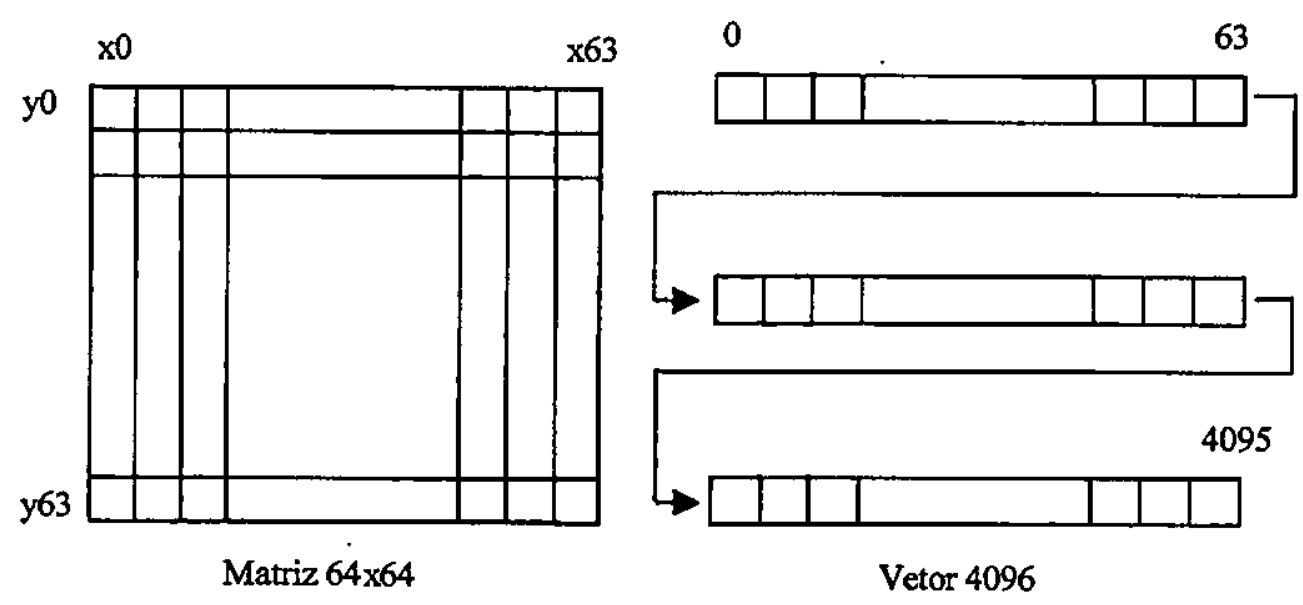

Figura 4.5: llustra a transformaçăo da Matrzz $64 \times 64$ em um Vetor de 4096 posiçbes.

\section{Cálculo dos Vetores Diferença}

O cálculo dos vetores de diferença é dado por:

$$
d_{j}=x_{j}-m
$$

Os vetores diferença são implementados pela que subtração, posição a posição, do vetor da imagem pelo vetor médio. Ou seja, $d_{1}=x_{1}(0)-m(0), x_{1}(1)-m(1), x_{1}(2)-m(2), \ldots, x_{1}(4095)-m(4095)$. Os vetores diferenças resultantes são todos de 4096 posições e são usados para calcular a matriz de covariância C.

\section{Cálculo da Matriz de Covariância}

A matriz de covariância $\mathrm{C}$ reflete o relacionamento entre as fotos da base de fotos. A fórmula abaixo mostra como essa matriz é calculada:

$$
\mathbf{C}=\frac{1}{s} \sum_{j=1}^{s} \mathbf{d}_{j} \mathbf{d}_{j}^{T}
$$

Onde s é o número de fotos da base de fotos.

A matriz de covariância possui $4096 \times 4096$ elementos, e é utilizada nos cálculos para os auto-vetores $u_{k}$ e auto-valores $\lambda_{k}$, que são responsáveis pelo treinamento do reconhecimento. Devido ao seu tamanho $(4096 * 4096 * 4=67108864$ bytes, ou 68Mb) ela é armazenada em disco. Isso aumenta muito o tempo de 
processamento, pois o acesso a disco é bem mais lento que o acesso à memória RAM do computador. Muito embora o sistema aqui desenvolvido não vá ser utilizado para reconhecimento em tempo real, tal inconveniente deve ser evitado em versóes futuras do programa, com um melhor gerenciamento da memória RAM. Cabe notar que essa matriz só deve ser recalculada quando da introdução de uma nova foto na base de fotos, e não a cada reconhecimento realizado.

\section{Cálculo dos Auto-vetores e Auto-valores}

Foi implementado o método das potências para se calcular os auto-valores e auto-vetores para a matriz de covariância C. Segue a descrição do algoritmo utilizado [Jam93]:

Seja A uma matriz n x n (essa matriz será tratada como um vetor, para facilitar a implementação);

Sejam $\lambda_{1}, \lambda_{2}, \ldots, \lambda_{n}$ os auto-valores de $\mathbf{A}$ e $\mathbf{u}_{1}, \mathbf{u}_{2}, \ldots, \mathbf{u}_{\mathbf{n}}$ seus auto-vetores;

Sup̃̃e-se que $\left|\lambda_{1}\right|>\left|\lambda_{2}\right| \geq \ldots \geq\left|\lambda_{n}\right|$ e pelo método das potências quer-se determinar $\lambda_{1}$;

Seja $\mathbf{y}_{\mathbf{k}}$ um vetor coluna de $\mathrm{n}$ componentes, o qual será escrito como combinação linear dos auto-vetores.

Supõe-se que seja $\mathbf{y}_{0}=(1, \ldots, n)$

A partir de um vetor $y_{k}$ constroi-se dois outros vetores $y_{k+1}$ e $z_{k+1}$, do seguinte modo:

$$
\begin{gathered}
\mathbf{z}_{k+1}=\mathbf{A} \mathbf{y}_{\mathbf{k}} \\
\mathbf{y}_{k+1}=\frac{1}{\boldsymbol{\alpha}_{k+1}} \mathbf{z}_{k+1} \quad \text {, onde } \boldsymbol{\alpha}_{\mathrm{k}+1}=\max \left|\left(\mathbf{z}_{\mathrm{k}+1}\right) \mathbf{r}\right|
\end{gathered}
$$

ou seja, dado $\mathrm{y}_{0}$, constroi-se:

$$
\begin{aligned}
& \mathbf{z} 1=\mathbf{A y}_{0} \\
& \mathbf{y}_{1}=\frac{1}{\alpha_{1}} \mathbf{z}_{1}=\frac{1}{\alpha_{1}} \mathrm{~A} \mathrm{y}_{0} \\
& \mathbf{z}_{2}=\mathbf{A} \mathbf{y}_{1}=\frac{1}{\boldsymbol{a}_{1}} \mathbf{A}^{2} \mathbf{y}_{0} \\
& y_{2}=\frac{1}{a_{2}} z_{2}=\frac{1}{a_{1} a_{2}} A^{2} y_{0} \\
& z_{3}=A y_{2}=\frac{1}{a_{1} \alpha_{2}} A^{3} y_{0} \\
& \mathbf{y}_{k}=\frac{1}{\boldsymbol{\alpha}_{k}} \mathbf{z}_{k}=\frac{1}{\boldsymbol{\alpha}_{1} \boldsymbol{\alpha}_{2} \cdots \boldsymbol{\alpha}_{k}} \mathbf{A}^{k} \mathbf{y}_{0} \\
& \mathbf{z}_{k+1}=\mathbf{A} \mathbf{y}_{k}=\frac{1}{\boldsymbol{\alpha}_{1} \boldsymbol{\alpha}_{2} \cdots \boldsymbol{\alpha}_{z}} \mathbf{A}^{k+1} \mathbf{y}_{0}
\end{aligned}
$$


Assim,

$$
\lim _{k \rightarrow \infty} \frac{\left(\mathbf{z}_{k+1}\right)_{r}}{\left(\mathbf{y}_{k}\right)_{r}}=\lim _{k \rightarrow \infty} \frac{\left(\mathbf{A}^{k+1)} \mathbf{y}_{0}\right)_{r}}{\left(\mathbf{A}^{k} \mathbf{y}_{0}\right)_{r}}=\lambda_{1}
$$

$\lambda_{1}$ é o primeiro auto-vetor para a matriz de covariância.

$\mathbf{y}_{1}=\mathbf{y}_{\mathrm{k}}$ são os auto-vetores correspondentes.

O cálculo dos próximos auto-valores e auto-vetores é dado pelos seguintes passos:

Seja $\mathbf{a}^{\mathbf{t}}$ a primeira linha da matriz $\mathbf{A}$;

Cria-se a matriz $\mathbf{A}_{1}=\mathbf{A}-\mathbf{y}_{1} \mathbf{a}^{\mathrm{t}}$

Com base na matriz $\mathbf{A}_{1}$ cria-se a matriz $\mathbf{B}$, que é de ordem n-1, eliminando-se a primeira linha e coluna da matriz A.

Agora é só aplicar o método das potências de novo, na nova matriz B, para calcular o auto-valor $\lambda_{2}$ (da matriz $\mathbf{A}_{1}$ e A) e o auto-vetor $\mathbf{y}_{2}$ (da matriz $\mathbf{A}_{1}$ ).

Para se chegar ao auto-vetor da matriz A faz-se: $\mathbf{y}_{2}=\mathbf{y}_{1}+\mathbf{c z}$, onde:

$$
c=\frac{\lambda_{2}-\lambda_{1}}{\mathbf{a}^{t} \mathbf{z}}
$$

A quantidade de auto-vetores que serão calculados, bem como a precisão que se quer para o auto-valor, são definidos pelo usuário no sistema multimídia. $\mathrm{Na}$ atual versão do programa, tem-se um arquivo config.txt, o qual traz as configurações para o algoritmo de reconhecimento de faces. Nesse arquivo é armazenado a quantidade de fotos, o número de auto-vetores desejado, precisão do auto-valor (número de iterações) e se deseja treinar o algoritmo (1) ou apenas fazer o reconhecimento (0). Os valores padrão para a quantidade de auto-vetores e precisão do auto-vetor são 5 e 10 respectivamente. Tem-se agora um conjunto de auto-vetores que representam as imagens da base de fotos. A figura 4.6 ilustra a etapa do reconhecimento descrita até agora. Essa etapa é referenciada como treinamento do algoritmo, ou seja, ela prepara a projeção dos vetores num auto-espaço que será responsável pelo reconhecimento. $\mathrm{O}$ treinamento deve ser repetido toda vez que uma nova foto é inserida na base de fotos, mas não necessariamente toda vez que se deseja apenas reconhecer uma foto entre aquelas da base.

\section{Projeção no Auto-espaço}

Depois de calculados os auto-vetores, que são matrizes de $64 \times 64$, inicia a fase de reconhecimento propriamente, em que qualquer dado $\mathbf{x}$ (no caso, uma imagem) pode ser projetada num auto-espaço de 
acordo com a formula abaixo:

$$
\omega_{k}=\mathbf{u}_{k}^{\ell}(\mathbf{x}-\mathbf{m})
$$

Onde $\omega$ são as coordenadas no auto-espaço, e $\mathbf{x}-\mathbf{m}$ são as diferenças já calculadas no início do algoritmo (vetores de diferença d), e $\mathbf{u}_{\mathrm{k}}^{\mathrm{t}}$ são os auto-vetores calculados no passo anterior $\left(\mathbf{y}_{\mathrm{k}}\right)$.

$O$ vetor $\Omega=\left(\omega_{1}, \omega_{2}, . . \omega_{s-r}\right)$ pode ser interpretado como um vetor característica que descreve propriedades estatísticas do conjunto de dados.

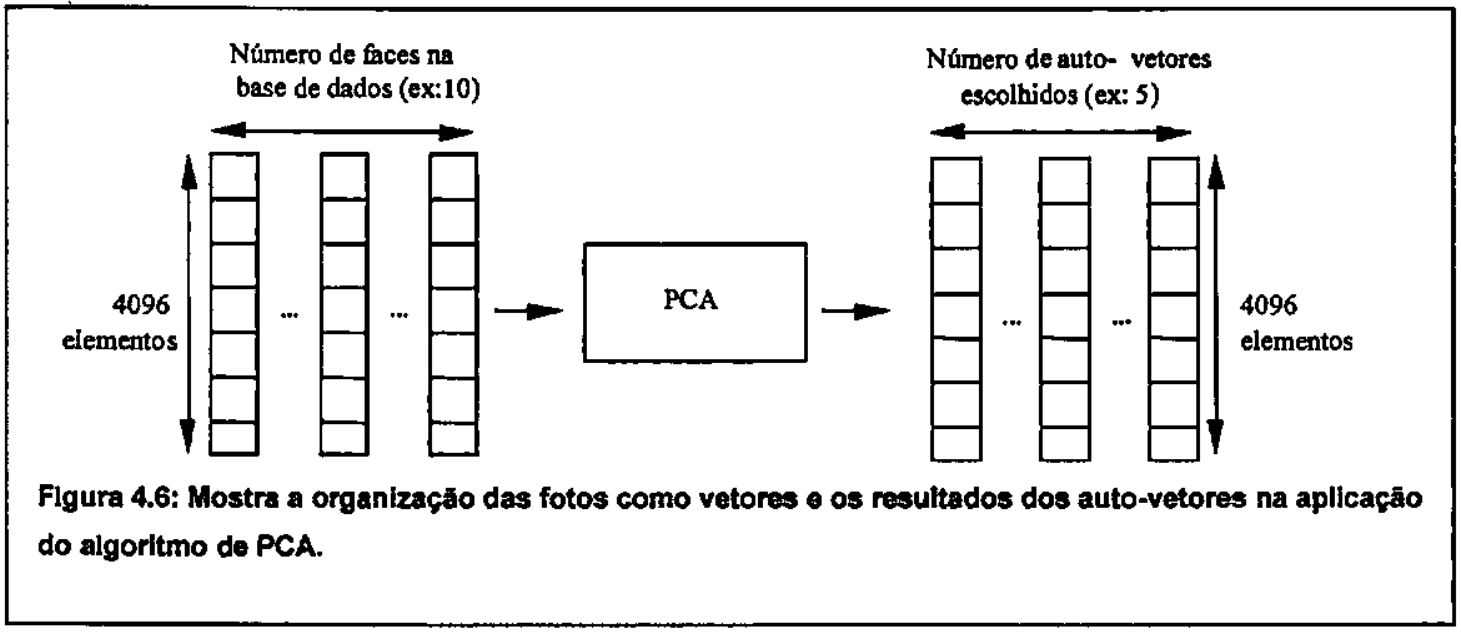

\section{Fazendo o Reconhecimento}

Para se fazer o reconhecimento, calcula-se todas as projeções, como descrito acima, para as imagens da base de fotos $\left(\Omega_{\mathrm{k}}\right)$ e calcula-se a projeção para a imagem que se quer reconhecer, usando o mesmo processo $\left(\Omega_{\text {vovo }}\right)$.

Calcula-se então a Distância Euclidiana entre as projeçð̃es de acordo com a fórmula:

$\varepsilon_{\mathrm{k}}=\left\|\Omega_{\mathrm{novo}}-\Omega_{\mathrm{k}}\right\|$

e ordena-se o resultado da menor para a maior distância. As que estiverem mais próximas de zero são as que mais se assemelham com a imagem procurada.

\section{Estrutura do Algoritmo de Reconhecimento}

A estrutura do programa de reconhecimento segue os passos descritos acima. As rotinas que o compõem são:

- ler_fotos 
Essa rotina lê a base de fotos e cria a imagem média.

Entrada: número de fotos e prefixo do nome do arquivo das fotos (foto).

Saída: imagem média, armazenada em disco (media.pgm).

\section{- diferença}

Essa rotina calcula as diferenças entre as imagens da base de fotos e a média calcula na rotina acima.

Entrada: número de fotos, prefixo do nome do arquivo das fotos (foto) e media.pgm.

Saida: vetores diferenças armazenados em discos no formato: prefixo + número da foto (ex: dif0, difl, $\operatorname{dif} 2$, etc).

\section{- matriz_covar}

Essa rotina calcula a matriz de covariância, que é tratada como um vetor de 4096x4096 posiçס̃es.

Entrada: número de fotos, vetores diferença calculados na rotina anterior.

Saída: matriz de covariância, armazenada em disco (covar).

- auto_vet_covar

Essa rotina calcula os auto-vetores de uma matriz. É utilizado com a matriz de covariância calculada na rotina matriz_covar.

Entrada: número de fotos, número de auto-vetores que se deseja calcular, número de iterações no cálculo dos auto-valores, matriz para o cálculo.

Saída: auto-vetores armazenados em disco no formato: prefixo + número do auto-vetor (ex: av0, avl, av2, etc).

O conjunto de rotinas descrito acima faz parte do treinamento do algoritmo de PCA. Conforme mencionado acima, no treinamento estão envolvidas todas as fotos da base. Conforme mencionado anteriormente, esse treinamento só deve ser realizado quando houver a inserção de uma nova imagem na base de fotos. Esse é o processo mais demorado do programa de reconhecimento, com complexidade $\mathrm{O}\left(\mathrm{N}^{2}\right)$, onde $\mathrm{N}$ é o número de fotos da base.

As rotinas descritas abaixo fazem parte da etapa de reconhecimento do algoritmo de PCA. Esse reconhecimento é bem mais rápido, de complexidade $O(N)$ chegando muito próximo de tempo real dependendo em computadores atuais e com base de dados relativamente pequena.

- calc_omega

Essa rotina calcula a projeção no auto-espaço dos auto-vetores obtidos na rotina de auto_vet_covar.

Entrada: número de fotos, número de auto-vetores calculados, auto-vetores e vetores-diferença. 
Saída: vetores ômega que contêm as projeções dos auto-vetores. Esses vetores são armazenados em disco no formato: omega + número do auto-vetor (ex: omega0, omega1, omega2, etc).

\section{- omega_novo}

Essa rotina calcula a projeção no auto-espaço para a imagem a ser reconhecida.

Entrada: número de auto-vetores, imagem média (media.pgm), auto-vetores e imagem a ser reconhecida (nova.pgm).

Saída: vetor ômega da imagem a ser reconhecida.

\section{- calc_dist_euclidiana}

Essa rotina calcula a distância euclidiana entre os ômegas das imagens da base de fotos e o ômega da imagem a ser reconhecida, e faz a ordenação das distâncias obtidas.

Entrada: número de fotos, número de auto-vetores calculados, prefixo do nome do arquivo das fotos, vetores ômega e vetor ômega da imagem a ser reconhecida.

Saída: arquivo texto (ordem.txt) com a seqüência das fotos reconhecidas por similaridade.

Conforme mencionado anteriormente, o algoritmo foi implementado em $\mathrm{C}++$. A estrutura ainda pode ser melhorada, para a generalização do código para outras aplicações que envolvam a análise do componente principal (PCA). A seguir são apresentados alguns dos testes realizados com a implementação do algoritmo de reconhecimento de faces por PCA.

\subsection{Alguns Testes do Reconhecimento Automático}

Uma das funções principais do sistema, na sua atual versão, é a ordenação das imagens da base de fotos em relação a uma nova imagem a ser pesquisada por ordem de semelhança (reconhecimento automático de faces). A figura 4.7 mostra as 10 fotos que foram utilizadas para treinar o algoritmo de PCA para os testes.

Serão aqui apresentados 5 tipos de testes: o primeiro tinha como objetivo tentar reconhecer uma foto idêntica a uma presente na base de fotos; o segundo em tentar reconhecer uma foto semelhante a uma presente na base de fotos. Esse "semelhança" seria a mesma pessoa, mas com outro tipo de iluminação ou fisionomia; o terceiro teste foi colocar na base de fotos uma nova imagem (foto11.pgm), que é a pessoa da foto4, mas utilizando óculos (figura 4.8) e verificar se as fotos 4 e 11 eram ordenadas em primeiro lugar; o quarto teste foi colocar uma faixa branca no nariz, olhos e boca da foto0 e verificar como se comportava o reconhecimento; e o último teste foi tentar reconhecer a pessoa da foto 3 com peruca (figura 4.9) e depois colocar essa imagem (foto12.pgm) na base de fotos e verificar o que ocorre quando se tenta reconhecer a mesma pessoa com e sem peruca e com uma peruca diferente (figura 4.10). 


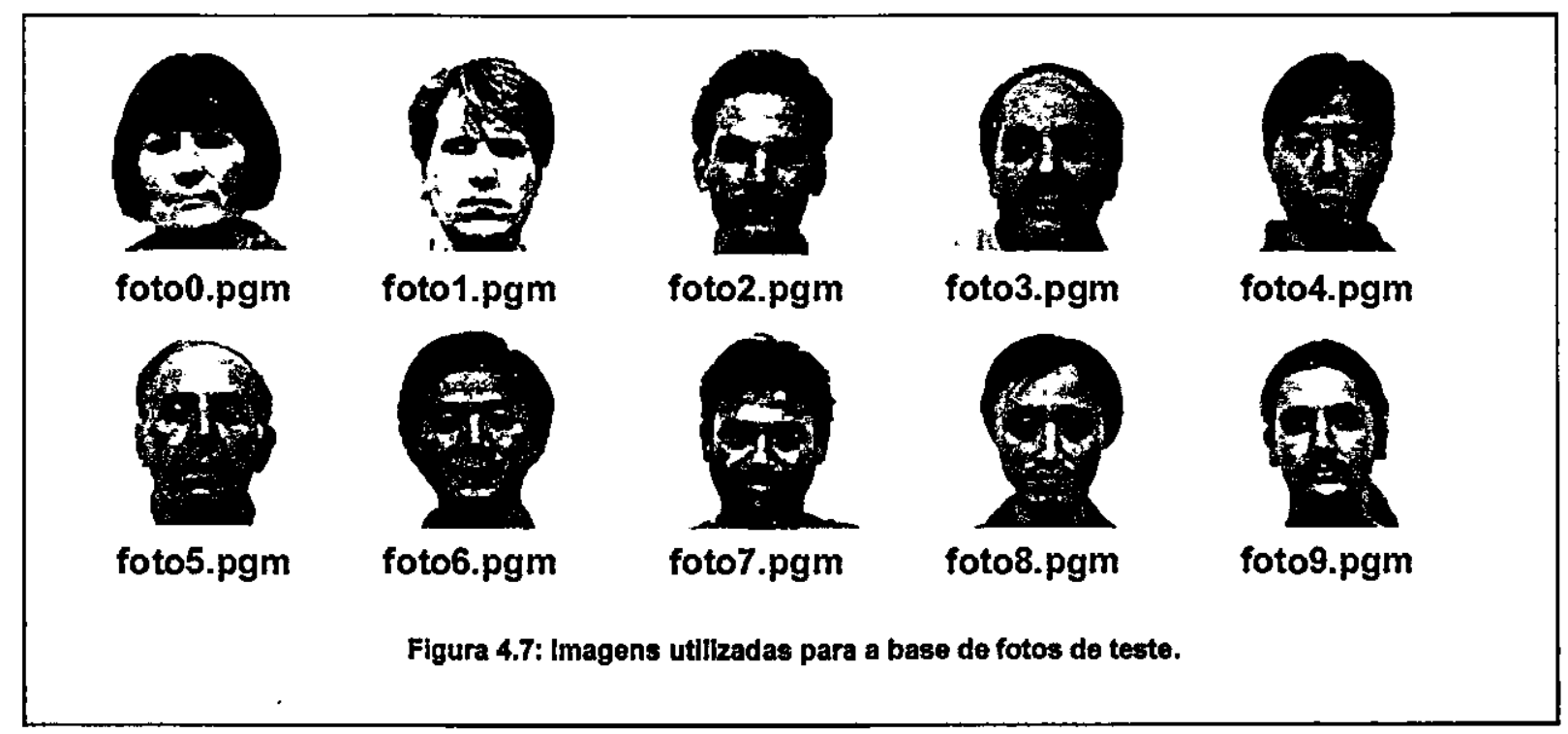

Os testes foram realizados com dois tipos diferentes de treinamento para o algoritmo de PCA. No primeiro foram calculados 3 auto-vetores e no segundo foram calculados 10 auto-vetores. Teoricamente, quanto maior for o número de auto-vetores, mais preciso deve ser o reconhecimento. Entretanto, quanto mais auto-vetores são calculados, maior é o custo computacional. Deve-se lembrar também que uma vez feito o treinamento, esse só é refeito quando uma nova foto é inserida na base de fotos.

\section{- $\quad$ Teste 1}

Nesse primeiro teste, tenta-se reconhecer uma foto presente na base de fotos. Foi feito o treinamento do PCA com as fotos mostradas na figura 4.7 e depois pesquisou-se cada foto individualmente na base de fotos. Em todos os casos a foto pesquisada foi ordenada em primeiro lugar, resultando numa eficiência de $100 \%$, tanto para o caso de 3 quanto para 10 auto-vetores.

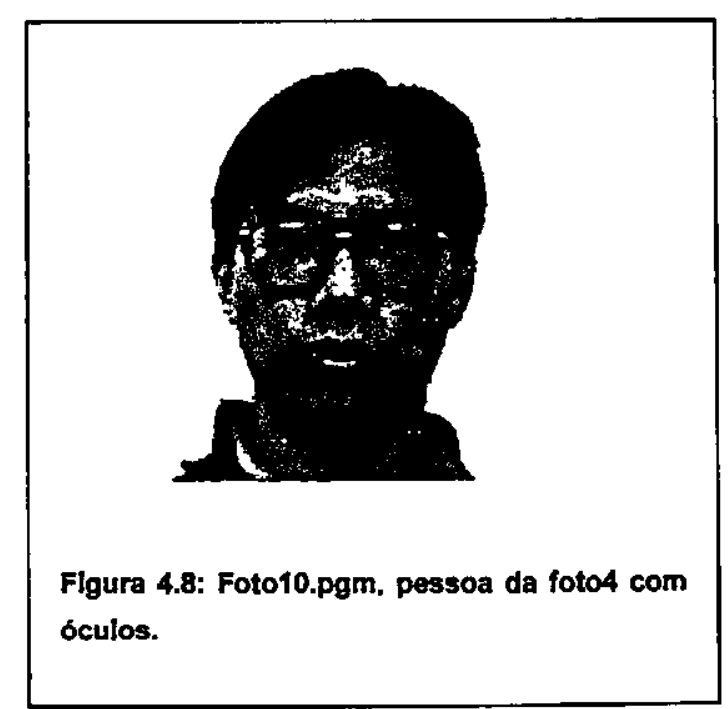



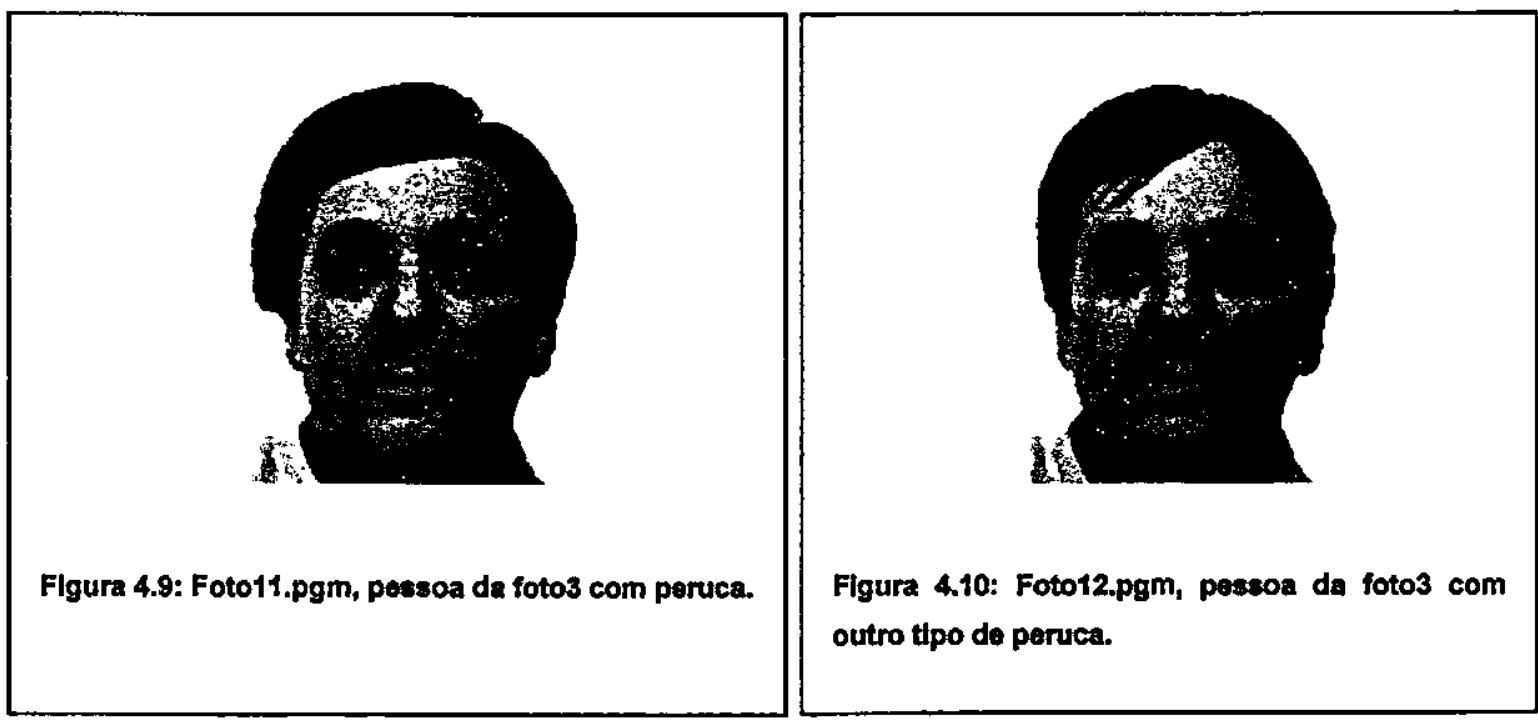

\section{- Teste 2}

Nesse teste, tentou-se verificar um reconhecimento para outras fotos que não foram treinadas na base de fotos. Foram usadas para o reconhecimento fotos das pessoas da base de fotos, mas que possuíam fisionomias diferentes, usavam óculos ou que tinha outro tipo de iluminação. A figura 4.11 mostra as imagens que foram usadas no teste de reconhecimento junto com a foto da figura 4.12. Essa foto é de uma pessoa que não existe. Ela foi criada artificialmente por computador só para efeito de teste. Essa foto é a metamorfose da pessoa da foto0 (50\%) com a pessoa da foto3 (50\%). Para a criação dessa foto_G, foi usado um programa chamado MorphPlus da ASDG que executa em plataforma Amiga. A intenção aqui é verificar o comportamento do algoritmo mediante uma foto que levava metade das características de cada pessoa.

A tabela 4.1 mostra o resultado do reconhecimento obtido para as fotos da figura 4.11 e 4.12 em relação à base de fotos.

Como pode ser visto, na tabela 4.1, o algoritmo apresentou um bom desempenho tanto com três como com dez auto-vetores. Todas as fotos foram reconhecidas e ordenadas como primeiras da lista, com exceção de duas, a foto_E e a foto_G. Na foto_E a diferença de iluminação afetou o reconhecimento. Nesse caso, o tratamento com mais auto-vetores deu resultado ligeiramente melhor. Como dito anteriormente, as imagens precisam passar por um pré-processamento para obter-se uma da etapa inicial do tratamento da imagem.

Quanto à foto_G, que é a metamorfose das fotos 0 e 3, elas não foram reconhecidas, ou melhor, não foram ordenadas no topo da lista, mas sim no final, obtendo uma ordenação um pouco mais adiantada quando o treinamento foi realizado com 10 auto-vetores. Apesar dela não constar do começo da lista, o que era previsível, o teste foi válido pois através dele nota-se que as fotos 0 e 3 são sempre ordenadas na 
sequência, confirmando o conjunto de similaridades entre ambas e foto de pesquisa.
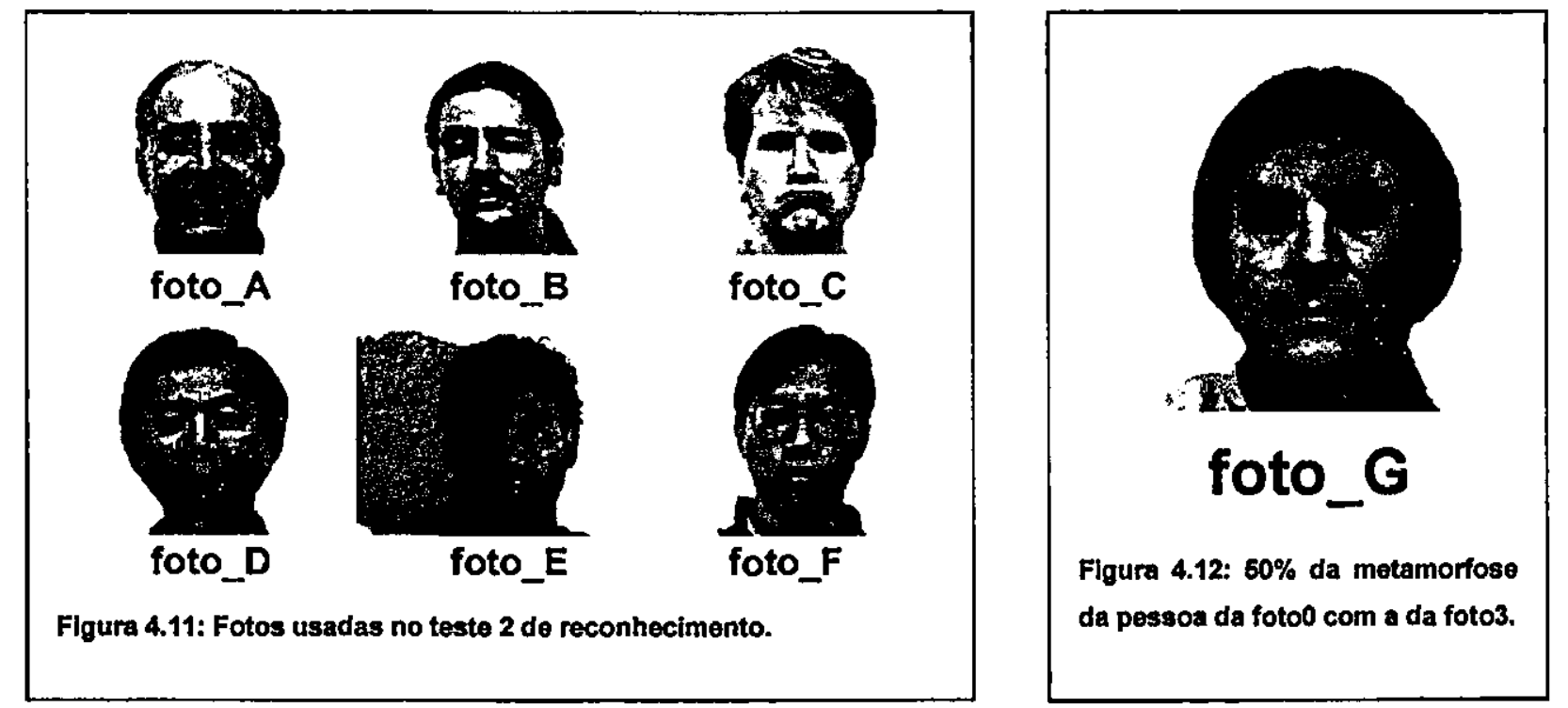

\begin{tabular}{|c|c|c|c|c|c|c|c|}
\hline \multicolumn{8}{|c|}{ Treinamento com 3 auto-vetores } \\
\hline Ordem/Nova & foto $A$ & foto $B$ & foto $\mathrm{C}$ & foto $D$ & Foto $\mathrm{E}$ & foto $F$ & foto $G$ \\
\hline 1 & 5 & 9 & 1 & 6 & 6 & 4 & 6 \\
\hline 2 & 9 & 3 & 7 & 4 & 4 & 8 & 4 \\
\hline 3 & 3 & 5 & 2 & 8 & 8 & 7 & 8 \\
\hline 4 & 2 & 2 & 8 & 7 & 7 & 1 & 1 \\
\hline 5 & 1 & 1 & 3 & 1 & 1 & 2 & 7 \\
\hline 6 & 7 & 7 & 9 & 0 & 2 & 6 & 2 \\
\hline 7 & 8 & 8 & 4 & 2 & 3 & 3 & 5 \\
\hline 8 & 4 & 4 & 5 & 3 & 0 & 9 & 9 \\
\hline 9 & 6 & 6 & 6 & 9 & 9 & 5 & 3 \\
\hline 10 & 0 & 0 & 0 & 5 & 5 & 0 & $\mathbf{0}$ \\
\hline \multicolumn{8}{|c|}{ Treinamento com 10 auto-vetores } \\
\hline 1 & 5 & 9 & 1 & 6 & 6 & 4 & 6 \\
\hline 2 & 9 & 5 & 7 & 4 & 4 & 8 & 4 \\
\hline 3 & 3 & 3 & 8 & 8 & $\overline{7}$ & 1 & 8 \\
\hline 4 & 2 & 2 & 2 & 0 & 8 & 7 & 1 \\
\hline 5 & 7 & 7 & 3 & 1 & 1 & 2 & 7 \\
\hline 6 & 1 & 1 & 4 & 7 & 2 & 3 & 2 \\
\hline 7 & 8 & 8 & 5 & 2 & 3 & 6 & 3 \\
\hline 8 & 4 & 4 & 9 & 3 & 0 & 5 & 0 \\
\hline 9 & 6 & 6 & 6 & 5 & 5 & 9 & 5 \\
\hline 10 & 0 & 0 & 0 & 9 & 9 & 0 & 9 \\
\hline
\end{tabular}

Tabela 4.1: Resultados dos teste 2.

\section{- Teste 3}

O objetivo desse teste era verificar se, quando existem duas imagens semelhantes na base de fotos, como é o caso das fotos 4 e 10, essas são reconhecidas em primeiro lugar e ordenadas na sequência. A tabela 
4.2 mostra os resultados obtidos.

\begin{tabular}{|c|c|c|c|c|}
\hline & \multicolumn{2}{|c|}{ Treinamento com 3 auto-vetores } & \multicolumn{2}{c|}{ Treinamento com 10 auto-vetores } \\
\hline Ordem/nova & foto4.pgm & Foto10.pgm & foto4.pgm & foto10.pgm \\
\hline 1 & 4 & $\mathbf{1 0}$ & 4 & 10 \\
\hline 2 & 10 & 4 & 10 & 4 \\
\hline 3 & 8 & 8 & 8 & 8 \\
\hline 4 & 2 & 2 & 2 & 2 \\
\hline 5 & 0 & 0 & 6 & 6 \\
\hline 6 & 6 & 6 & 1 & 1 \\
\hline 7 & 1 & 1 & 0 & 0 \\
\hline 8 & 3 & 3 & 3 & 3 \\
\hline 9 & 9 & 9 & 9 & 9 \\
\hline 10 & 5 & 5 & 5 & 5 \\
\hline 11 & 7 & 7 & 7 & 7 \\
\hline
\end{tabular}

Tabela 4.2: Resultados do teste 3.

Como pode ser visto na tabela acima, o reconhecimento foi preciso, colocando sempre em primeiro lugar a imagem pesquisada e em segundo lugar a mais semelhante, que nesse caso, é da mesma pessoa com a única diferença sendo os óculos.

\section{- Teste 4}

A figura 4.13 mostra as 3 fotos usadas para esse teste. O objetivo aqui era ver se mesmo faltando uma parte da foto, essa poderia ser reconhecida ou ordenada de modo eficiente. Para todas as fotos testadas $(\mathrm{H}$, I e J) o reconhecimento foi $100 \%$ preciso. A foto 0 foi sempre apresentada como sendo a foto pesquisada para os 3 casos, e esteve sempre em primeiro lugar na ordenação. Cumpre notar que, pela própria natureza do PCA, o resultado poderia ter sido menos preciso se, na base de fotos, existissem outras pessoas com semelhanças físicas àquela da foto encontrada (foto0). Ainda assim, na ordenação, 0 resultado seria razoável.
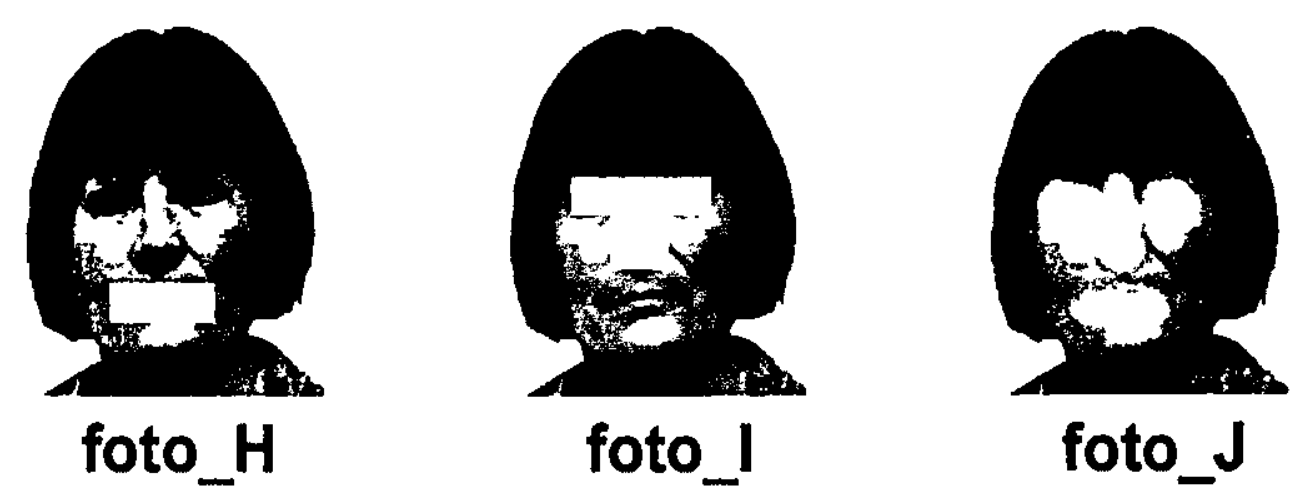

Figura 4.13: Fotos usadas no teste 4. 


\section{- Teste 5}

O teste 5 consistiu em verificar a ordenação quando se pesquisava na base de fotos por uma imagem contida lá (foto3), porém usando peruca (figura 4.9). Depois a foto da figura 4.9 foi inserida na base de fotos e o treinamento foi refeito, seguido do reconhecimento. Por último tentou-se o reconhecimento usando-se a foto da figura 4.10, que é da mesma pessoa da foto3, porém utilizando um outro tipo de peruca. Depois tentou-se o reconhecimento usando as fotos 6 e 3 . A tabela 4.3 mostra os resultados obtidos.

\begin{tabular}{|c|c|c|c|c|c|}
\hline \multicolumn{7}{|c|}{ Treinamento com 3 auto-vetores } \\
\hline Ordem/nova & $\begin{array}{c}\text { foto11.pgm } \\
\text { Antes de inserir essa } \\
\text { foto na base de fotos }\end{array}$ & foto11.pgm & foto12.pgm & Foto6.pgm & Foto3.pgm \\
\hline 1 & 6 & 11 & 11 & 6 & 3 \\
\hline 2 & 2 & 2 & 2 & 2 & 9 \\
\hline 3 & 8 & 6 & 6 & 11 & 1 \\
\hline 4 & 4 & 8 & 8 & 8 & 5 \\
\hline 5 & 10 & 10 & 1 & 10 & 11 \\
\hline 6 & 3 & 4 & 10 & 4 & 2 \\
\hline 7 & 1 & 0 & 4 & 0 & 6 \\
\hline 8 & 9 & 1 & 3 & 1 & 8 \\
\hline 9 & 5 & 3 & 0 & 3 & 10 \\
\hline 10 & 7 & 9 & 9 & 9 & 4 \\
\hline 11 & 0 & 5 & 5 & 5 & 0 \\
\hline 12 & - & 7 & 7 & 7 & 7 \\
\hline
\end{tabular}

Tabola 4.3: Resultados do teste 5.

Com base nesses resultados pode-se verificar a importância da região do cabelo para esse algoritmo. Pequenas alterações nessas áreas são reconhecidas pelo algoritmo, mas grandes alterações, como ter ou não cabelo, não são reconhecidas. Assim, com perucas diferentes uma pessoa é reconhecida, mas com cabelos muitos diferentes (ou sem cabelo), não. No reconhecimento da foto6 isso tornou-se mais evidente, pois a fotoll (com peruca) apareceu ordenada em terceiro lugar e a foto3 (sem peruca) apareceu só ordenada em nono lugar, e a única diferenças dessas fotos era o uso ou não da peruca.

Todos os testes foram úteis para testar a versatilidade do algoritmo PCA implementado nesse projeto e sua adequação à aplicação a que se propõe. Com bases nesses testes, fica claro que uma das etapas mais importantes é a etapa de captura e pré-processamento das fotos, tanto da base de fotos como da foto a ser pesquisada. Quanto melhor for esse pré-processamento, maior a probabilidade de uma ordenação positiva, se a foto estiver contida na base de fotos. Iluminação, brilho, contraste e posição da face na imagem são fatores decisivos para um ótimo reconhecimento. Também os testes inspirou a possibilidade de verificações alternativas, como fazer as buscas com vários tipos de perucas e adereços, como óculos e chapéus. Mais testes são necessários para verificar a adequação em todas as possiveis situações reais. 


\section{Dificuldades}

A maior dificuldade no desenvolvimento desse sistema esteve na implementação do algoritmo proposto para o reconhecimento (PCA). O problema maior foi tratar com uma matriz muito grande (4096x4096), o que resultou num arquivo de 67108864 bytes, ou aproximadamente $68 \mathrm{Mb}$ de memória, só para armazenar a matriz de covariância. Para se calcular os auto-valores e auto-vetores, mais 4 matrizes desse porte foram utilizadas, o que tornou impossível armazenar todas as matrizes na memória RAM do computador. Foi decidido então trabalhar com essas matrizes em disco, o que resolveria todos os problemas de memória RAM, mas tornou o cálculo mais lento.

O treinamento da base de fotos de 10 imagens, com 10 auto-vetores, levou cerca de 4 horas para ser executada em um computador rápido (Pentium 200MHz). Conseguiu-se um ganho relativo de velocidade (de $4 \mathrm{hs}$.para $3 \mathrm{hs}$ ), quando foi feito o mesmo treinamento usando-se um disco rígido SCSI-II de $8 \mathrm{mb} / \mathrm{s}$, o qual é mais rápido de o disco rígido IDE originalmente utilizado.

Deve-se levar em conta também, que uma vez o algoritmo treinado para uma base de fotos, o reconhecimento de uma nova imagem alcançou tempo real, levando-se apenas poucos segundos para ordenar as fotos.

\subsection{Integração entre o Sistema Multimídia e o PCA}

A identificação de pessoas através de suas características faciais é um tema que vem recebendo muita atenção em aplicações computacionais nos últimos anos. O mesmo ocorre com relação à construção de base de dados multimídia.

A integração desses dois temas vem representar um avanço em termos de uma ferramenta muito conveniente para tarefas policiais e de segurança em geral, principalmente no que se refere ao aumento da produtividade na localização e apreensão de suspeitos.

O sistema de banco de dados desenvolvido aqui será integrado ao reconhecimento de faces através de AppleScript, que acompanha o sistema operacional do computador Apple Macintosh desde a versão 7.0. AppleScript dá ao usuário um modo não interativo de operar o computador. Com ele é possível dar ao computador uma lista de coisas que se deseja que ele faça, associada a um determinado comando ou evento. Essa lista é chamada de script. O Apple Macintosh possui um programa que permite que se crie scripts de uma maneira muito fácil e rápida. Ele simplesmente grava todos os movimentos e cliques que o usuário der com o mouse e quando o usuário executa esse script repete todas as ações de modo automático.

Será utilizado o AppleScript para poder executar o algoritmo de reconhecimento de faces de dentro do 
sistema multimídia programado em FoxPro. A integração se dará da seguinte forma:

- Quando clica-se no botão de reconhecimento o programa de reconhecimento será executado através de um AppleScript, realizará o reconhecimento e criará uma arquivo (ordem.txt) com o nome das imagens indexadas por ordem de semelhança com a foto procurada. A figura 4.14 mostra um arquivo exemplo com uma base de fotos de 10 suspeitos.

- Com base nesse arquivo (ordem.txt), o sistema multimídia montará uma base de dados chamada ordem.dbf com o nome das fotos e código dos suspeitos que serão apresentados num slide show.

Antes de realizar as etapas acima, o programa deverá ser recompilado para o código do Apple Macintosh Quadra.

Os demais aprimoramentos sugeridos, além das conclusões alcançadas com esse trabalho de mestrado,

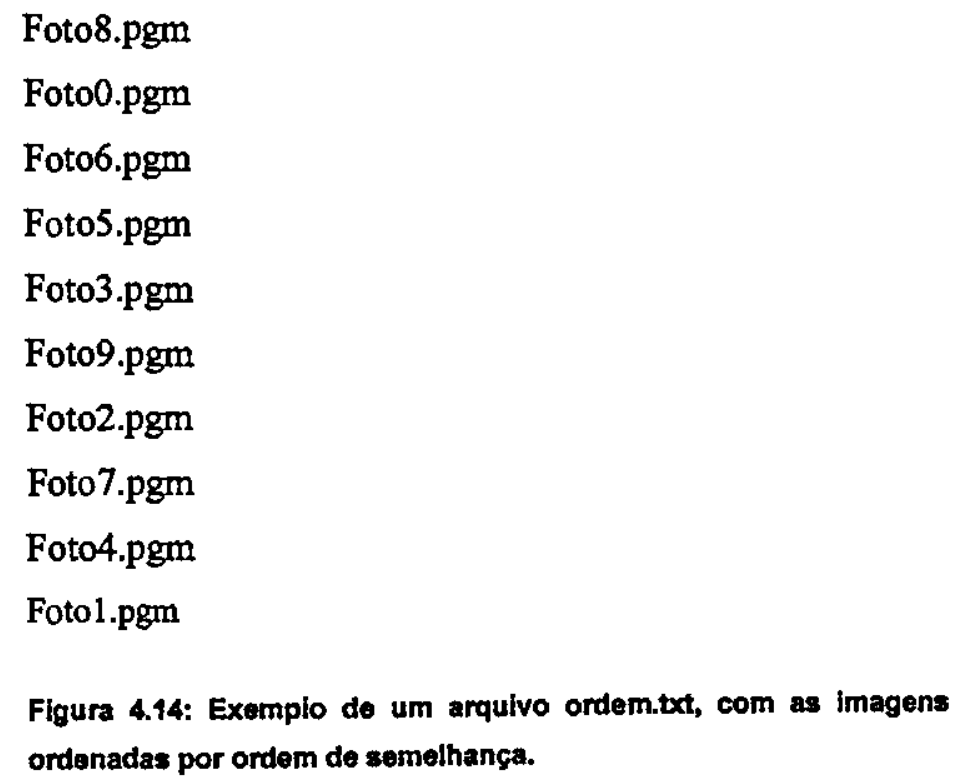

\subsection{Trabalhos Futuros e Conclusões}

Esta seção apresenta uma análise resumida do trabalho desenvolvido e suas extensões, bem como as conclusões alcançadas.

\section{Perspectivas}

Há ainda muito trabalho pela frente para tornar o sistema multimídia, aqui desenvolvido, um sistema sólido e que abranja todas as necessidades policiais. Este trabalho de mestrado foi responsável pelo passo inicial, que atende a todos os requisitos de cadastramento dessa atividade policial e à versão básica do 
algoritmo de reconhecimento. Entretanto, certeza muita coisa pode ser feita ainda para melhorar o sistema e torná-lo uma ferramenta muito útil para ajudar o processo criminal e agilizar a elucidação de crimes. A seguir é apresentada uma lista de sugestões para outros trabalhos, que visam completar a aprimorar o sistema aqui desenvolvido:

- Realizar a integração do reconhecimento por PCA o sistema de cadastramento apresentado na seção 4.1. Esse passo está preparado e deve demandar um pequeno esforço de programação.

- Testar outros tipos de algoritmos para reconhecimento de faces, como redes neurais ou transformada de Walsh, para tentar obter um ganho de velocidade no processo de treinamento do sistema;

- Inserir no sistema multimídia, buscas alternativas, com fotos alteradas por características físicas mutáveis (como cor do cabelo) e adereços.

- Permitir cadastro no Sistema de Banco de Dados de outras características pessoais, tais como: voz, impressão digital e íris.

- Implementar algoritmos para reconhecimento de voz, impressão digital e íris.

- Acelerar do treinamento do PCA através do gerenciamento criterioso do acesso ao disco.

- Acoplar o sistema de retrato falado ao sistema multimídia, permitindo que ele possa fazer a pesquisa por características na base de fotos, conforme objetivo descrito na seção 4.1 .

- Como um objetivo mais ambicioso, transformar o sistema em um site de internet, onde haveria a integração da polícia de todo o país fornecendo fotos e dados para a base de dados. Isso sem dúvida iria agilizar em muito o processo de identificação de suspeitos a nível nacional.

\section{Conclusões}

O estudo do reconhecimento de faces é relativamente recente. A maioria dos projetos existentes nessa área, até 2 anos atrás, eram experimentais. Agora estão surgindo os primeiros sistemas profissionais para reconhecimento automático de faces. Não há ainda um algoritmo que se destaque dos outros; há muitas pesquisas nessa área, mas a maioria está em processo de formação e consolidação de suas bases teóricas. Foi visto neste projeto um número de algoritmos e de alternativas para se elaborar um sistema de reconhecimento automático de faces. Foi implementado o algoritmo que se achou mais adequado para a solução do problema aqui proposto. Embora o algoritmo não seja o mais rápido no que se refere ao treinamento, ele demonstrou ser um algoritmo confiável e com uma taxa de erro aceitável. $O$ algoritmo se mostrou adequado à aplicação já que no enfoque dado ao projeto, não se quer determinar com exatidão se a foto está ou não na base de fotos, mas sim ordenar a base por similaridade.

O sistema de cadastramento atende aos requisitos determinados pela Polícia Militar de São Carlos, e 
deverá ser colocado em uso tão logo ocorra a integração com o reconhecimento.

Com o passo inicial dado pela criação, seleção e desenvolvimento do sistema, as demais etapas do projeto DETECT poderão ser abordadas. 


\section{Bibliografia}

[Alm96] Almeida, A. C, "Desenvolvimento de uma Base de Dados Multimídia pata Apoio à Identificação de Indivíduos", Relatório Interno do Projeto Detect, ICMSC, 1996.

[Ad098] Adobe Photoshop, http://www.adobe.com, Adobe Systems Inc, 1998.

[Asp95] Identikit in a PC, http://fast-multimedia.com/fast/html/products/dev/user/ F0995_20.html, Aspley Ltd, 1995.

q [Ban97] Banon, G. J. F., "Morphological Approach for Template Matching", Anais do X SIBGRAPI'97, Artigo 22, pp. 171-178, 1997.

[Ben96] Bender, B., http://www.odc.com/anthro/, Anthropometric Resource Center, Abril 1996.

[Bey93]

Beymer, D., "Face Recognition Under Varying Pose", MIT Artificial Intelligence Laboratory, AI Memo N. 1461, CBCL Paper N. 89, Dezembro de 1993.

[Boc96] ZN Bochum GmbH, http://www.zn.ruhr-uni-bochum.de/work/k1/s19e.htm, 1996.

[Bor98] Borland C + , http://www.borland.com.br, Borland International Inc, 1998.

[Bru92] Brunelli, R.; Poggio, T., "Face Recognition Through Geometrical Features", Proceedings of ECCV'92, S. Margherita Ligure, pp. 792-800, 1992. 
X.Bru93] Brunelli, R.; Poggio, T., "Face Recognition: Features versus Templates", IEEE Transactions on Pattern Analysis and Machine Intelligence, Vol. 15, N. 10, pp. 10421052, Outubro de 1993.

[Cod97] Inside CodeWarrior 9, Metrowerks, Imprimerie Gagne Itee, 1997.

[Cyg96] Cygansk, D., http://xfactor.wpi.edu/Works/MQP/avi96/mqp/node42.html, Template Matching, 1996.

[Dav91] Davalo, E.; Naïm, P, Neural Networks, The Macmillan Press Ltd, 1991.

[Elm94] Elmasri, R.; Navathe, S., Fundamentals of Database Systems, The Benjamin/Cummings Publishing Company Inc, 1994.

[Gom94] Gomes, J.; Velho, L., Computação Gráfica: Imagem, IMPA/SBM, Rio de Janeiro, 1994.

[Gre95] Green, C., Yu.G. Smetanin, "New Methods for the Diagnosis of the Intellectual Level of Subnormals.", Classics in the History of Psychology, York University, Toronto, 1995.

[Gro94] Groß, M., Visual Computing, Springer-Verlag, Verlog, 1994.

[I\&t99] IT, http:/www.europlanet.com.br/it, Informaçåo \& Tecnologia, Ano 1, Ed. 11, pp. 11, Fevereiro de 1999.

[Jam93] James, M.L.; Smith, G. M.; Wolford, J. C., Applied Numerical Methods for Digital Computation, Harper Collings College Publishers, $4^{\mathrm{a}}$ Edição, 1993.

[Jas98] Jasc PaintShop Pro, http://www.jasc.com, Jasc Software, 1998.

[Jia94] Jia, X; Nixon, M, “Analysing Front View Face Profiles for Face Recognition via the Walsh Transform", Pattern Recognition Letters, Vol. 15, pp. 551-558, Junho de 1994.

[Jia95] Jia, X.; Nixon, Ms, "Extending the Feature Vector for Automatic Face Recognition", IEEE Transactions on Patters Analysis and Machine Intelligence, Vol 17, N. 12, pp. 1167-1176, Dezembro de 1995. 
[Kir90] Kirby, M., "Application of the Karhunen-Loève Procedure for the Characterization of Human Faces", IEEE Transactions on Patters Analysis and Machine Intelligence, Vol. 12, N. I, pp. 103-108, Janeiro de 1990.

[Kru94] Kruizinga, P., "Optical Flow Applied to Person Identification", Proceedings of EUROSIM Conference on Massively Parallel Processing Applications and Development, pp. 871-878, Junho de 1994.

[Kru99] Kruizinga, P., http://www.cs.rug.nl/ peterkr/FACE/face.html, Face Recognition Home Page, 1999.

[Law94] Lawrence, S.; Giles, C., "Face Recognition: A Convolutional Neural Network Approach", IEEE Transactions on Neural Networks, Special Issue on Neural Networks and Pattern Recognition, pp.98-113, 1994.

[Lee93] Lee, E.; Whalen, T., "Computer Image Retrieval by Features: Suspect Identification", Proceedings of Interchi'93, pp. 494-499, Abril de 1993.

[Lee94] Lee, E.; Whalen, T., "Computer Image Retrieval by Features: Selecting the Best Facial Features for Suspect Identification Systems, Proceedings of the Third International Conference on Information and Knowledge Management (CIKM'94), pp. 105-111, Novembro de 1994.

[Lee95a] Lee, E.; Whalen, T., "Identification of Suspects by Features: Text or Pictorial Facial features?", Proceedings of Advances in Digital Libraries (ADL'95), pp. 65-75, Maio de 1995.

[Lee95b] Lee, E; Whalen, T., "Suspect Identification: Traditional Mugshot Album vs Computerized Feature System", Proceedings of IFIP'95, pp. 113-121, Junho de 1995, http://macbeth.stmarys.ca/papers/ifip-950/ifip' 950.htm.

[Lon93] Long, J., FoxPro - Guia do Programador, Berkeley, Rio de Janeiro, 1993.

[Mir95] Miros True Face, http://www.miros.com, Miros Inc, 1995. 
[Mog95] Moghaddam, B., An Automatic System for Model-Based Coding of Faces, M.I.T. media Laboratory Perceptual Computing Section Technical Report, No. 317, Março de 1995.

[Mur95] Murray, F. A., Applications of Neural Network, Vluwer Academic Publishers, 1995.

[Nas96] Best Template Matching, http://www.msfc.nasa.gov/irgrp/bestmatch.html, Nasa/Marshall Space Flight Center, 1996.

[Neu96] What is an Artificial Neural Network?, http://www.nd.com/welcome/ whatisnn.htm, NeuroSolutions, 1996.

[Oli95] Oliveira, P., "Reconhecimento de Faces", Monografia de Disciplina SCE 799 Computação Gráfica - ICMC-USP/SC, Novembro 1995.

[Per95a] Perelmuter, G.; Carrera, E., "Reconhecimento de Imagens Bidimensionais Utilizando Redes Neurais Artificiais", Anais do VIII Sibgrapi, pp. 197-203, Outubro de 1995.

[Per95b] Pereira, F. C. G., FACE: Um Ambiente para Composição e Identificaçăo de Retratos Falados, Dissertação de Mestrado, Universidade Federal de Pernambuco, Dezembro 1995.

[Pet77] Peterson, J., Before Fingerprinting: A Preface to the New Edition of Identification on Criminals, MAS Press, 1977.

[Pre94] Preece, J., Human Computer Interaction, McGraw-Hill, London, 1992.

[Ray96] Ray, B. K., "Subtraction From a Standard Face for Human Face Recognition", IEEE Transactlons on Patters Analysis and Machine Intelligence, Vol. 18, N. 4, pp. 123134, 1996.

[Rom97] Romdhami, S., http:/www.elec.gla.ac.uk/romdhani, Face Recognition Using Principal Components Analysis, 1997. 
[Sam93a] Samaria, F., "Automated Face Identification Using Hidden Markov Models", Proceedings of the International Conference of Advanced Mechatronics, The Japan Society of Mechanical Engineers, Tóquio, Agosto de 1993, http://ftp.camorl.co.uk/pub/docs/ORL/tr.93.2.ps.Z.

[Sam93b] Samaria, F., Fallside, F., "Face Identification and Feature Extraction Using Hidden Markov Models", Image Processing: Theory and Applications, G. Vernazza, Elsevier, Itália, Junho de 1993.

[Sam94] Samaria, F., Face Recognition Using Hidden Markov Models, Dissertação de Doutorado, University of Cambridge, Outubro de 1994.

[Sat97] Sato, K.; Shah, S., "Partial Face Recognition Using Basis Function Networks", IEEE Transactions on Neural Networks, Vol. 3, N. 81, pp. 375-381, 1997.

[Sch93] Schyns, P.; Bülthoff, H., "Conditions for Viewpoint Dependent Face Recognition", MIT Artificial Intelligence Laboratory, AI Memo N. 1432, CBCL Paper N. 81, Agosto de 1993.

[Sie96] Siemens Face VACS, http://www.snat.de/nc6/face.htm, Siemens Nixdorf Advanced Technologies GmbH, 1996.

[Sir87] Sirovich, L.; Kirby, M., "Low-Dimensional Procedure for the Characterization of Human Faces", Proceedings of the Optical Society of America, Vol. 4, N. 3, pp. 519-524, Março de 1987.

[Sme95] Yu.G. Smetanin, "Neural Networks as Systems for Pattern Recognition: a Review," Pattern Recognition and Image Analysis, Vol. 5, N. 2, pp. 254-293, 1995.

[Spa93] Spacek, L., "Face Recognition Through Learnt Boundary Characteristics", Applied Artificial Intelligence, Vol. 8(1), pp. 149-165, Janeiro de 1994.

[Swe95] Swets, D., "SHOSLIF-O: SHOSLIF for Object Recognition and Image Retrieval", Technical Report CPS 95-39, Michigan State University, Department of Computer Science, Outubro de 1995. 
[Tim98] The New York Times Journal, Teaching the Computer to Recognize a Friendly Face, pp. E7, 15 de Outubro de 1998.

[To093] Toole A J.; Abdi H., "Low-Dimensional Representation of Faces in Higher Dimensions of the Face Space", Proceedings of the Optical Society of America, Vol. 10, N. 3, pp. 405-411, Março de 1993.

[Val94] Valentin, D., "Connectionist Models of Face Processing: A Survey", Pattern Recognition, Vol. 27, pp. 1209-1230, Janeiro de 1994.

[Ve198] Velasco, J., Teaching the Computer to Recognize a Friendly Face, The New York Times Journal, Quinta-Feira, 15 de Outubro, pp. E7, 1998.

[Vis91] Computsketch, “User's Manual”, Visatex Corporation, 1991.

[Vos91] Vossen, G., Data Models, Database Languages and Database Management Systems, Addison-Wesley Publishing Company, 1991.

[Was89] Wasserman, P. D., Neural Computing - Theory and Practice, ANZA Research Inc., Van Nostrand Reinhold, New York, 1989.

[Wo096] Wood, J., "Invariant Pattern Recognition: A Review," Pattern Recognition, Vol. 29, N. 1, pp. 1-17, 1996. 


\section{Apêndice I}

Telas do Sistema de Base de Dados Multímídia

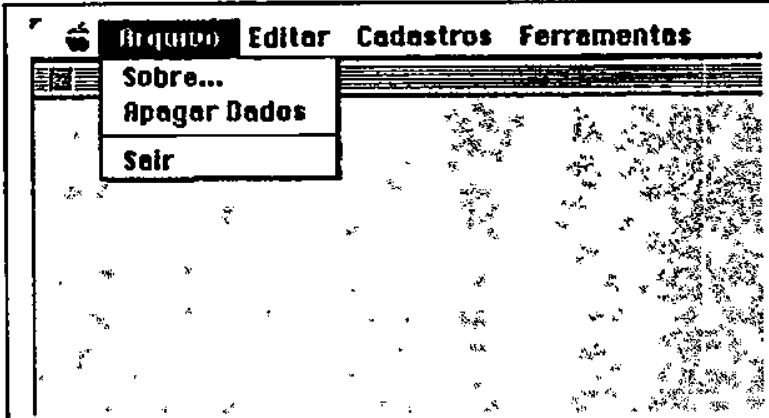

Tola 01: menu arqulvo, possul as opcoses Sobre, Apagar Dados e Salr do programa.

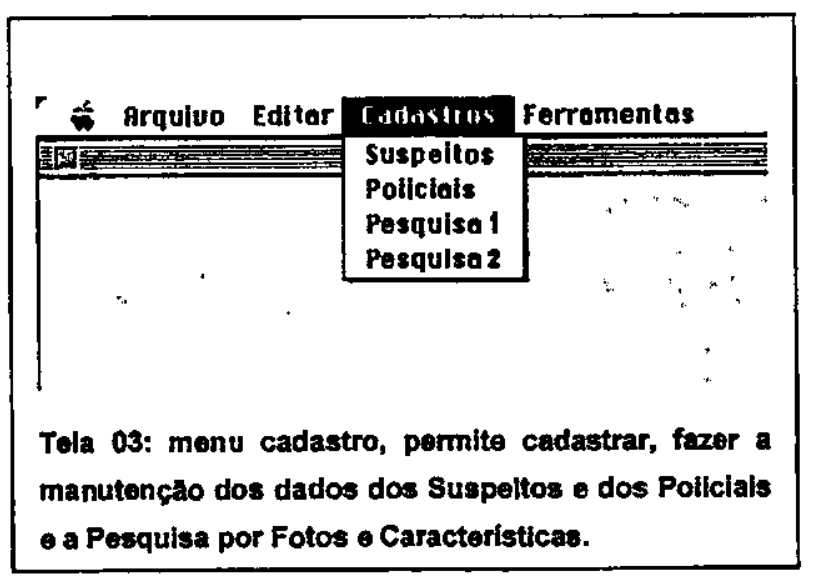

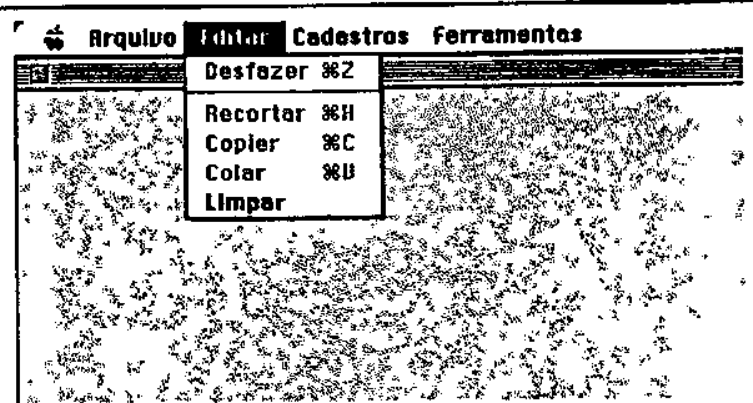

Tola 02: menu oditar, Possui as forramentas basicas para auxillar na digitaçăo de dados.

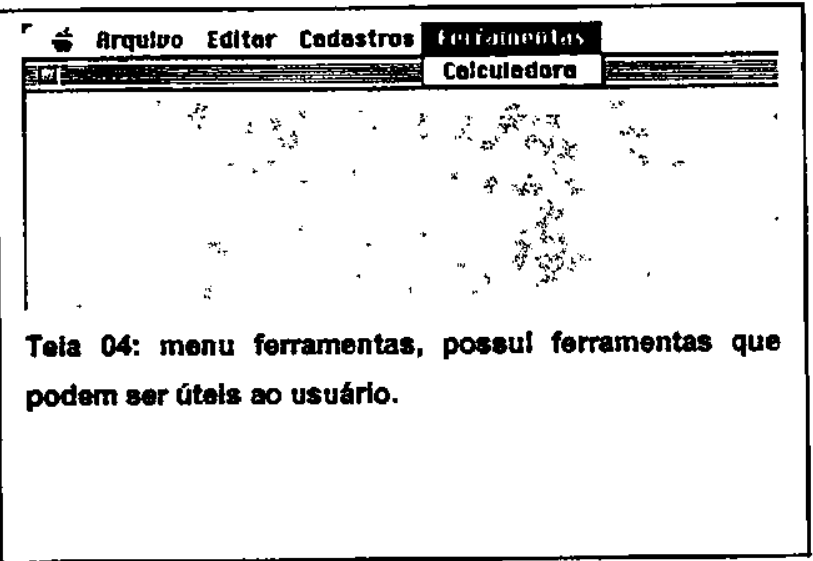




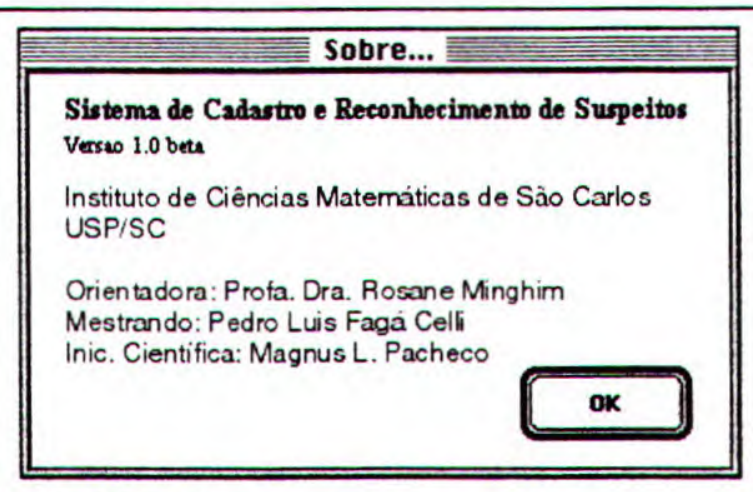

Tela 5: janela do menu sobre.

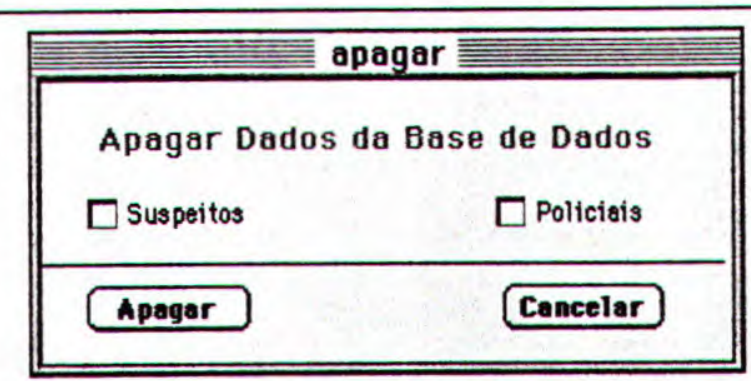

Tela 6: essa janela permite apagar todos os dados da base de dados. Pode-se escolher se deseja apagar suspeitos, policiais ou ambos.

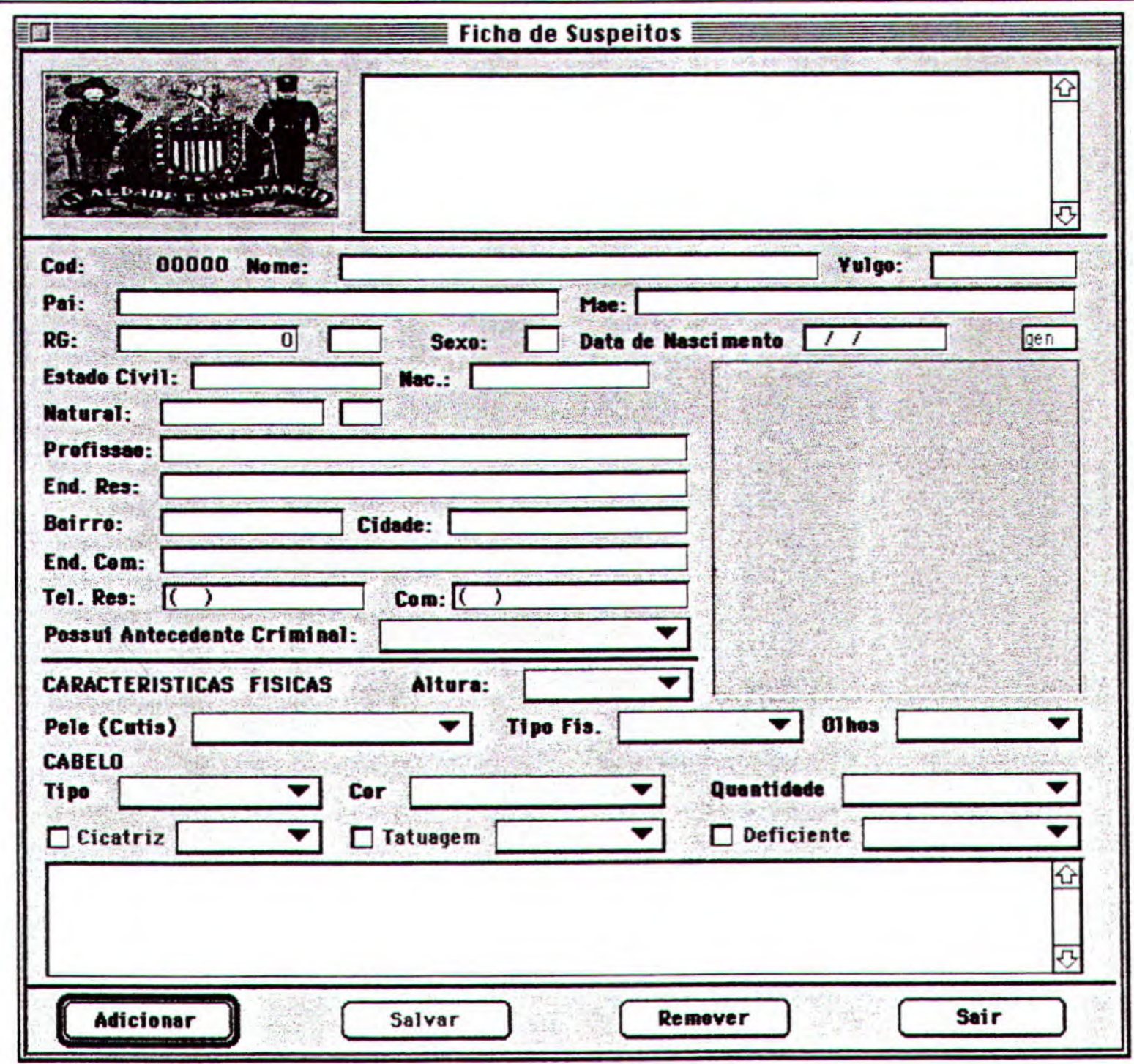

Tela 7: Ficha de cadastro de suspeitos. 


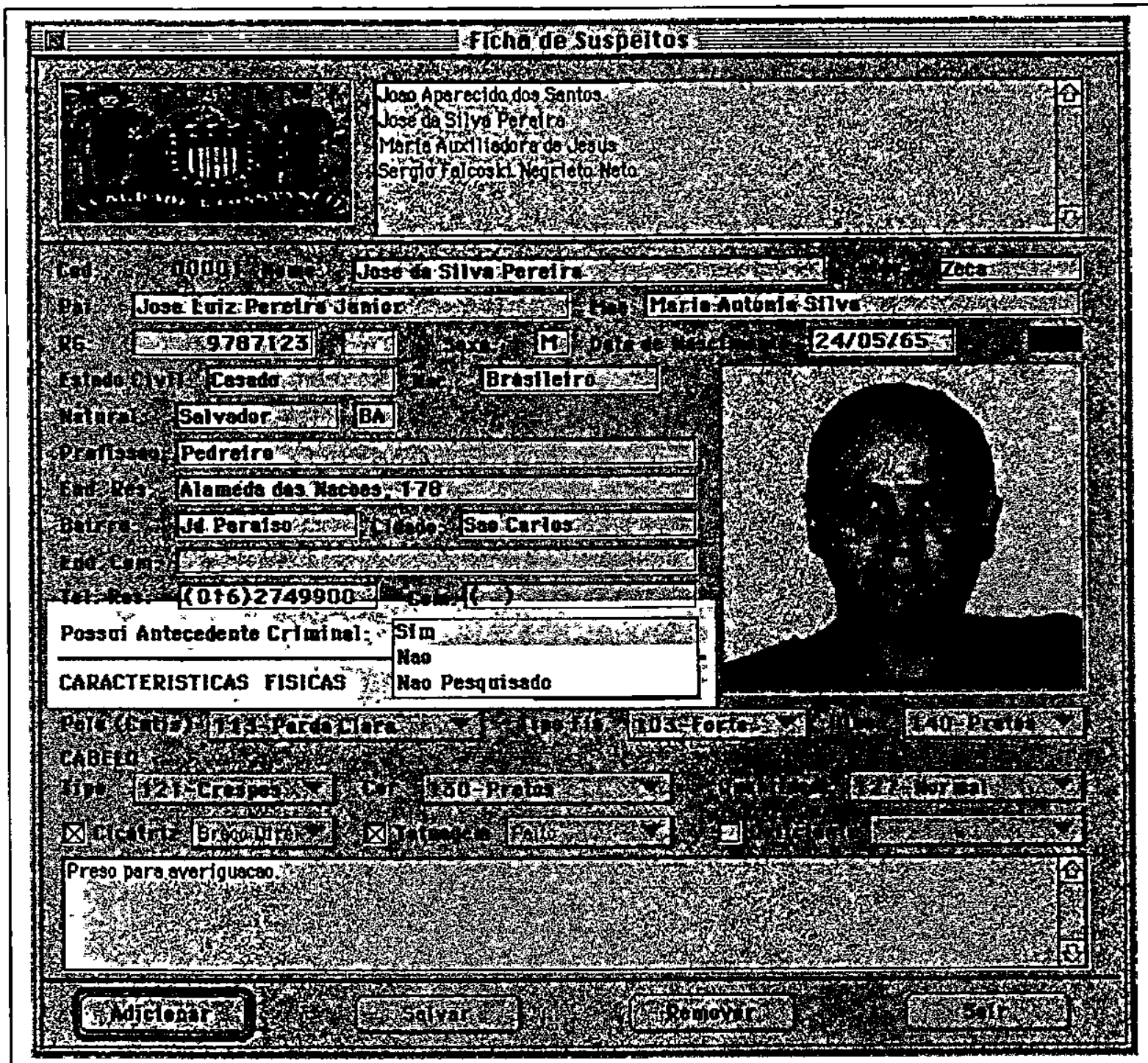

Tela 8: op̧̧őes para se o suspeito possul antecedentes criminals (Sim, Năo, Năo Pesquisado). 


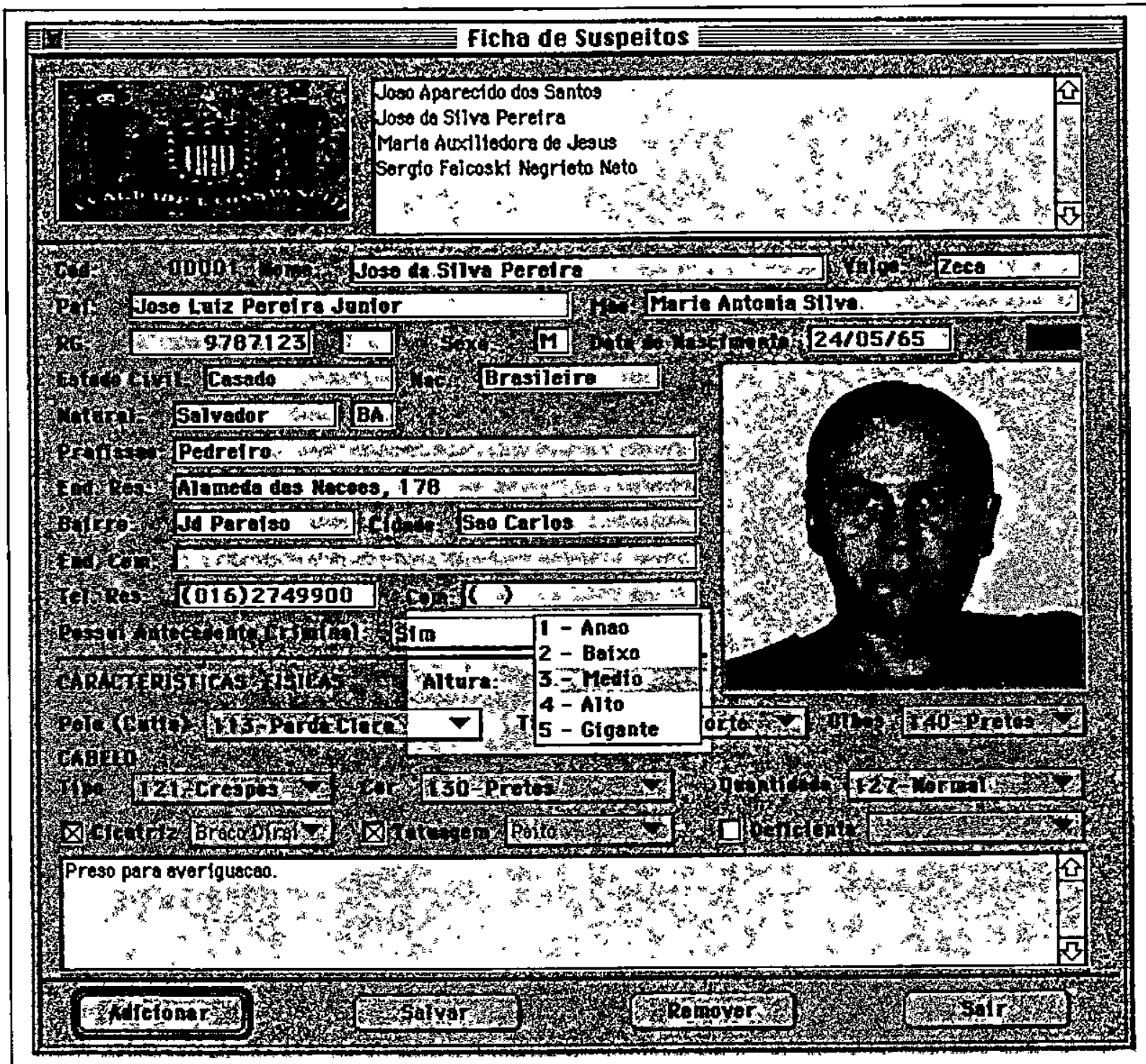

Tela 9: opçסిes para a altura do suspelto (Anão, Baixo, Médlo, Alto e Gigante). 


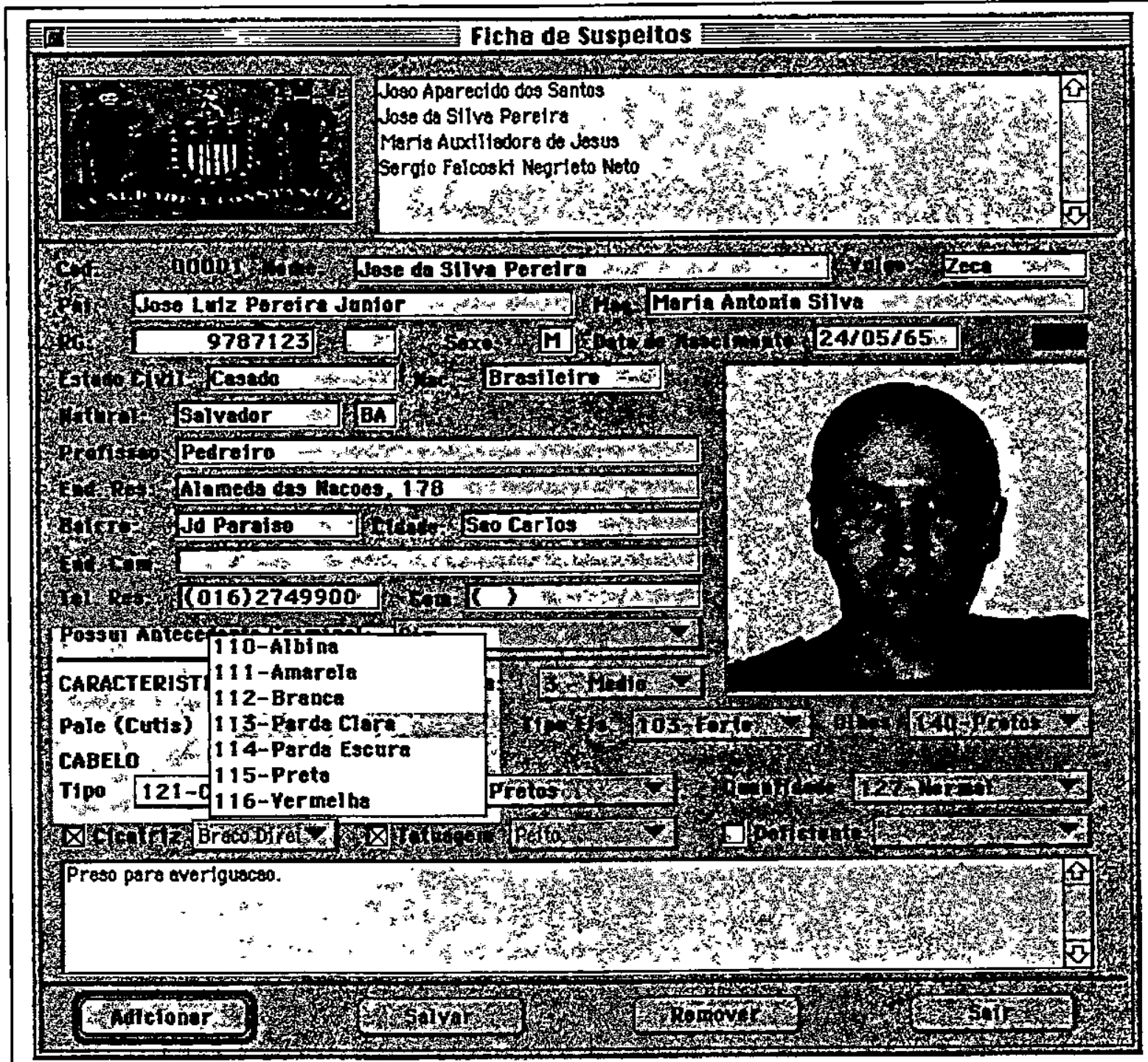

Tela 10: opçoes para o tipo de cutis (Albino, Amarelo, Branca, Parda Clara, Parda Escura, Preta, vermelha). 


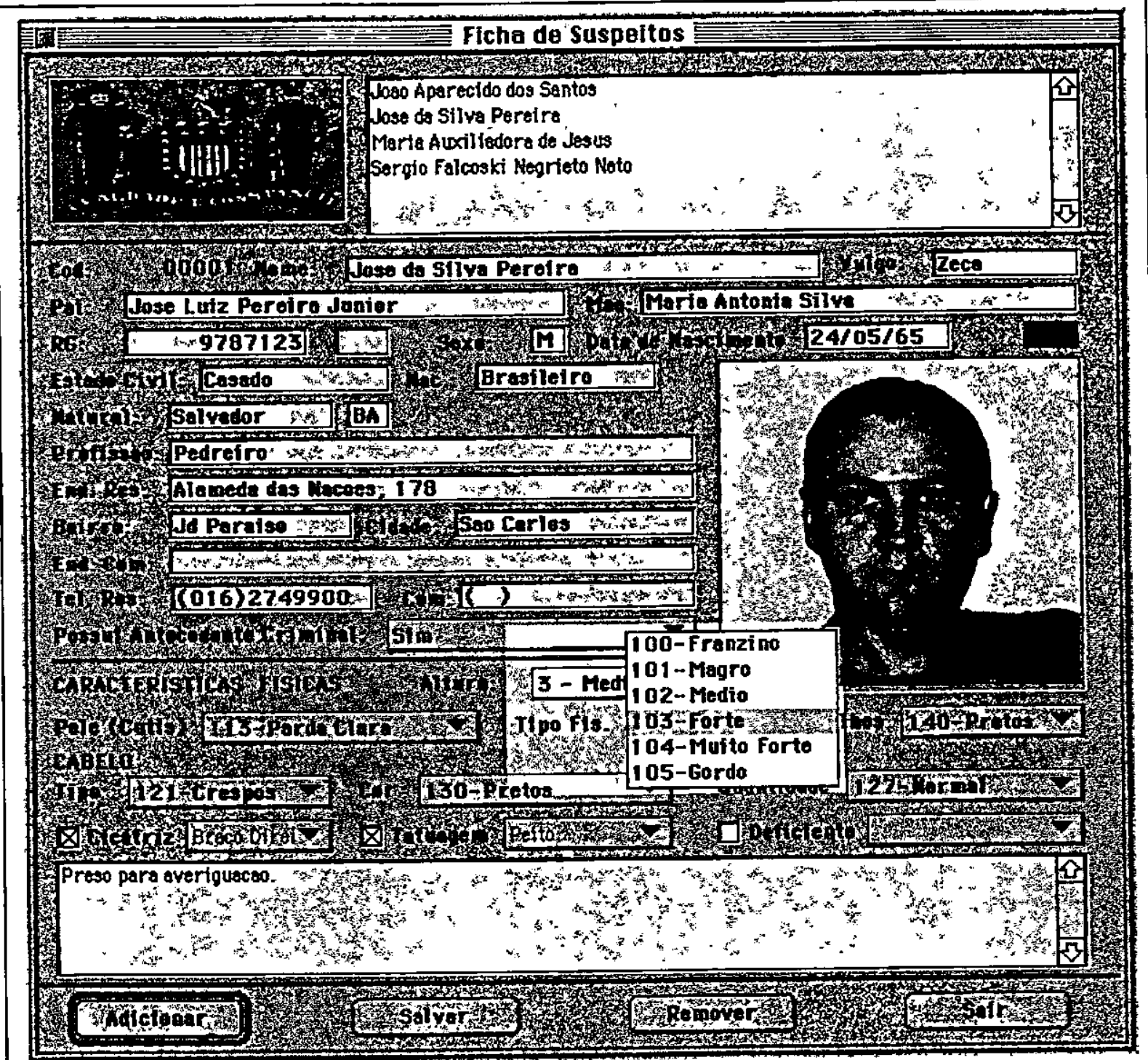

Tela 11: opçठes para o tipo fisico (Franzino, Magro, Médio, Forte, Muito Forte, Gordo). 


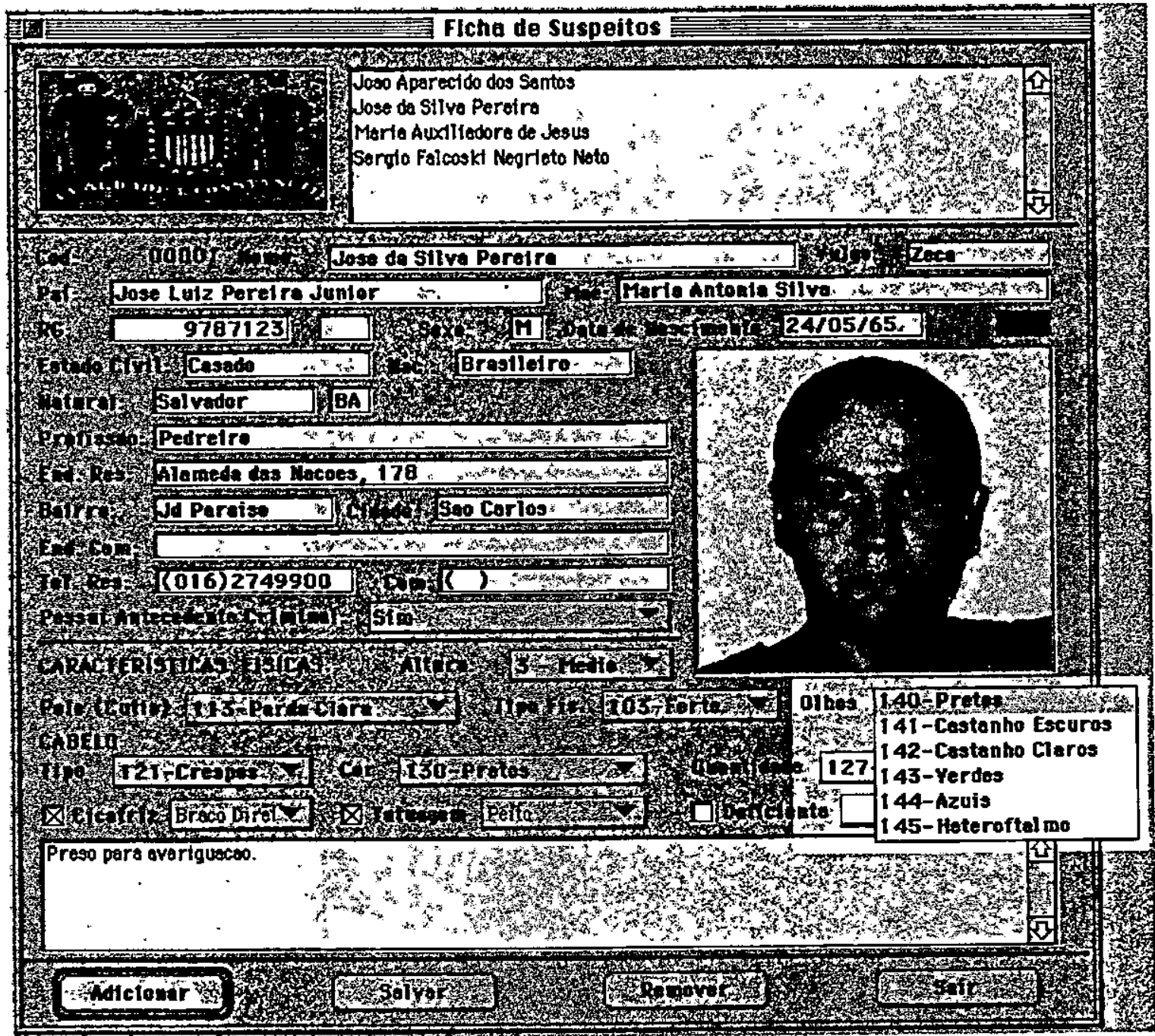

Tela 12: opçסos para a cor dos olhos (Pretos, Castanho Escuros, Castanho Claros, Verdes, Azuis o Heteroftalmo). 


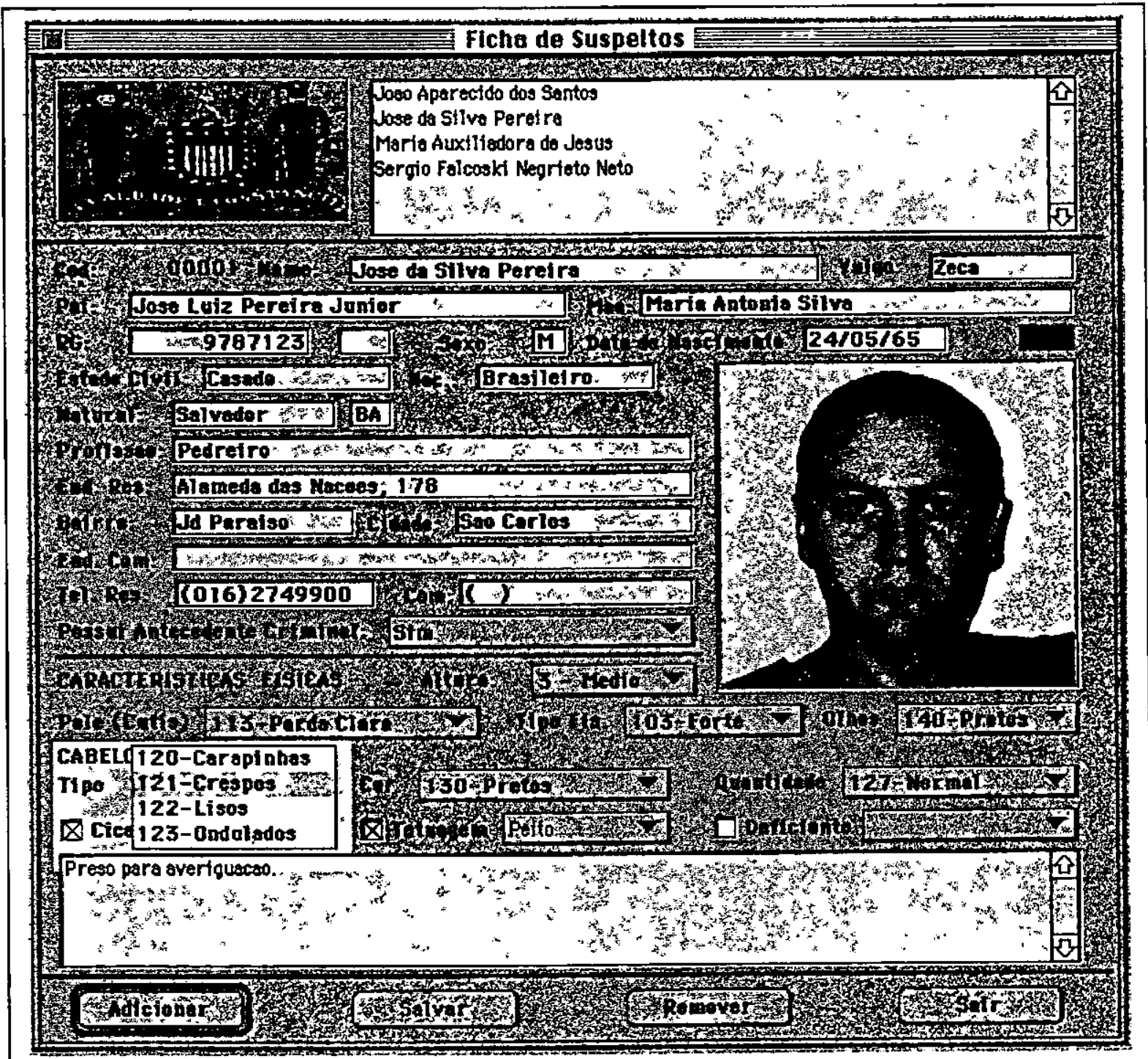

Tela 13: opçöes para tjpo do cabelo (Carapinhas, Crespos, Lisos, Ondulados). 


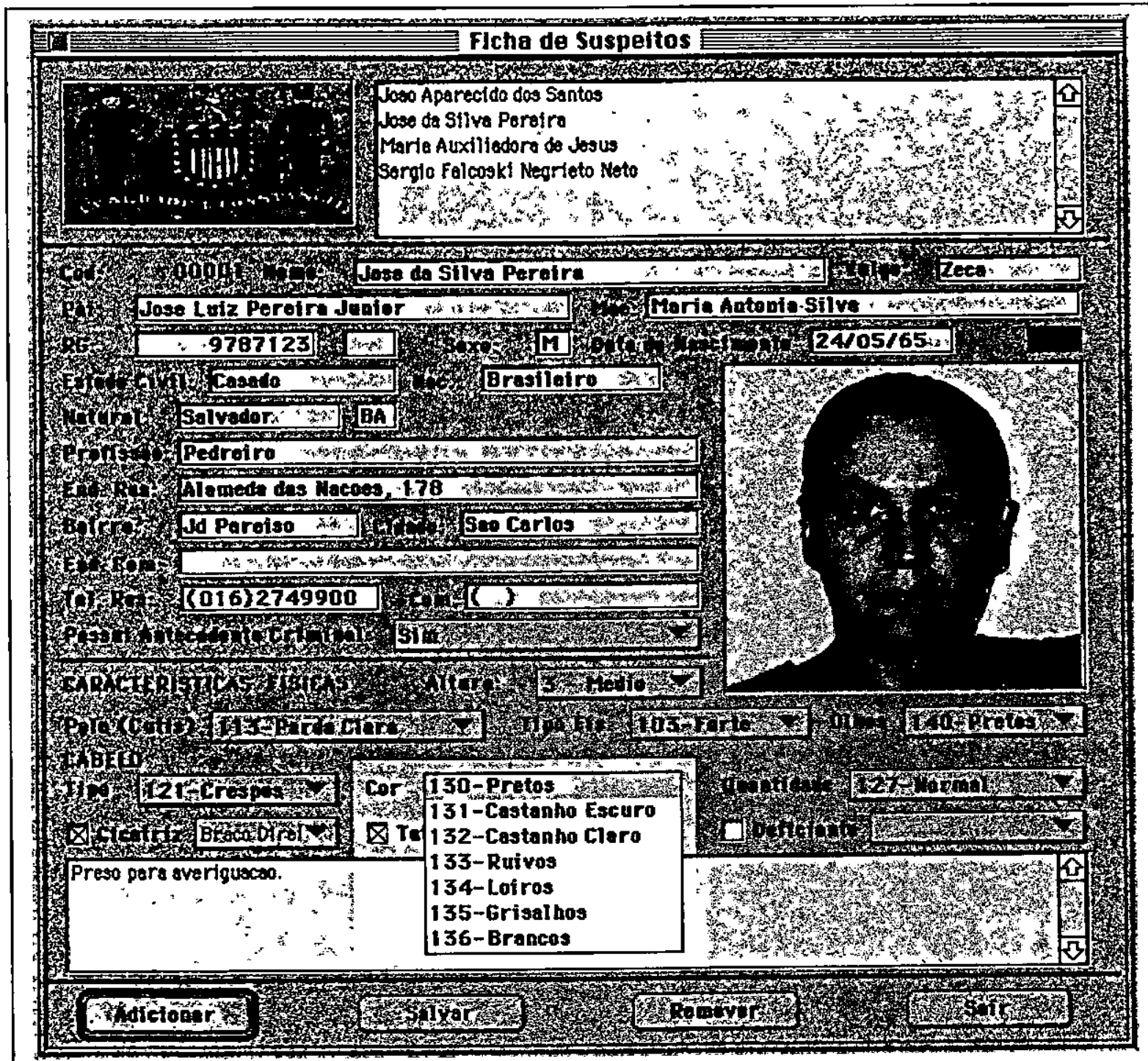

Tela 14: opçסes para a cor dos cabelos (Pretos, Castanho Escuro, Castanho Claro, Rulvos, Loiros, Grisalhos $\theta$ Brancos). 


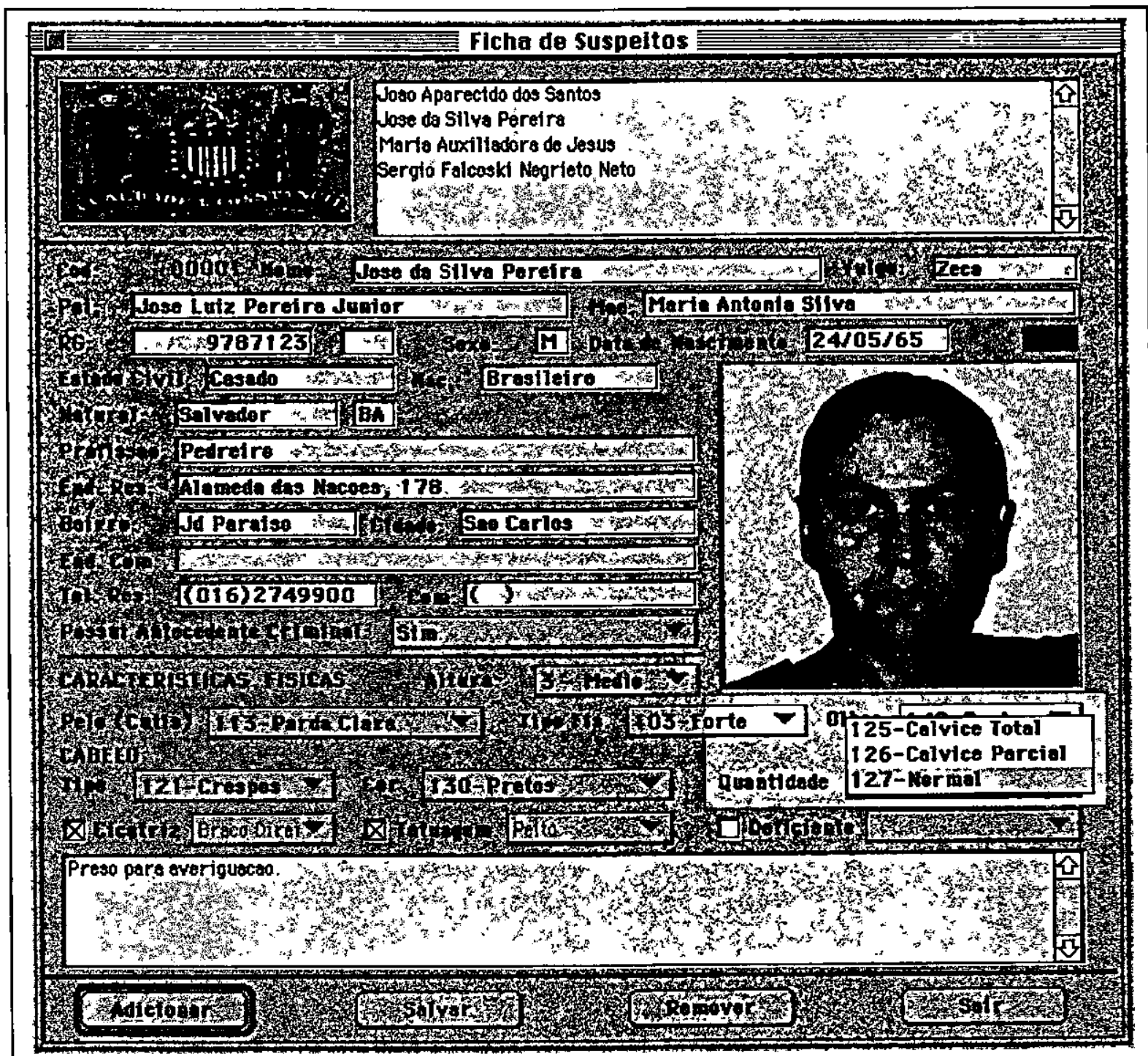

Tela 15: opços para a quantidade de cabelos (Caivlce Total, Calvice Parcial o Normal). 


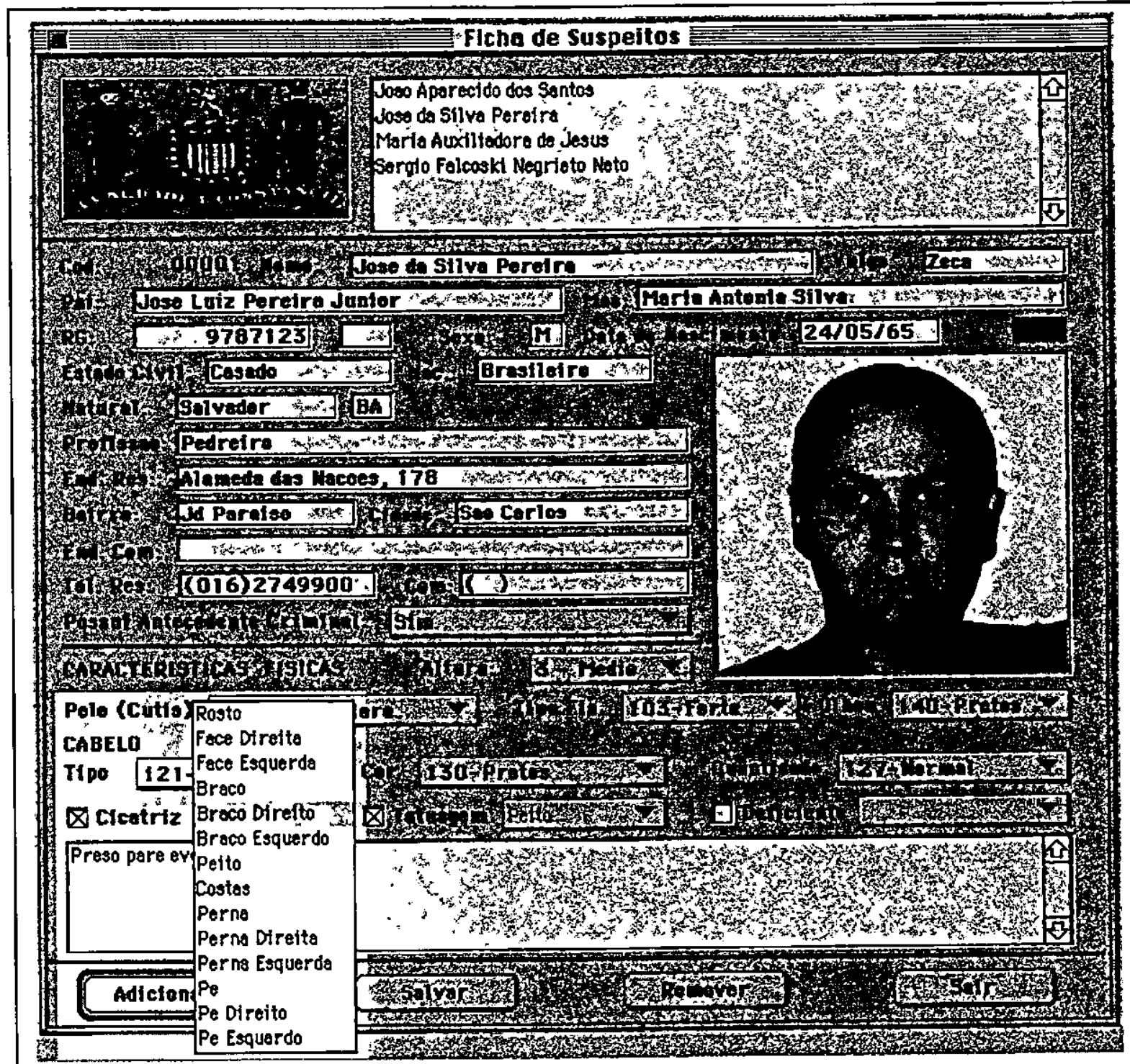

Tela 16: opçóes para a localizaçăo de cicatrı (Rosto, Face Direlta, Face Esquerda, Braço, Braço Direito, Braço Esquerdo, Pelto, Costas, Perna, Perna Direita, Perna Esquerda, P6́, Pé Direito, P6́ Esquerdo). 


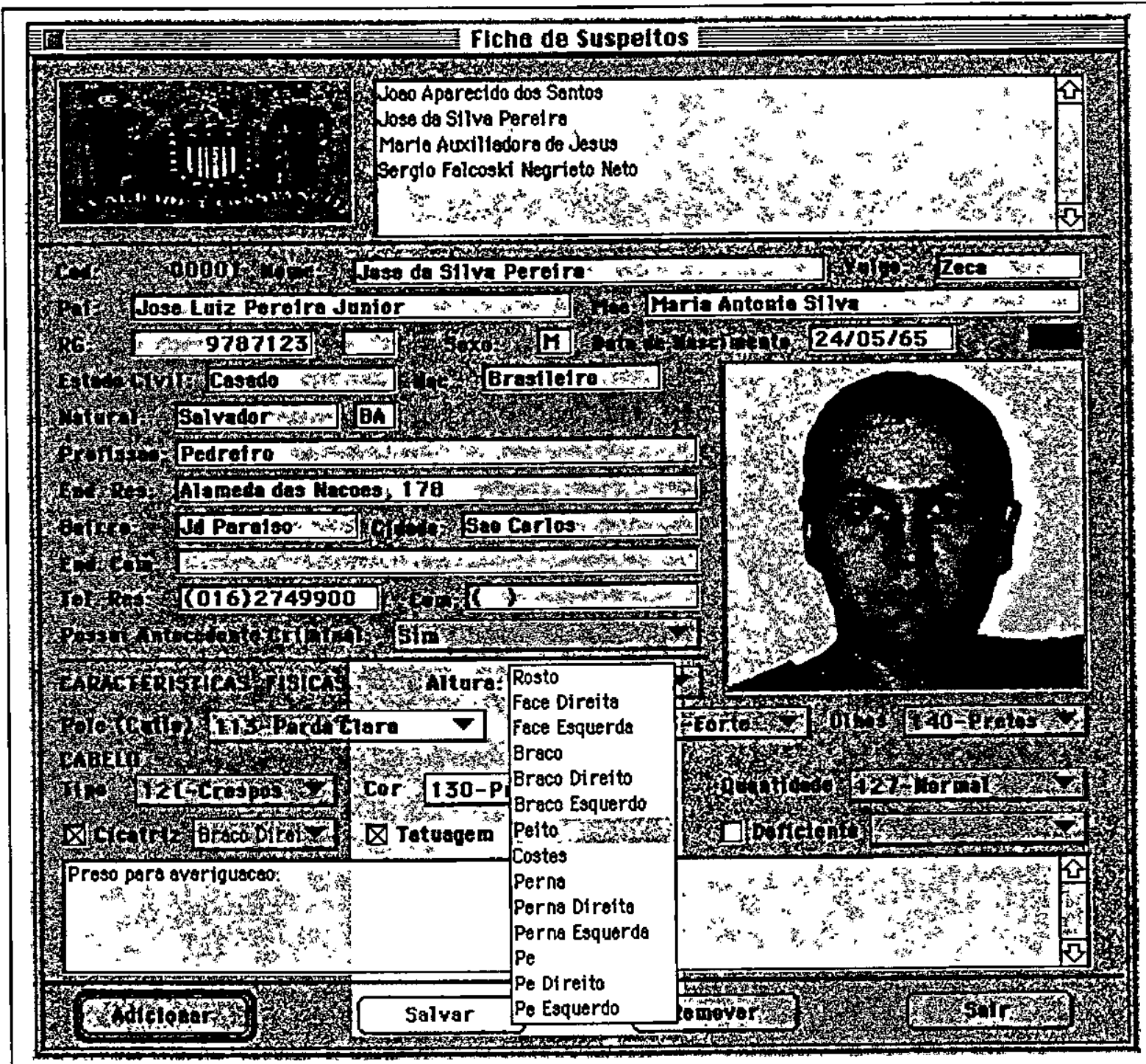

Tela 17: opços para a localização de cicatriz (Rosto, Face Direita, Face Esquerda, Braço, Braço Direito, Braço Esquerdo, Pelto, Costas, Perna, Perna Direita, Perna Esquerda, P6́, Pó Direito, Pé Esquerdo). 


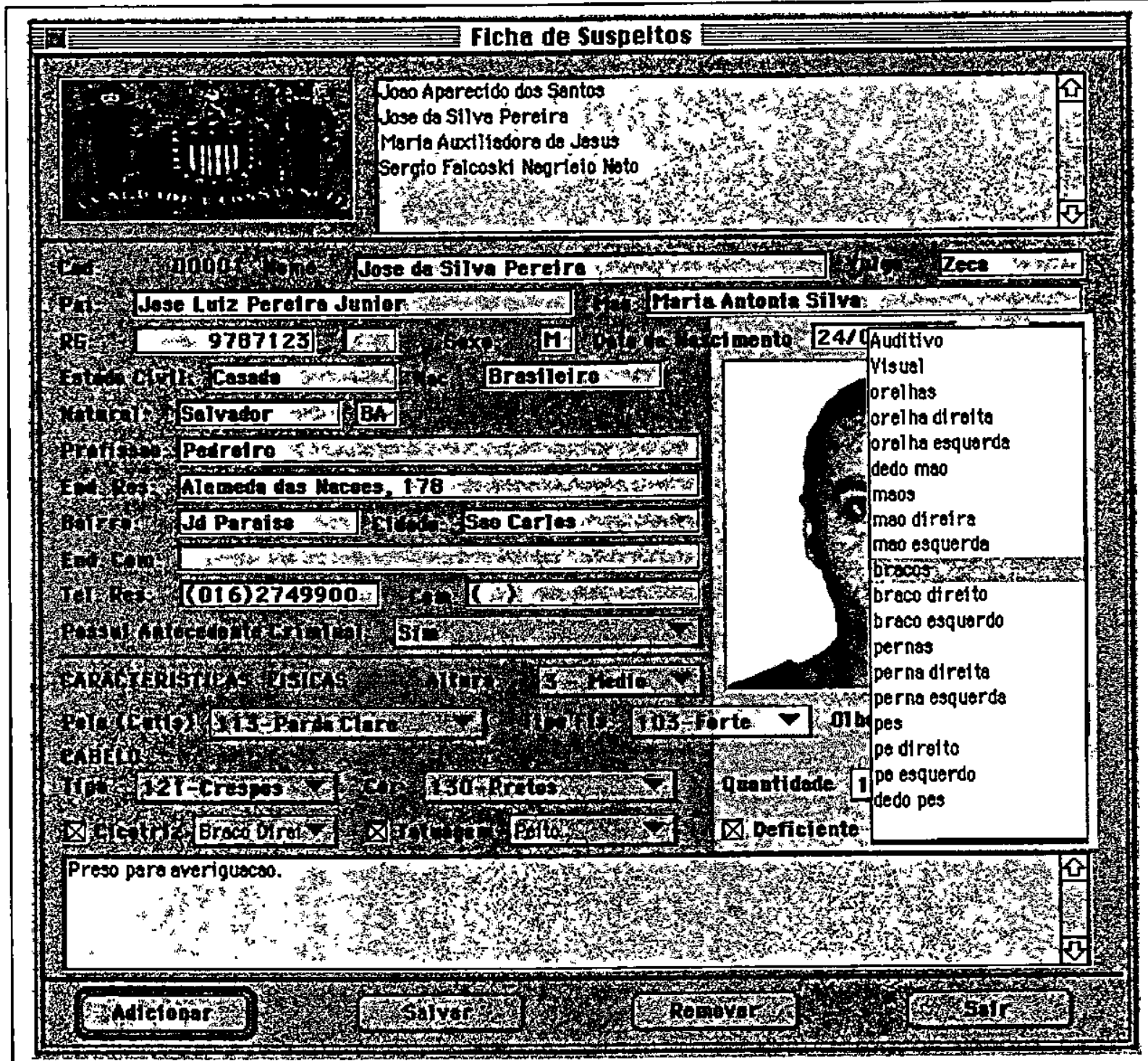

Tela 18: opç̋es para deficlência (Auditivo, Vlsual, Orelhas, Orelha Direita, Orelha Esquerda, Dedo Măo, Măos, Măo Direita, Măo Esquarda, Braços, Braço Direlto, Braço Esquerdo, Pernas, Perna Direita, Perna Esquerda, Pés, Pé Direito, Pe Esquerdo, Dedo Pés). 


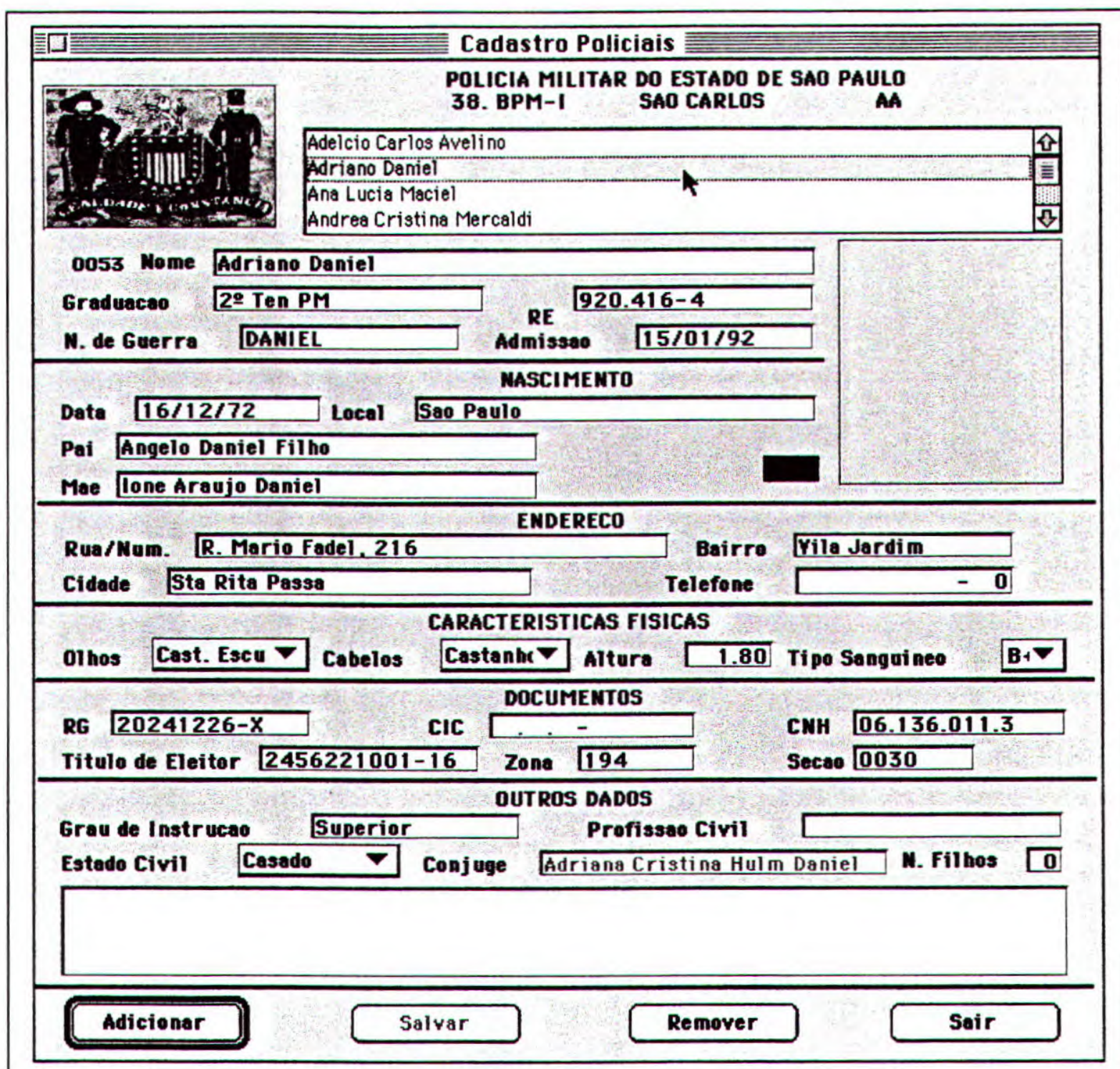

Tela 19: ficha de cadastro de policiais para uso interno da polícia. 


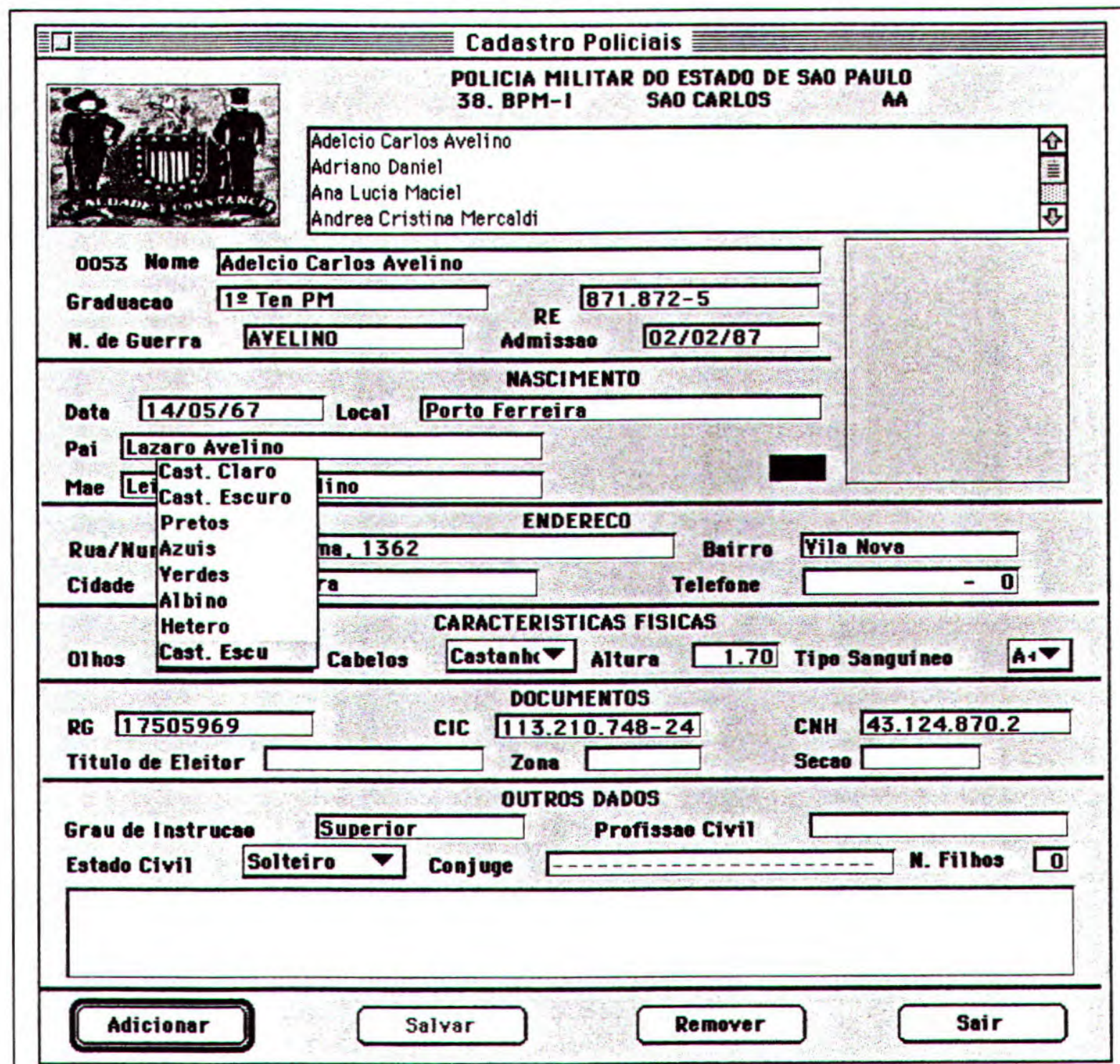

Tela 20: opç̋̄es para a cor dos olhos (Castanho Claro, Castanho Escuro, Pretos, Azuis, Verdes, Albino, Hetero). 


\section{Cadastro Policiais}

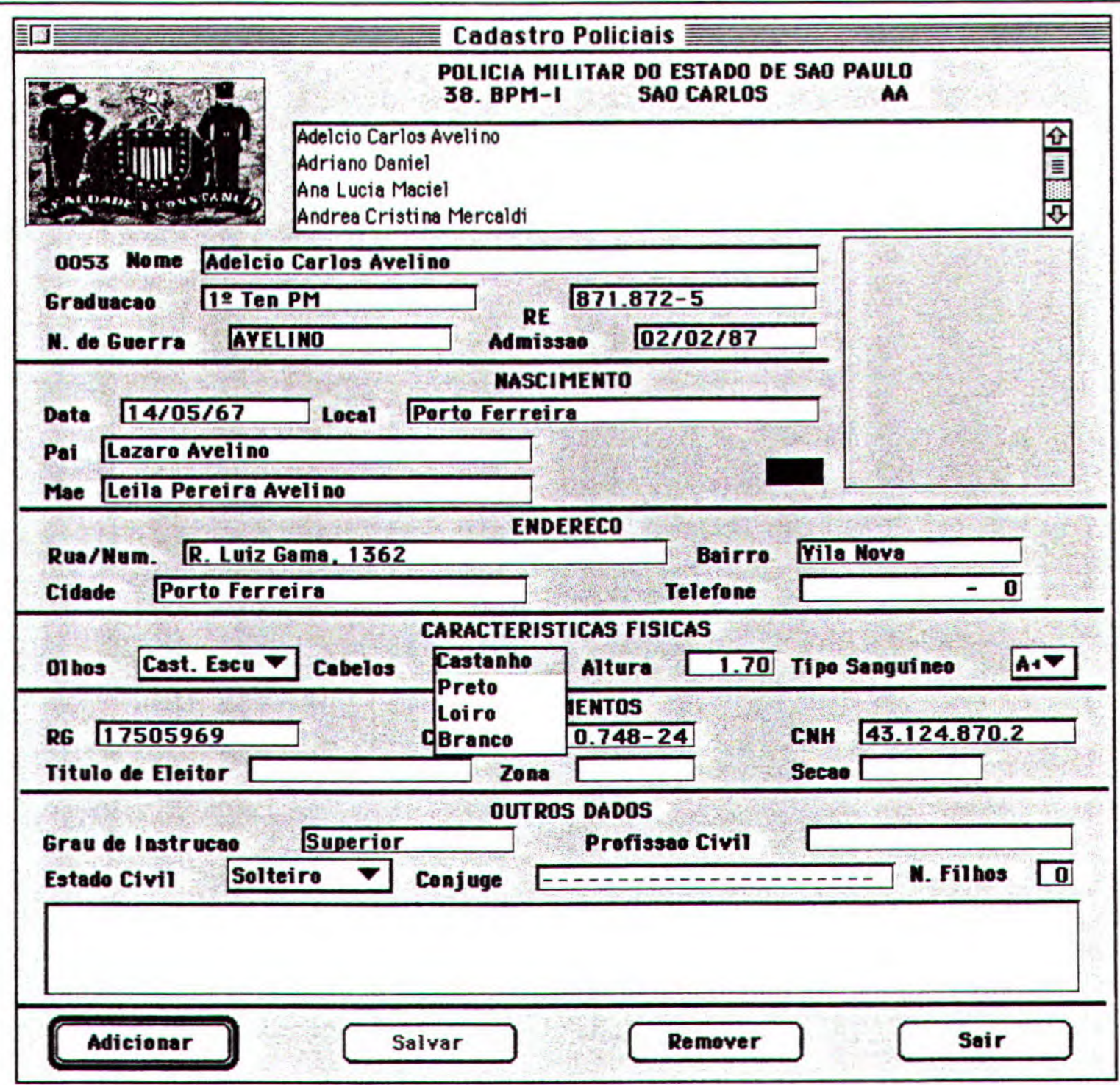

Tela 21: opçōes para a cor dos cabelos (Castanho, Preto, Loiro, Branco). 


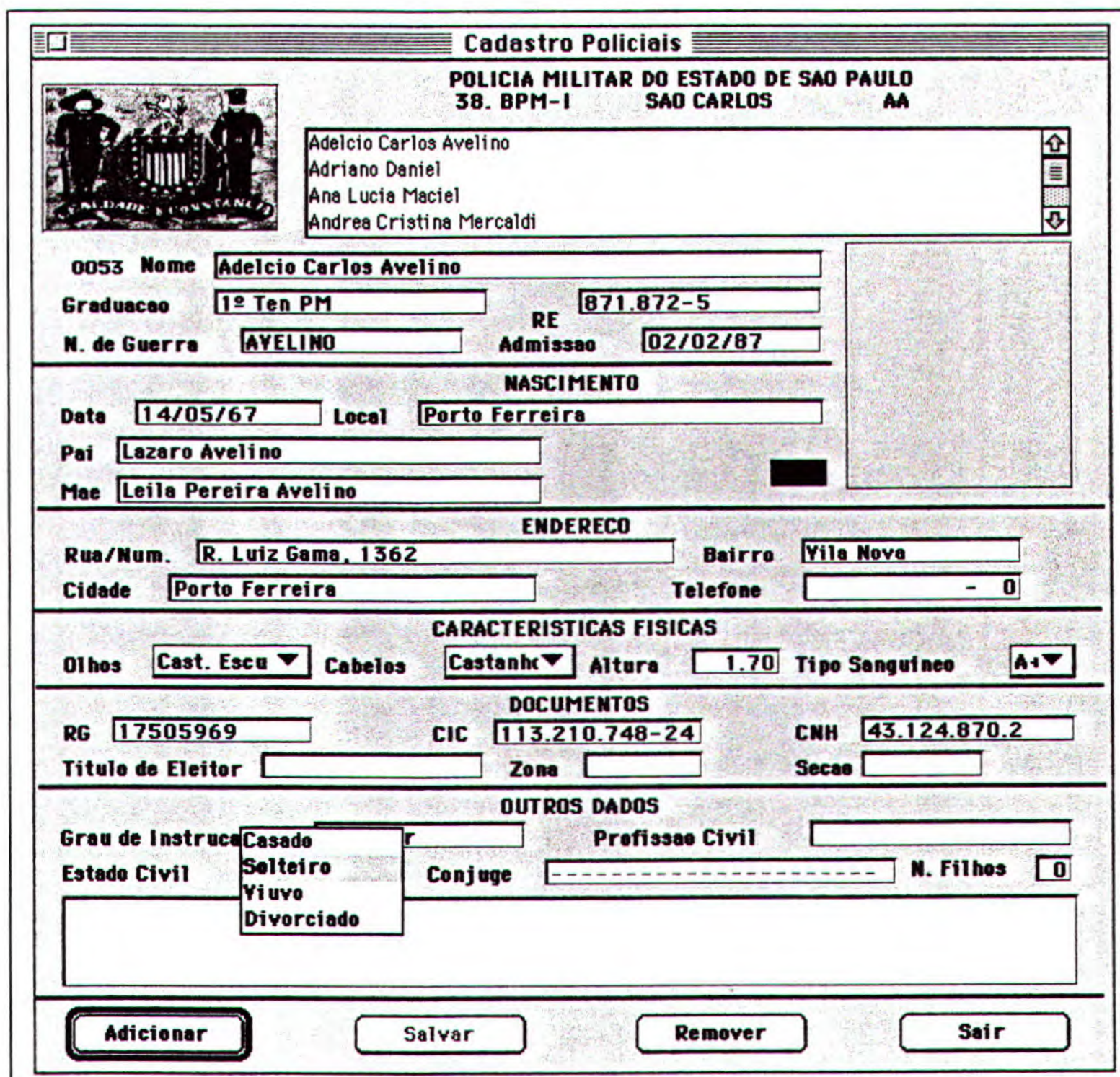

Tela 22: opçōes para o estado civil (Casado, Solteiro, Viúvo, Divorciado). 


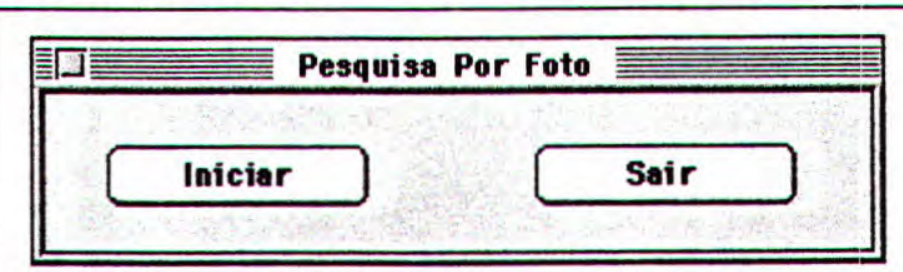

Tela 23: Pesquisa por similaridade entre a nova foto $e$ as da base de dados.

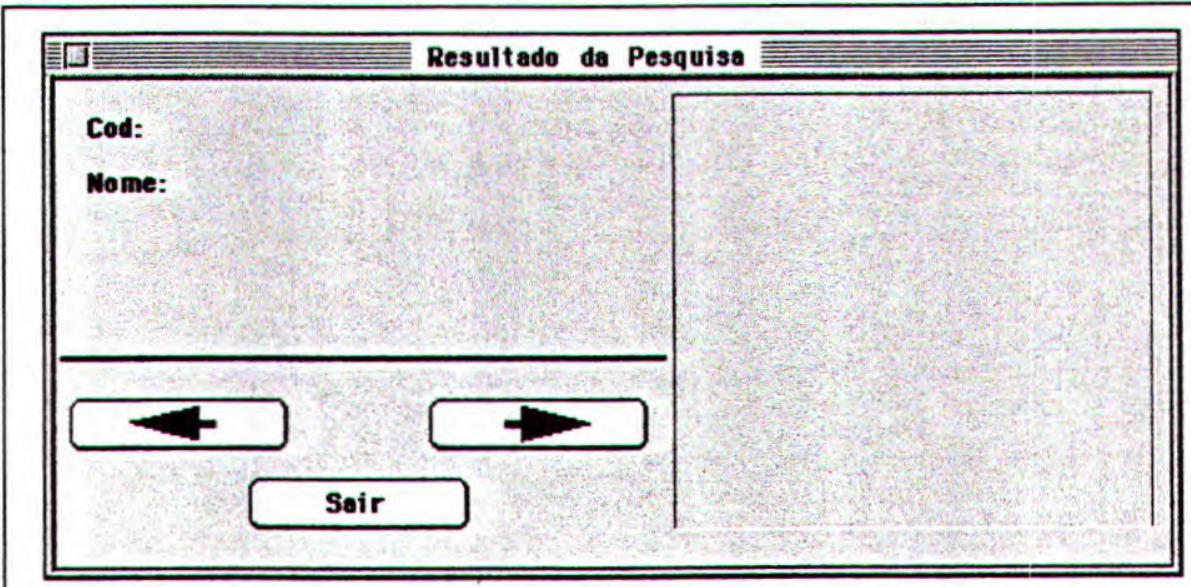

Tela 24: Resultado das pesquisas por foto e por características.

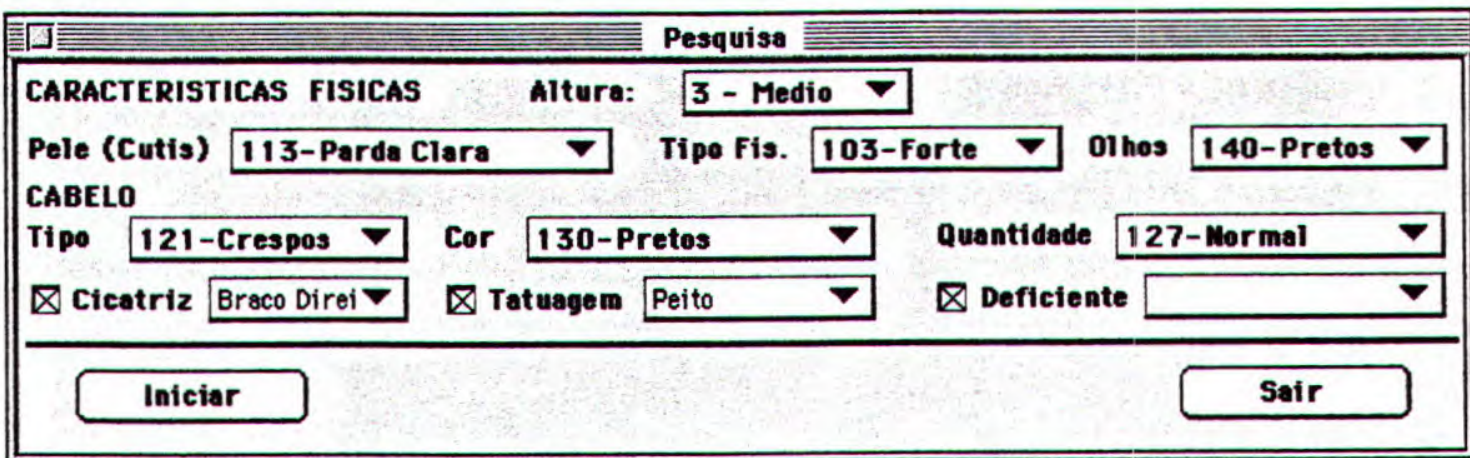

Tela 25: Pesquisa por similaridade de características entre o suspeito e os da base de dados. 


\section{Apêndice II}

Tabelas com os arquivos da base de dados para Suspeitos e Policiais.

\begin{tabular}{|c|c|c|c|c|}
\hline Campo & Nome & Tipo & Tamanho & Comentario \\
\hline 1 & $\overline{C O D}$ & Numérico & 5 & Código do suspeito, ate 99999. \\
\hline 2 & NOME & Caracter & 50 & Nome do suspeito \\
\hline 3 & VULGO & Caracter & 10 & Apelldo do suspeito \\
\hline 4 & $\overline{P A I}$ & Caracter & 30 & Nome do Pai do suspeito \\
\hline 5 & MAE & Caracter & 30 & Nome da Máe do suspeito \\
\hline 6 & RG & Numérico & 11 & Registro Geral do suspeito \\
\hline 7 & UF_DOC & Caracter & 2 & Estado de origem do RG \\
\hline 8 & SEXO & Caracter & 1 & Sexo do Suspeito (H ou M) \\
\hline 9 & NASCIMENTO & Data & 8 & Data de nascimento (DD/MM/AA) \\
\hline 10 & EST_CIVIL & Caracter & 10 & Estado civil do suspeito \\
\hline$\overline{11}$ & NATURAL & Caracter & 30 & Naturalidade do suspeito \\
\hline 12 & $\overline{U F}$ & Caracter & $\overline{2}$ & Estado onde nasceu o suspeito \\
\hline 13 & NACIONAL & Caracter & 15 & Nacionalidade do suspeito \\
\hline 14 & PROFISSAO & Caracter & 15 & Profissáo do suspeito \\
\hline 15 & ENDERECO & Caracter & 30 & Endereço residencial do suspeito \\
\hline 16 & BAIRRO & Caracter & 10 & Nome do bairro \\
\hline
\end{tabular}




\begin{tabular}{|c|c|c|c|c|}
\hline 17 & MUNICIPIO & Caracter & 30 & Nome da cidade \\
\hline 18 & TEL_HOME & Caracter & 13 & Telefone residencial \\
\hline 19 & END_TRAB & Caracter & 30 & Endereço do trabalho \\
\hline 20 & TEL_TRAB & Caracter & 13 & Telefone do trabalho \\
\hline 21 & ANTECEDENT & Caracter & 14 & Se o suspeito possui antecedentes \\
\hline 22 & FOTO & Geral & 10 & Foto do suspeito em formato PICT \\
\hline 23 & ALTURA & Caracter & 14 & Altura do suspeito em pontos \\
\hline 24 & COMPLEICAO & Caracter. & 15 & Tipo físico \\
\hline 25 & CUTIS & Caracter & 16 & Cor da pele \\
\hline 26 & CABEL_TIPO & Caracter & 14 & Tipo de cabelo \\
\hline 27 & CABL_QTDE & Caracter & 19 & Quantidade de cabelo \\
\hline 28 & CABEL_COR & Caracter & 21 & Cor do cabelo \\
\hline 29 & OLHOS & Caracter & 10 & Cor dos olhos \\
\hline 30 & OBS & Memo & 10 & $\begin{array}{l}\text { Algum tipo de observação sobre o } \\
\text { suspeito }\end{array}$ \\
\hline$\overline{31}$ & CICATRIZ & Numérico & 1 & Se possui cicatriz \\
\hline 32 & TATUAGEM & Numérico & 1 & Se possui tatuagem \\
\hline 33 & CICATAM & Caracter & 18 & Onde possui cicatriz \\
\hline 34 & TATUTAM & Caracter & 18 & Onde possui tatuagem \\
\hline 35 & DEFICIENTE & Numérico & 1 & Se possui deficiência \\
\hline 36 & TIPODEFIC & Caracter & 25 & Que tipo de deficiência \\
\hline
\end{tabular}

Tabela ll.1: Tabela DBF do FoxPro com as informaçбes sobre a base de dados de suspeltos. 


\begin{tabular}{|c|c|c|c|c|c|}
\hline Campo & Nome & Tipo & Tamanho & Decimal & Descrição \\
\hline 1 & NOME & Caracter & 30 & & Nome do Policial \\
\hline 2 & GRAD & Caracter & 15 & & Graduaçăo \\
\hline 3 & RE & Caracter & 10 & & Número do registo \\
\hline 4 & N_GUERRA & Caracter & 15 & & Nome de guerra (apelido) \\
\hline 5 & ADMISSAO & Date & 8 & & Data da admissāo \\
\hline 6 & DATA_NASC & Date & 8 & & Data de nascimento (DD/MM/AA) \\
\hline 7 & LOCAL_NASC & Caracter & 30 & & Naturalidade \\
\hline 8 & PAI & Caracter & 30 & & Nome do Pai \\
\hline 9 & MAE & Caracter & 30 & & Nome da Mãe \\
\hline 10 & END_RUA & Caracter & 30 & & Endereço residencial \\
\hline 11 & END_BAIRRO & Caracter & 15 & & Nome do bairro \\
\hline 12 & END_CIDADE & Caracter & 30 & & Nome da cidade \\
\hline 13 & OLHOS & Caracter & 10 & & Cor dos olhos \\
\hline 14 & CABELO & Caracter & 10 & & Cor do cabelo \\
\hline 15 & ALTURA & Numérico & 3 & 2 & Altura em metros (ex: 1,82) \\
\hline 16 & SANGUE & Caracter & 5 & & Tipo sangüíneo \\
\hline 17 & INSTRUCAO & Caracter & 10 & & Grau de instruçáo \\
\hline 18 & PROFISSAO & Caracter & 20 & & Profissão \\
\hline$\overline{19}$ & EST_CIVIL & Caracter & 10 & & Estado Civil \\
\hline 20 & CONJUGE & Caracter & 30 & & Nome do marido/esposa \\
\hline 21 & FILHOS & Numérico & 2 & & Quantidade de filhos \\
\hline 22 & TELEFONE & Numérico & 10 & & Telefone residencial \\
\hline 23 & RG & Caracter & 15 & & Número do Registro Geral \\
\hline 24 & $\mathrm{CIC}$ & Caracter & 15 & & Número do ClC \\
\hline
\end{tabular}




\begin{tabular}{|l|l|l|l|l|l|}
\hline 25 & CNH & Caracter & 15 & & Número da carteira de motorista \\
\hline 26 & TIT_ELEIT & Caracter & 15 & & Número do títuḷo de eleitor \\
\hline 27 & TIT_ZONA & Caracter & 5 & & Zona eleitoral I \\
\hline 28 & TIT_SECAO & Caracter & 10 & & Seção eleitoral \\
\hline 29 & OBS & Memo & 10 & & Alguma observação sobre o policial \\
\hline 30 & FOTO & Geral & 10 & & Foto do policial no formato PICT \\
\hline
\end{tabular}

Tabela Il.2: Tabela DBF do FoxPro com as Informaçoes sobre a base de dados de pollclais. 